Portland State University

PDXScholar

$1-1-2011$

\title{
Leveraging Weigh-In-Motion (WIM) Data to Estimate Link-Based Heavy-Duty Vehicle Emissions
}

Heba Naguib Alwakiel

Portland State University

Follow this and additional works at: https://pdxscholar.library.pdx.edu/open_access_etds

Part of the Civil and Environmental Engineering Commons

Let us know how access to this document benefits you.

Recommended Citation

Alwakiel, Heba Naguib, "Leveraging Weigh-In-Motion (WIM) Data to Estimate Link-Based Heavy-Duty Vehicle Emissions" (2011). Dissertations and Theses. Paper 247.

https://doi.org/10.15760/etd.247

This Thesis is brought to you for free and open access. It has been accepted for inclusion in Dissertations and Theses by an authorized administrator of PDXScholar. Please contact us if we can make this document more accessible: pdxscholar@pdx.edu. 
Leveraging Weigh-In-Motion (WIM) Data to Estimate

Link-Based Heavy-Vehicle Emissions

by

Heba Naguib Alwakiel

A thesis submitted in partial fulfillment of the requirements for the degree of

Master of Science

In

Civil and Environmental Engineering

Thesis Committee:

Christopher Monsere, Chair

Miguel Figliozzi

Ashley Haire

Portland State University

(C)2011 


\begin{abstract}
This research examines the use of archived weigh-in-motion (WIM) data to estimate link-based heavy-vehicle emissions for Oregon highways. This research combined data on vehicle speed, highway grade, and gross vehicle weight and relationship between these elements in published research to estimate the carbon dioxide $\left(\mathrm{CO}_{2}\right)$ and nitrogen oxide $\left(\mathrm{NO}_{x}\right)$ emissions from trucks. Sensitivity analysis was conducted on the impact of uphill grade and gross vehicle weight on truck speed and emissions. The results suggest that with the data available in the weigh-in-motion archive and with a reasonable set of assumptions, link-based emissions for heavy-duty vehicles can be estimated. The carbon dioxide $\left(\mathrm{CO}_{2}\right)$ and nitrogen oxide $(\mathrm{NO} \times)$ emissions are found to increase when the speed, gross vehicle weight, or road grade increases. The relationship between nitrogen oxide $\left(\mathrm{NO}_{\mathrm{x}}\right)$ emissions and vehicle weight was estimated to be linear. The potential to estimate the linkbased heavy-vehicle emissions for Oregon highways using the weigh-inmotion data archive, which was mainly designed to estimate truck counts, has a great value in setting new measures to mitigate the heavy-vehicle emissions.
\end{abstract}




\section{DEDICATION}

This thesis is dedicated to my loving husband who has been so understanding and encouraging, my parents, sister, and brother for their invaluable support, and to my little Karim for his cooperation and patience! 


\section{ACKNOWLEDGEMENTS}

I would like to express my special thanks and sincere appreciation to Dr. Monsere for his guidance throughout the completion of this research. Thanks go to my committee members, Dr. Monsere, Dr. Figliozzi, and Dr. Haire, for their valuable suggestions and comments. I gratefully acknowledge Oregon Department of Transportation for making the weigh-in-motion (WIM) data available for this research. Lastly but not least, I am thankful to my colleagues in the Intelligent Transportation Systems (ITS) Lab for their continuous help and making my stay at the university a memorable experience. 
TABLE OF CONTENTS

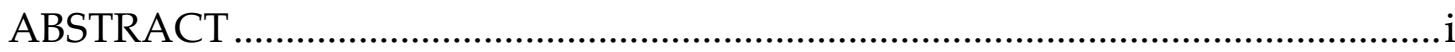

ACKNOWLEDGEMENTS ............................................................................ iii

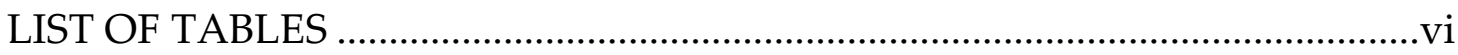

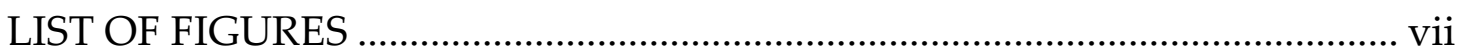

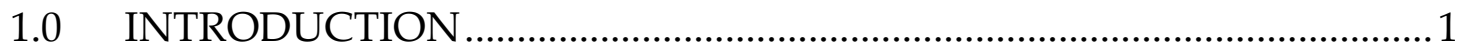

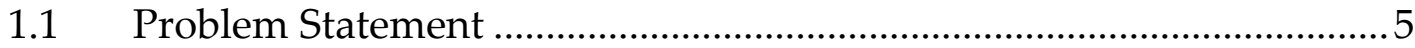

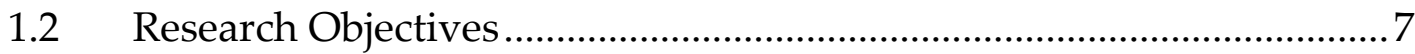

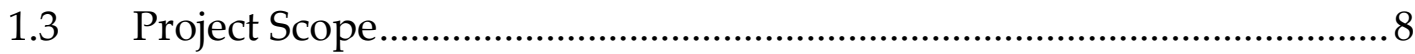

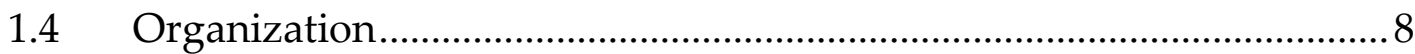

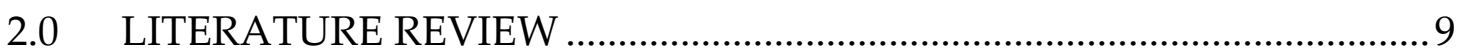

2.1 Factors Affecting Heavy-Duty Vehicle Emissions................................... 9

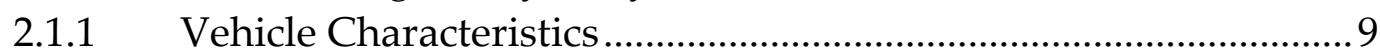

2.1.1.1 Vehicle Class and Weight............................................................

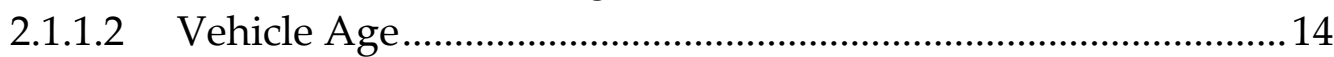

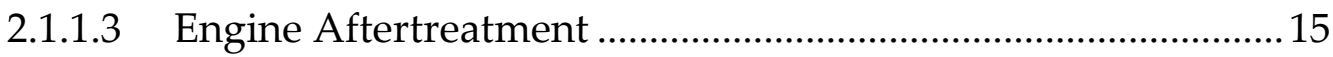

2.1.2 Driving Mode.............................................................................16

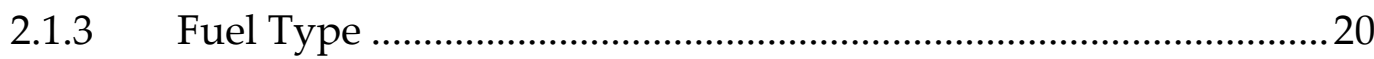

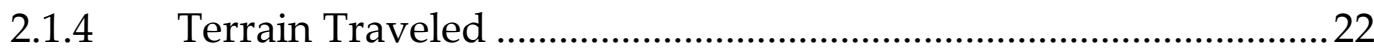

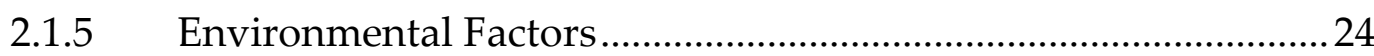

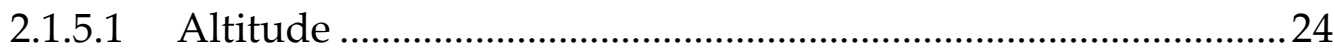

2.1.5.2 Ambient Temperature and Humidity .......................................... 25

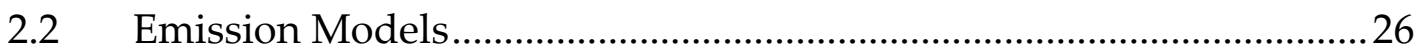

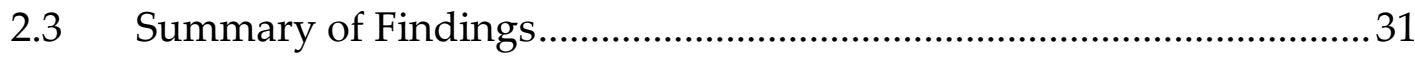

2.4 Conclusions and Recommendations.......................................................

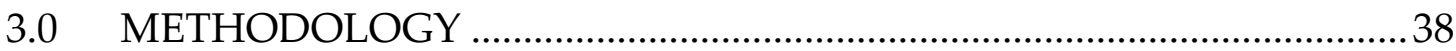

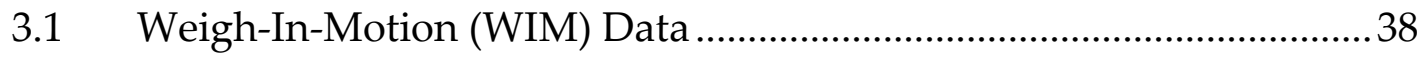

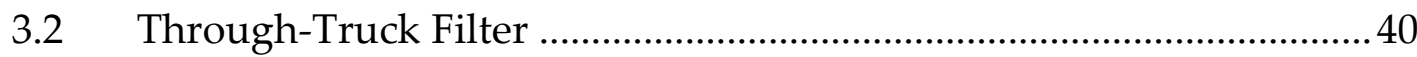

3.3 Estimating Link-Based Heavy-Vehicle Emissions....................................43

3.3.1 Extracting Vehicle Weight and Speed from WIM Database ........43

3.3.2 Effect of Grade on Heavy-Duty Vehicle Speeds ............................ 47

3.3.3 Estimating Link-Based $\mathrm{NO}_{x}$ Emissions ........................................52

3.3.4 Estimating Link-Based $\mathrm{CO}_{2}$ Emissions ...........................................5 


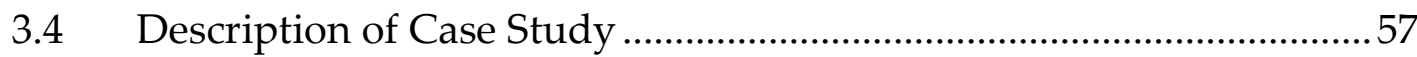

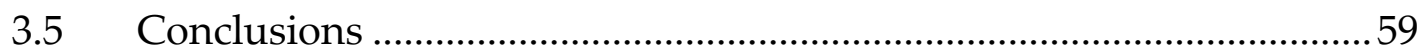

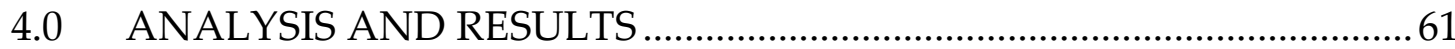

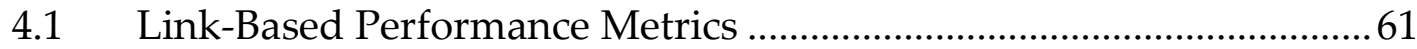

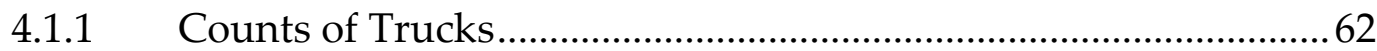

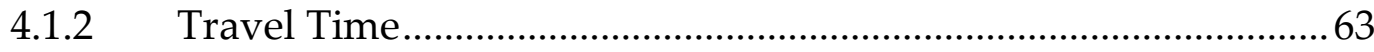

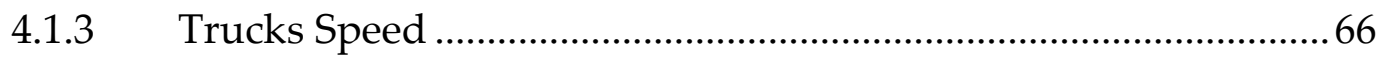

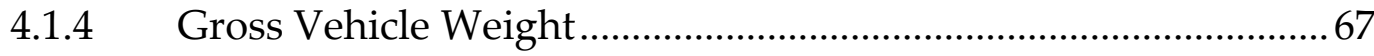

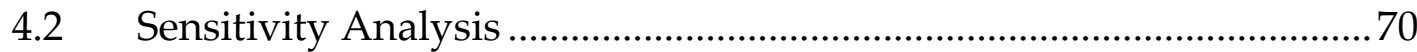

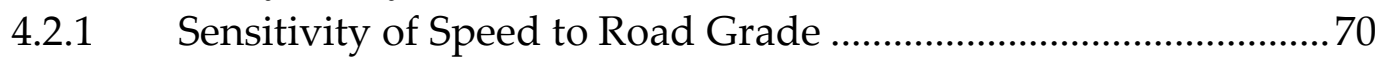

4.2.2 Sensitivity of Emissions to Speed ...................................................75

4.3 Link-Based Emissions Estimation ........................................................77

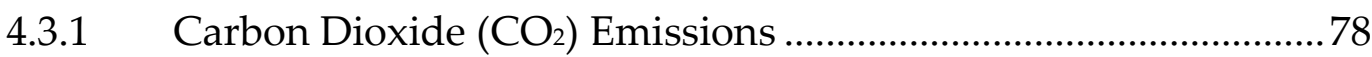

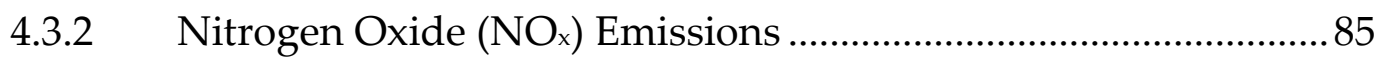

4.4 Summary of Key Findings..................................................................... 90

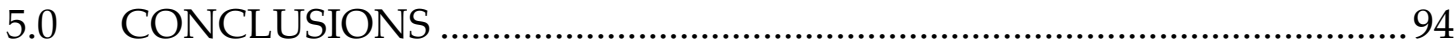

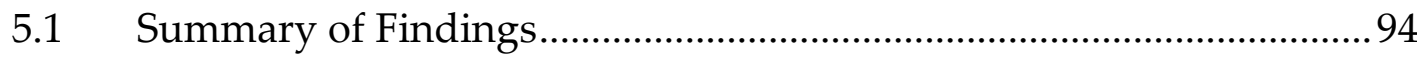

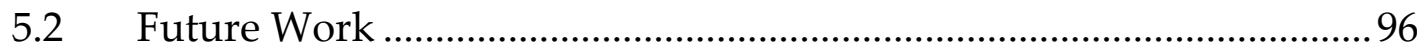

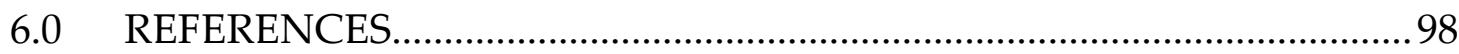

Appendix A: Steps for Estimating Link-Based Nitrogen Oxide $\left(\mathrm{NO}_{\mathrm{x}}\right)$ and

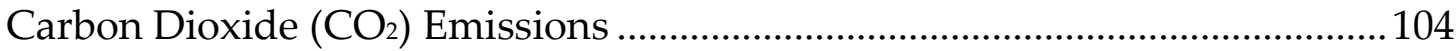




\section{LIST OF TABLES}

Table 1: List of Truck Parameters (Façanha et al., 2010) ......................................... 28

Table 2: Relation Between Influencing Characteristics and Emission Rates ....32

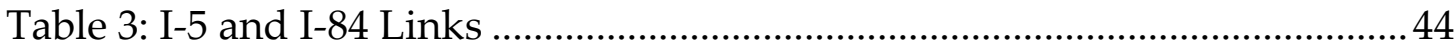

Table 4: Approximated Grade Segments for Link 211 ........................................... 60

Table 5: Minimum and Maximum Values of Speed-Variation Percentages on

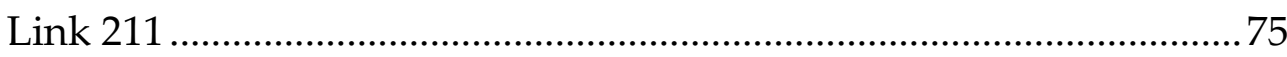

Table 6: Average CO2 Emission Rates (in Grams) for Heavy-Duty Trucks -

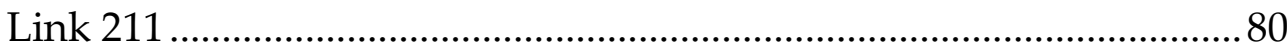

Table 7: Ratios of Maximum to Minimum Link Emission Rates - Link 211...... 82

Table 8: Average $\mathrm{NO}_{x}$ Emission Rates (in Grams) for Heavy-Duty Trucks -

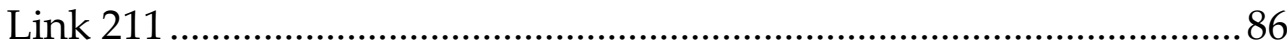




\section{LIST OF FIGURES}

Figure 1: Factors Affecting Vehicle Emissions (Sinha and Labi, 2007) ................. 4

Figure 2: FHWA Trucks Classification (Yoon et al., 2004).................................... 10

Figure 3: Variation of Fuel Consumption and Emissions with the Average Speed (Pandian et al., 2009)....................................................................... 17

Figure 4: Effect of Various Factors on PM Emissions..............................................33

Figure 5: Effect of Various Factors on $\mathrm{NO}_{x}$ Emissions ...........................................33

Figure 6: Oregon Green-Light Locations.................................................................. 39

Figure 7: CMEM Modelled $\mathrm{CO}_{2}$ Emissions as a Function of Speed for Various

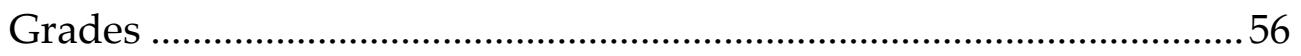

Figure 8: Link 211 on I-5 by Google Earth .......................................................... 58

Figure 9: Grade Profile for Link 211 .................................................................. 59

Figure 10: Counts of Transponder-Equipped and Through Trucks - Link 211,

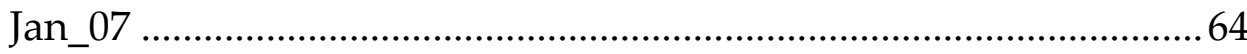

Figure 11: Counts of Through and Non-Through Trucks - Link 211, Jan_07 ..64

Figure 12: Percentage of Through Trucks on Link 211 - Link 211, Jan_07.........65

Figure 13: Travel Time Frequency for Link 211 on January_07 .............................65

Figure 14: Speed Frequency for Link 211 on January_07........................................66

Figure 15: Frequency of Gross Vehicle Weight in Bin_1 - Link 211, Jan_07 .....68

Figure 16: Frequency of Gross Vehicle Weight in Bin_2 - Link 211, Jan_07 .....68

Figure 17: Frequency of Gross Vehicle Weight in Bin_3 - Link 211, Jan_07 .....69

Figure 18: Percentage of Speed Change on Grades - Empty Trucks - Link 211,

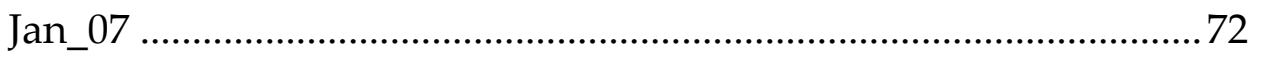

Figure 19: Percentage of Speed Change on Grades - Medium Trucks - Link

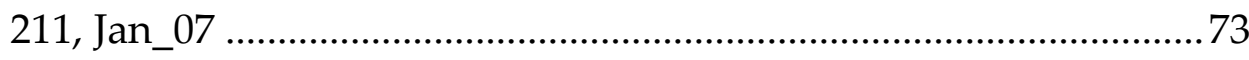


Figure 20: Percentage of Speed Change on Grades - Full Trucks - Link 211, Jan_07 .74

Figure 21: Variation of $\mathrm{CO}_{2}$ Emissions with Speed - Link 211 on January_07.76 Figure 22: Variation of $\mathrm{NO}_{x}$ Emissions with Speed - Link 211 on January_07 77 Figure 23: Through-Truck Count by Time of Day for Link 211 on January_0779 Figure 24: Through-Truck Carbon Dioxide Emissions - Link 211, Jan_07 .......79 Figure 25: Counts of Transponder-Equipped Trucks - Link 211, Jan_07........... 83 Figure 26: Carbon Dioxide Emissions for Link 211 on January_07....................... 84 Figure 27: Through-Truck Nitrogen Oxide Emissions - Link 211, Jan_07 ......... 85 Figure 28: Relationship between Nitrogen Oxide Emissions and GVW - Link 211, Jan_07 87

Figure 29: Nitrogen Oxide Emissions for Link 211 on January_07 .89 


\subsection{INTRODUCTION}

The efficient movement of freight is critical to the United States' (U.S.) economy. According to estimates by the Bureau of Transportation Statistics (BTS) of the U.S. Department of Transportation's Research and Innovative Technology Administration (RITA) and Federal Highway Administration (FHWA), over 19 billion tons of freight, valued at $\$ 13$ trillion, was carried over 4.4 trillion ton-miles in the United States in 2002 (Bureau of Transportation Statistics, 2006). This means that approximately 53 million tons of freight with a value of $\$ 36$ billion were moved each day (Bureau of Transportation Statistics, 2006). The Freight Analysis Framework (FAF) estimates that by 2035 the tons transported by all modes will nearly double. Trucks currently move the majority of the freight by value and tonnage. Trucking moved 11,500 million tons ( $\$ 8,856$ billion) in 2002, 12,900 million tons ( $\$ 9,764$ billion) in 2007 , and is expected to carry 22,800 million tons (\$23,767 billion) in 2035 (Schmitt et al., 2008). As the economy grows and technology improves, these numbers become more staggering. Miles traveled by ground freight transportation have increased due to just-in-time (JIT) manufacturing, faster delivery services, and internet-based shopping (Scora et al., 2010). 
Although heavy-duty vehicles represent a relatively small portion of the overall fleet population, they contribute a substantial fraction of greenhouse gases and toxic pollutants to the on-road vehicle emission inventory. The emission inventory is a list, by source, of the amounts of air pollutants emitted per unit time in a community (U.S. EPA, 2009). Currently, the emission inventory models are based on speed-time and torque-time measurements for heavy-duty engines which follow the Transient Federal Test Procedure (FTP) (Ramamurthy and Clark, 1999). The process of removing the engine to apply the FTP test makes it expensive and time-consuming. That is why the chassis dynamometer test with the engine in a vehicle is sometimes preferred.

Heavy-duty diesel vehicles (HDDVs) are considered the major mobile emissions sources of nitrogen oxides $\left(\mathrm{NO}_{\mathrm{x}}\right)$ and diesel particulate matters (PM). In 2002, HDDVs' share in the nationwide on-road vehicle emission inventory was approximately $46 \%$ of $\mathrm{NO}_{x}$ and 54\% of PM10 (Frey et al., 2008). However, HDDVs contribute with lesser amount of carbon monoxide (CO) and hydrocarbons (HC). With their high durability and reliability, and with increases in movements of goods, these vehicles will continue to play a major role in the emissions inventory (Barth et al., 2004). Better estimation of 
emissions inventories is necessary to assess the effectiveness of heavy-duty engine regulations, to understand air pollution problems, and to serve as a keystone of successful regional air quality management planning (Yanowitz et al., 2002). Societal and legislative pressures to mitigate diesel emissions are rising, which is reflected in the existing and projected heavy-duty certification standards of these emissions.

Emissions rates from HDDV's are affected by various factors. The major variables that affect the level of emissions can generally be classified as follows: travel-related, driver-related, roadway-related, vehicle-related, fuel type, and environmental (Figure 1). Travel-related factors include vehicle miles traveled, speed, and vehicle-engine operating modes. Driver behavior varies significantly by person and by traffic conditions, and can influence emission rates. Roadway-related variables such as terrain configuration, lane channelization, lane width, curvature, and super elevation can affect vehicles' operating speeds or modes. Vehicle emissions are influenced by the gross vehicle weight (GVW), engine power, engine type, vehicle class, engine maintenance, engine aftertreatment, vehicle age, vehicle aerodynamics, and tire rolling resistance. In addition, environmental conditions such as 
temperature, humidity, and altitude have a significant impact on the emissions rates (Bigazzi and Bertini, 2009).

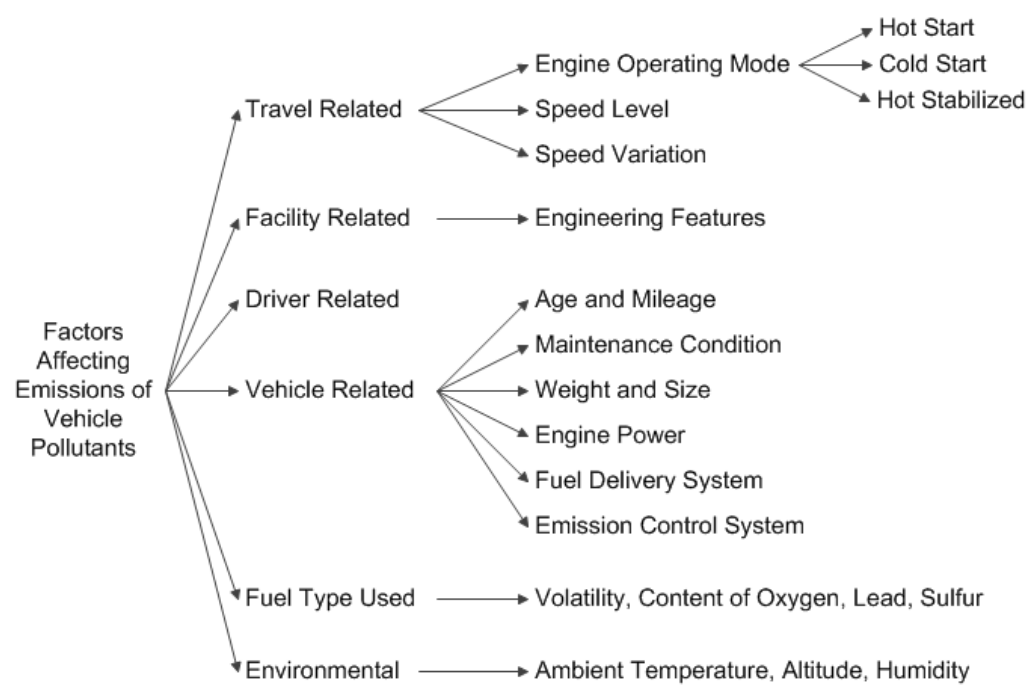

Figure 1: Factors Affecting Vehicle Emissions (Sinha and Labi, 2007)

In recent years, there have been significant improvements in transportation and emissions modelling for better evaluation of transportation operational effects and the resulted vehicle emissions. Most of the effort has concentrated on developing instantaneous or modal emissions models for a wide range of light-duty vehicles (LDVs). However, less effort has been devoted to heavy-duty diesel vehicles. The main reason that HDDV emission models are less developed than those of LDV's is that there are relatively fewer amounts of HDD emissions data than the available LDV emissions data. To be fair, large amounts of HDD engine certification data from laboratory 
tests are available, but these data do not actually reflect the real-world on-road vehicle emissions (Barth et al., 2004). The majority of emission models estimate emission rates using limited characteristics such as speed and acceleration because they can be easily quantified (Pandian et al., 2009). The effect of other significant characteristics such as road grade and vehicle operating weight for example are not taken into account when estimating the emissions inventories. This is primarily because of the high cost and difficulty of gathering in-use fleet data for a large number of heavy-duty vehicles. The growing concern about mitigating vehicle emissions has encouraged the National Research Council (NRC) committee to set: (a) the outdoor measures versus actual human exposure, (b) characterization of emission sources, (c) air-quality model development, and (d) testing among their ten highest priority research areas (Singh et al., 2003).

\subsection{Problem Statement}

Oregon's geographic location makes its economy highly dependent on reliable transportation and optimizing the freight mobility is essential to continue the economic prosperity. According to the Oregon Transportation Plan (OTP), trucking handles the majority of freight movement and will increase by $80 \%$ in the next 20 years due to tendency toward smaller and more time-sensitive 
shipments. A major percentage of this freight movement is concentrated on Interstate 5 (I-5) and Interstate 84 (I-84). These highways connect main population centers and transportation infrastructure in north-south and eastwest directions, respectively.

In 2004, the greenhouse gas (GHG) emissions in Oregon were estimated to be 67.5 million metric tons of carbon dioxide equivalent $\left(\mathrm{MMTCO}_{2} \mathrm{e}\right)$ (Sadler, 2007). This presented nearly one percent of the United States' GHG emissions, which were more than seven billion metric tons of $\mathrm{CO}_{2} \mathrm{e}$. Oregon's 2004 GHG emissions were 22 percent higher than those of 1990 (55.5 $\mathrm{MMTCO}_{2} \mathrm{e}$ ). The largest source of emissions (40 percent) was gasoline and diesel fuel use in transportation. According to the Department of Energy, Oregon's GHG emissions is forecasted to be 61 percent higher by 2025 (Sadler, 2007).

Currently, estimation of heavy-duty emissions is primitive and precise data are lacking. This gap is due to problems in quantifying emissions rates, inaccurate vehicle activity estimates, and test cycles that do not represent the real-world conditions. The insufficient data for heavy-duty vehicles emissions can be partially overcome by using Oregon's archived Weigh-In-Motion (WIM) data. 


\subsection{Research Objectives}

The archived weigh-in-motion (WIM) database provides information about the gross vehicle weight, vehicle class, and average link speed for a subset of vehicles equipped with transponders that can be uniquely identified between WIM stations. Previous research (Monsere et al., 2009) developed a technique to identify through trucks from the WIM database. Link properties such as grade are also known. In addition, the weather characteristics (temperature, humidity) are available at various locations in the corridor from fixed weather observing locations.

The objective of this thesis is to explore use of archived WIM data to estimate link-based emission factors for Oregon corridors. The method proposed will develop emission factors from published research and apply the model/factors in a case study to key freight corridors in Oregon.

Leveraging the additional information provided by the WIM data for estimating truck emissions is a new contribution, where these data have previously been mainly used to estimate truck counts and for use in pavement design (Qu et al., 1997). 


\subsection{Project Scope}

The estimation of link-based emissions studied in this research will focus on the weigh-in-motion (WIM) data for Link 211 on Interstate 5 (I-5) during January 2007. This link is bounded by the fixed WIM stations at Ashland Port Of Entry (POE) (NB, MP 18.08) and Booth Ranch (NB, MP 111.07).

\subsection{Organization}

The organization of the rest of this thesis is as follows. Chapter 2 of this document provides a literature review of the factors affecting heavy-duty vehicle emissions and their significant impact, and a brief highlight of the most-used models and their areas of strength, weakness, and their potential improvements. The literature review closes with a summary of the findings. Next, Chapter 3 presents the data used in this research, and describes the methodology (and assumptions) used to estimate link-based emissions. The methodology is applied in a case study to the I-5 corridor between the two WIM stations and a summary of the key findings are provided in Chapter 4. Finally, Chapter 5 provides the conclusions of the research and suggests possible future work. 


\subsection{LITERATURE REVIEW}

This literature review encompasses a survey of work done concerning the factors that most significantly impact the emissions of heavy-duty vehicles. First, a brief background of these factors and how they influence heavy-duty vehicle emissions is included. This background is followed by a discussion of the most-used models for the prediction of emissions inventory, the strengths and shortcomings in mentioned models, and the areas for potential improvements to enhance emissions inventory. The chapter concludes with a summary of the findings.

\subsection{Factors Affecting Heavy-Duty Vehicle Emissions}

\subsubsection{Vehicle Characteristics}

The in-use heavy-duty vehicles have diverse characteristics such as class, weight, engine design, fuel type, etc. Each one of these features is found to have significant effect on emissions (Pandian et al., 2009).

\subsubsection{Vehicle Class and Weight}

Vehicle classes are defined in several ways, usually depending on the gross vehicle weight, which is used by the vehicle manufacturers. However, the Federal Highway Administration (FHWA) classifies vehicles in terms of their configuration rather than weight. A schema for FHWA truck classification 
(Classes 5 through 13) is presented in Figure 2. The most dominant types of heavy-duty vehicles traveling on highways (and mentioned in this research) are Classes 7, 8, and 9. A truck is identified as Class 7 if it is on a single frame and with four or more axles. Class 8 trucks have four or less axles and consist of two units, one of which is the tractor or straight truck power unit. All fiveaxle vehicles consisting of two units, one of which is the tractor or straight truck power unit, are classified as Class 9 trucks.

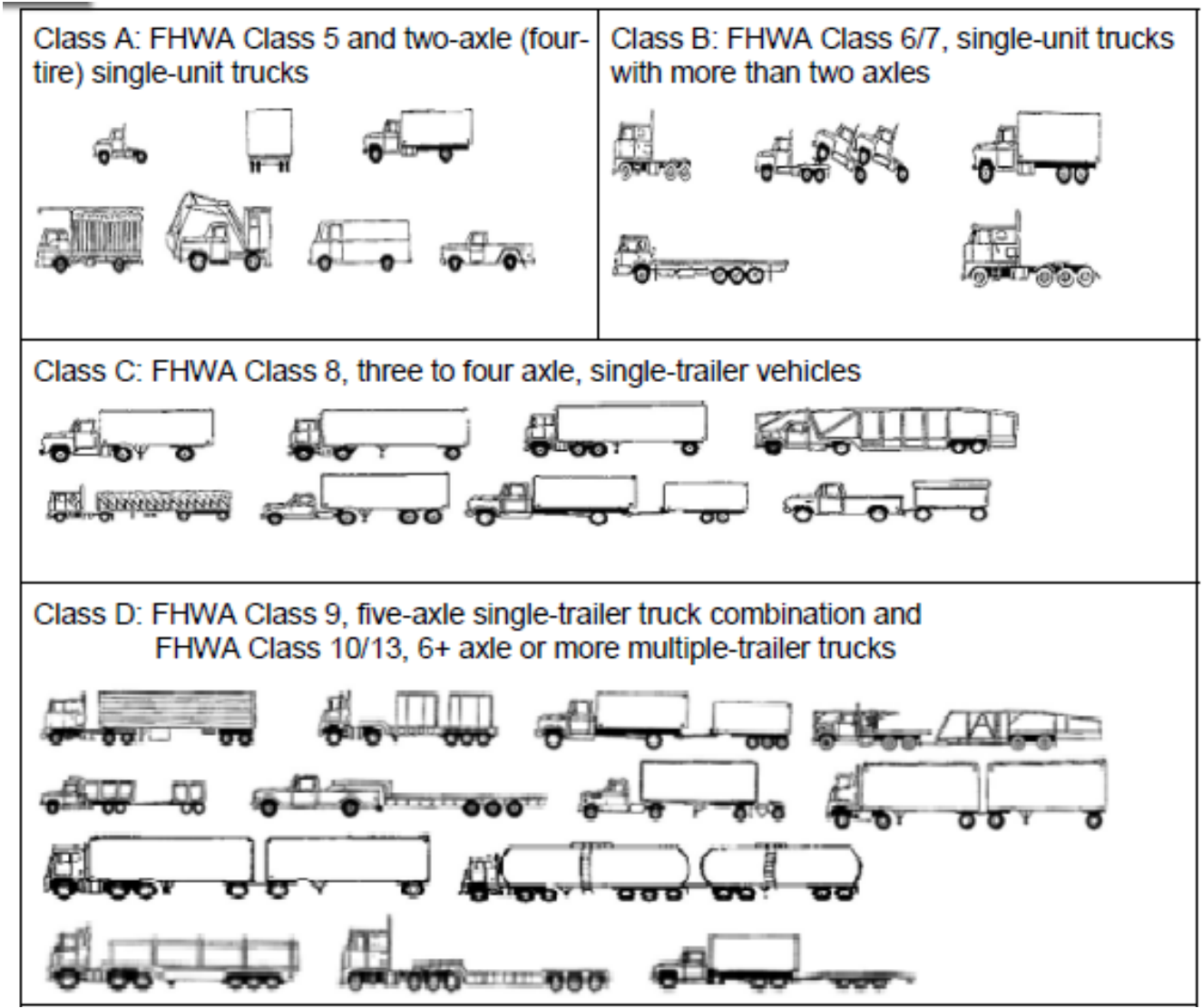

Figure 2: FHWA Trucks Classification (Yoon et al., 2004) 
Clark et al. (2002) and Feng et al. (2005) found that emissions varied directly with vehicle class, since higher truck classes are heavier. As more power is needed for larger truck weight, the amount of fuel burned increases and consequently the emissions grow.

Gajendran and Clark (2003) examined the weight effects for Class 7 and 8 trucks on emissions. They determined that nitrogen oxide $(\mathrm{NO} \times)$ emissions increased by approximately $54 \%$ when doubling the test weight, with a nearly linear correlation between $\mathrm{NO}_{x}$ emissions and weight. There was a linear increase in carbon dioxide $\left(\mathrm{CO}_{2}\right)$ emissions with increasing weight. Carbon monoxide $(\mathrm{CO})$ and particulate matter (PM) emissions were strongly affected by vehicle weight during transient operation, but not affected during steadystate operation. Hydrocarbon ( $\mathrm{HC}$ ) emissions were found to be insensitive to the change in weight because $\mathrm{HC}$ emissions from modern diesel engines (examined in the study) are very low and are not affected by the vehicle weight. Brodrick et al. (2004) applied on-road tests to heavy-duty diesel tractor (Class 8) and concluded that an increase in the gross vehicle weight (GVW) from $52,000 \mathrm{lb}$ to $80,000 \mathrm{lb}$ resulted in approximately $40 \%$ or greater increases in $\mathrm{NO}_{\mathrm{x}}$ emissions during the acceleration and higher-speed steady-state operations. The conclusion was checked using ADVISOR (ADvanced VehIcle 
SimulatOR) simulation model result and found to agree with it. The result of this study was consistent with the findings of Gajendran and Clark (2003) who reached similar conclusions when they used a speed-acceleration approach to predict the $\mathrm{NO}_{x}$ emissions for a 1994 model year vehicle at different weights, tested on a five-mile route. The test resulted in a linear relationship between weight and $\mathrm{NO}_{\mathrm{x}}$ emissions. Yanowitz et al. (1999) tested 21 in-use heavy-duty diesel vehicles on a chassis dynamometer and also concluded that PM and $\mathrm{NO}_{x}$ emissions increased with increasing test weight.

Scora et al. (2010) used the Comprehensive Modal Emission Model (CMEM) to examine the effect of vehicle weight on carbon dioxide $\left(\mathrm{CO}_{2}\right)$ emissions. The study found that weight mostly affects $\mathrm{CO}_{2}$ emissions at moderate speeds, whereas at very low and high speeds the effect is much less. In addition, the variability of $\mathrm{CO}_{2}$ emissions across all speeds decreased as the truck weight increased. Another important conclusion was that the optimal driving speed (at which the $\mathrm{CO}_{2}$ emissions were minimal) increased with higher weights.

Frey et al. (2008) developed a speed-acceleration modal emission approach using single rear-axle and tandem-axle dump trucks to estimate link-based emission rates. Single rear-axle trucks were found to have lower 
emission rates than tandem-axle trucks for carbon dioxide $\left(\mathrm{CO}_{2}\right)$, particulate matter (PM), nitric oxide (NO), and hydrocarbon (HC), but higher carbon monoxide ( $\mathrm{CO})$ emissions. Loaded trucks had higher fuel use and emission rates than unloaded trucks.

Durbin et al. (2000) studied the effect of payloads on exhaust emissions of light heavy-duty diesel and gasoline pickup trucks. The trucks were tested over a combination of test weights (empty, half-loaded, and fully loaded) using different driving cycles. The particulate matter (PM) and carbon dioxide $\left(\mathrm{CO}_{2}\right)$ emissions of diesel trucks increased significantly with increasing weight. However, the nitrogen oxide (NOx) emissions increased only modestly with a detected relationship to the amount of work performed by the engine. In the case of gasoline vehicles, carbon monoxide (CO) and carbon dioxide $\left(\mathrm{CO}_{2}\right)$ emissions increased with increasing payload.

Yanowitz et al. (2002) developed a model, which used heavy-duty vehicle speed to estimate vehicle engine speed and load. The model was validated using chassis dynamometer tests. The tests showed that minor changes in vehicle speeds could lead to doubling of engine load and consequently the emissions. 
Ramamurthy et al. (1999) tested different types of heavy-duty vehicles by chassis dynamometer test to predict the nitrogen oxide $\left(\mathrm{NO}_{\mathrm{x}}\right)$ emissions and represented the results in the form of $\mathrm{NO}_{\times} / \mathrm{CO}_{2}$ ratio. It was found that vehicle type and test cycle both influenced emission rates. The average value of $\mathrm{NO}_{\times} / \mathrm{CO}_{2}$ ratio for all vehicles was 0.0141 , which corresponds to an emissions contribution of 0.0423 gram of $\mathrm{NO}_{x}$ for every gram of diesel burned. Clark and Gajendran (2003) used data from a 1996 transit bus to find the $\mathrm{NO}_{\times} / \mathrm{CO}_{2}$ ratio and also found that the average value was 0.014 . These results agreed with remote sensing or road tunnel study data for trucks.

It can be concluded that all studies agreed that an increase in the vehicle class and weight would result in higher emission rates.

\subsubsection{Vehicle Age}

Most studies have found that with the increase in vehicle deterioration with age and more mileage travelled, the rate of emissions increases (Pandian et al., 2009). Clark et al. (2002) stated that there are few available data that compare emissions from the same heavy vehicle when it is new and after certain useful life. They found that a 1998 engine would produce less nitrogen oxides (NOx) by a factor of 2.5 and less particulate matter (PM) by a factor of 12 compared 
to a 1988 engine. Another important result was that fuel economy decreased as the mileage increased.

However, when Yanowitz et al. (1999) measured regulated emissions from 21 in-use heavy-duty diesel vehicles using chassis dynamometer test, the study concluded that nitrogen oxides $\left(\mathrm{NO}_{\mathrm{x}}\right)$ emissions were not affected by the model year for the vehicles tested.

Yoon et al. (2004) investigated engine model year and other vehicle characteristics for heavy (i.e. long-haul) heavy-duty diesel vehicles (HHDDV's) through a cordon survey in the 21-county Atlanta metropolitan area. The survey showed that the average engine model year was 1998 and the average engine age was 4.5 years. The findings suggested that the average HHDDV in the fleet is younger than the average age of 5.3 years that was found in other survey conducted in 1999.

\subsubsection{Engine Aftertreatment}

Despite their ability to affect emissions, few heavy-duty vehicles are equipped with aftertreatment devices. Clark et al. (2002) grouped diesel exhaust aftertreatments into three main types: diesel oxidation catalysts, particulate traps, and continuously regenerating traps. The presence of an aftertreatment device has substantial effect on emissions. For example, the continuously 
regenerating traps can reduce particulate matter (PM) by a factor of 3.5 , and nitrogen oxides $\left(\mathrm{NO}_{\mathrm{x}}\right)$ by nearly $10 \%$. Whereas, a catalytic converter can lower the PM by $24 \%, \mathrm{NO}_{x}$ by $9 \%$, and carbon monoxide (CO) by at least $8.3 \%$.

Few studies were found that explored the effect of engine aftertreatment on heavy-duty diesel vehicle emission rates.

\subsubsection{Driving Mode}

Emission factors derived from laboratory tests only describe a particular operating condition, and do not reflect the real-world case. This is because the effect of speed on emissions under different driving modes (acceleration, deceleration, cruising, idle) is not considered in laboratory tests (Pandian et al., 2009). Pandian et al. (2009) stated that fuel consumption and emissions decreased with an increase in instantaneous speed, as shown in Figure 3. Brodrick et al. (2004) found that driving mode explains most of the variation and had significant effects on all emissions species. Similarly, Clark and Gajendran (2003) conducted research on a large amount of laboratory data and concluded that the test cycle (driving mode) had a significant effect on the predicted emission values. Yanowitz et al. (1999) indicated that the difference in test cycle (driving mode) could affect the emissions estimation of carbon monoxide $(\mathrm{CO})$ and particulate matter (PM) by 50 to $100 \%$, and by lower 
percentages for other pollutants. The test results revealed that the central business district (CBD) cycle employed in the chassis dynamometer simulation, which is considered the most aggressive cycle as it had the most accelerations, produced the highest emissions. Holmen and Niemeier (1998) also found that driving manner (e.g. duration and intensity of acceleration) had a significant effect on measured emissions.

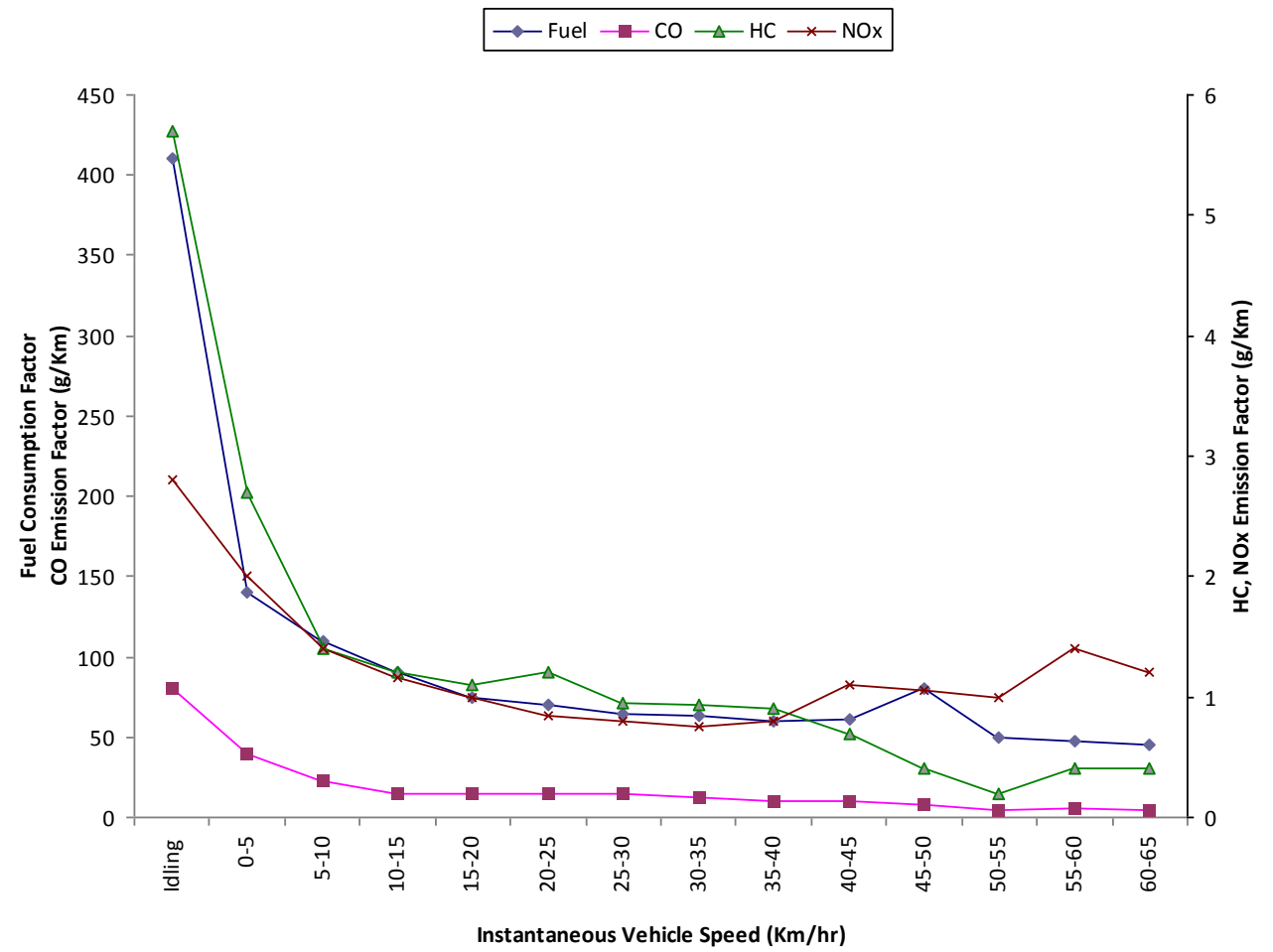

Figure 3: Variation of Fuel Consumption and Emissions with the Average Speed (Pandian et al., 2009)

Clark et al. (2002) concluded that driving with more acceleration and more sustained high acceleration produces higher emissions. The study confirmed that the carbon monoxide $(\mathrm{CO})$ and particulate matter $(\mathrm{PM})$ 
emissions were sensitive to engine loading, while the nitrogen oxides $\left(\mathrm{NO}_{x}\right)$ emissions remained stable. They found that local driving with frequent stops is likely to raise emissions, which will be additionally affected by driver-todriver variations. Bigazzi and Bertini (2009) emphasized that high steady speed, and accelerations resulting from speed variability, resulted in high emission rates. Modifying driving behaviour, with steady speed and less aggressive accelerations, has the potential to decrease emission by 5 to $25 \%$. Figliozzi (2010) states that the relationship between travel speed and emission rates is non-linear, as the fuel consumption and the rate of carbon dioxide $\left(\mathrm{CO}_{2}\right)$ emissions per mile decrease up to speeds of 55-65 $\mathrm{mph}$ then tend to increase again. Singh et al. (2003) found that the emission rates dropped to approximately half with an increase in speed from 12 to $50 \mathrm{mph}$, while most of the reduction (by a factor of 0.6 ) occurred with an increase in speed from 12 to $27 \mathrm{mph}$.

Scora et al. (2010) collected a large amount of emissions data for heavyduty diesel vehicles using California-Riverside's Mobile Emissions Laboratory (MEL) to examine the operational variability on greenhouse gas emissions, mainly carbon dioxide $\left(\mathrm{CO}_{2}\right)$. The results of tests indicated that using average speed alone to define $\mathrm{CO}_{2}$ emission factors was not enough, and that measures 
of driving patterns (driving modes) should be considered. In addition, they concluded that the relationship between $\mathrm{CO}_{2}$ emissions $(\mathrm{g} / \mathrm{mi})$ and speed becomes more linear with increasing uphill grade.

Hao et al. (2010) studied the relationship between driving activity and real-world emission data of heavy-duty diesel buses. It was determined that high speed or acceleration resulted in higher instantaneous emission rates. They also found that emissions on minor arterials were the highest due to frequent stop-and-go and serving stops, while the emissions on expressways were the lowest. At bus stations, where buses would slow down, idle, and accelerate, the emissions were far higher than those on regular road segments. On a temporal basis, the emissions during rush hours were higher than those during off-peak hours. The $11.15 \%$ increase in speed on bus exclusive lanes over speed on normal lanes reduced all types of emissions by more than $10 \%$ except for particulate matter (PM).

Frey et al. (2008) conducted benchmark comparisons for link-based emission rates. The comparison showed that nitric oxide $(\mathrm{NO})$ emission rates increase with speed, but $\mathrm{CO}$ and $\mathrm{HC}$ emission rates were not as sensitive to change in speed as NO emissions. 
Brodrick et al. (2002) studied the effect of accessory loading and engine speed on idling emissions. It was found that engine model year, engine speed, and accessory load had a great effect on emissions during idling. The length of idling time over which emissions were measured could affect the $\mathrm{NO}_{\mathrm{x}}$ emissions levels. While idling, the $\mathrm{NO}_{x}$ emissions (g/gal) were twice as high as emissions when the vehicle was traveling at $55 \mathrm{mph}$ in highway operation. The $\mathrm{CO}_{2}$ emissions were similar during idling and highway operation. The study suggested that using the lowest engine speed with the smallest accessory load could minimize idling emissions of $\mathrm{NO}_{x}$ and $\mathrm{CO}_{2}$.

\subsubsection{Fuel Type}

Different fuels other than traditional diesel may provide an opportunity to reduce heavy-duty engine emissions, especially fuels that do not require engine modifications such as a reformulated diesel.

Clark et al. (2002) stated that complete fuel reformulation could significantly reduce $\mathrm{NO}_{x}$ and $\mathrm{PM}$ emissions. Diesel fuel additives, in particular the cetane number enhancer, have proven to reduce emissions. In addition, the use of biodiesel fuel strongly decreased the $\mathrm{CO}$, hydrocarbon (HC), and PM emissions, but increased the $\mathrm{NO}_{x}$ emissions. 
Frey et al. (2008) estimated link-based emission rates for single rear-axle and tandem-axle dump trucks using a speed-acceleration modal emission approach. Similarly, they found that using biodiesel fuel instead of diesel fuel for heavy-duty trucks reduced PM, CO, and HC emissions, while it may decrease tailpipe nitric oxide (NO) exhaust emissions. Both fuels (biodiesel and diesel) were found to produce the same carbon dioxide $\left(\mathrm{CO}_{2}\right)$ emissions. Similar results were obtained by the study of Frey and Kim (2006) when they compared emissions for dump trucks fuelled with B20 biodiesel versus petroleum diesel. They observed that the average fuel consumption and $\mathrm{CO}_{2}$ emissions rates were nearly the same for both types of fuels, but when using B20 biodiesel fuel instead of petroleum diesel, the average emissions rates of nitric oxide (NO), $\mathrm{CO}, \mathrm{HC}$, and PM decreased by $10 \%, 11 \%, 22 \%$, and $10 \%$, respectively.

The chassis dynamometer test applied on 21 in-use heavy-duty diesel vehicles in the study by Yanowitz et al. (1999), analyzed a subset of particulate samples for sulfate. It was found that sulfate was not well correlated with total PM emissions, nor comprised a significant portion (less than 1\%) of them. In 1992, when the allowable sulfur content in diesel fuel was 5000 ppm, emission tests found that PM emissions included 11\% (on average) of sulfate. This 
suggested that reducing sulfur content in the diesel fuel to $500 \mathrm{ppm}$ (the allowable sulfate level in the diesel fuel used in the study) was effective in reducing $\mathrm{PM}$ emissions.

\subsubsection{Terrain Traveled}

Studies show that road grade highly affects fuel consumption and emissions. Clark et al. (2002) and Pierson et al. (1996) have examined terrain effects on emissions of heavy-duty vehicles. Clark et al. (2002) used a model to investigate the effect of a $7 \%$ upgrade on nitrogen oxide $\left(\mathrm{NO}_{\mathrm{x}}\right)$ emissions of a

Class 8 tractor-trailer for different axle power. The study showed that the relationship between the $\mathrm{NO}_{\mathrm{x}}$ emissions and the power was directly proportional. Pierson et al., who conducted early grade-effects research on heavy-duty vehicles in the Fort McHenry Tunnel under Baltimore Harbor, obtained similar results. They found that carbon monoxide $(\mathrm{CO})$, carbon dioxide $\left(\mathrm{CO}_{2}\right)$, nitrogen oxide $(\mathrm{NO} \times)$, and nonmethane hydrocarbon $(\mathrm{HC})$ emissions on upgrades (grades to $3.76 \%$, average $3.3 \%$ ) were generally double emissions on downgrades (grades to $-3.76 \%$, average $-1.8 \%$ ). However, Kean et al. (2003) found that when driving uphill, the increase in $\mathrm{NO}_{x}$ emissions with vehicle speed was not as much as compared with CO emissions. 
Boriboonsomsin and Barth (2009) used real-world experimental data from light-duty vehicles, and revealed that fuel economy (and thus $\mathrm{CO}_{2}$ emissions) on flat terrain was better by approximately $15-20 \%$ lower than on hilly terrain. However, fuel consumption rates were less on downgrades than on flat routes. The relationship between fuel consumption and road grade was found to be non-linear. Scora et al. (2010) used heavy-duty truck test data and found a strong relationship between grade and $\mathrm{CO}_{2}$ emissions, which agrees with results obtained by Boriboonsomsin and Barth (2009). The test results showed that in the range of $0 \%$ to $2 \%$ grade, a $1 \%$ increase in grade could raise the $\mathrm{CO}_{2}$ emissions by about $35 \%$. They concluded that the relationship between $\mathrm{CO}_{2}$ emissions $(\mathrm{g} / \mathrm{mi})$ and speed becomes more linear at higher uphill grades. It was found that at large downgrades, the $\mathrm{CO}_{2}$ emission rates at high speed-driving beyond the point of minimum $\mathrm{CO}_{2}$ emissions was generally much less than at lower speeds. Another conclusion was that the grade effect increased emissions at lower speed and decreased emissions at higher speeds. When comparing two routes for the same trip, one flat and the other with up and downgrades, it was concluded that if the flat route was not twice as long as the hilly one, then taking the flat route would result in fuel savings. This 
factor of 2 in fuel consumption was not consistent with the $15-20 \%$ factor found by Boriboonsomsin and Barth (2009).

\subsubsection{Environmental Factors}

\subsubsection{Altitude}

At high altitudes the air density becomes less due to reduction in atmospheric pressure (Agudelo et al., 2009). Reduced air density results in loss of vehicle horsepower. The reason of this power loss is that diesel engines compress the air to create the heat necessary to ignite this air and fuel mixture. Lack in air, and consequently oxygen needed for ignition process, results in less heat which negatively affects fuel consumption and engine power.

There was little literature found that discussed the effect of altitude on heavy-duty diesel vehicle emissions. One study by Bishop et al. (2001) analysed on-road emissions of carbon monoxide (CO), hydrocarbons (HC), and nitric oxide (NO) obtained from 5,772 heavy-duty diesel trucks at five different locations in the United States and Europe. The results from the analysis showed slight increases in emissions with increasing altitude. NO had a significant increase of $4.1 \pm 1 \mathrm{gNO} / \mathrm{kg}$ of fuel consumed $/ \mathrm{km}$ increase in the altitude. The increase in $\mathrm{CO}$ and $\mathrm{HC}$ emissions had proven to be statistically significant as well. 


\subsubsection{Ambient Temperature and Humidity}

Pandian et al. (2009) found that ambient temperature directly affects evaporative hydrocarbon (HC) emissions. At very low ambient temperatures (e.g. below $20^{\circ} \mathrm{F}$ ), emissions at ignition could be influenced and result in cooling of the catalyst of some vehicles during short stops. Similarly, Bigazzi and Bertini (2009) stated that temperature and humidity affect the evaporative emission rates both during engine operation and rest. Cold weather affected exhaust emissions as a result of decreased engine efficiency and catalytic converters. High ambient temperatures encourage the use of air conditioning, which increases engine loads. On the contrary, Wenzel et al. (2000) showed that very high ambient temperature had the least effect on exhaust emissions because engine load would increase due to the use of the air conditioner. The increase in ambient humidity was found to decrease the nitrogen oxide $\left(\mathrm{NO}_{\mathrm{x}}\right)$ emissions (Pandian et al., 2009). SwRL (2003) concluded that humidity had some effect on decreasing the $\mathrm{NO}_{x}$ emissions of heavy-duty engines, but Hearne (2004) did not find any conclusive trends between $\mathrm{NO}_{\mathrm{x}}$ emissions and humidity. 


\subsection{Emission Models}

The majority of emission models include a number of vehicle characteristics, travelled mileage, and driving modes, but other important factors like vehicle weight, road grades, and weather effects are not sufficiently addressed as they are difficult to predict or measure. The main types of emission models are: speed-based, modal, and fuel-based models. The first two types are the most used. In speed-based models, the main input is the average speed (Bigazzi et al., 2009). Simplicity and limited data needs are their main advantages, but they do not account for driver (speed fluctuations) and roadway influences. Examples of speed-based emissions include EPA MOBILE (recent version named MOVES), COPERT, and EMFAC (by California Air Resources Board, CARB). Modal models are based on vehicle's operating mode determined from roadway, driver, and traffic factors to calculate emissions. Using speed and acceleration enhances the model accuracy, but the data requirements are more intensive. The fuel-based models estimate emissions based on amount of fuel consumed in various operating modes to directly predict the carbon dioxide $\left(\mathrm{CO}_{2}\right)$ emissions.

As stated by Façanha et al. (2010), MOBILE6 and EMFAC2007 meet the requirements of NEPA (National Environmental Policy Act) and are the 
approved models for State Implementation Plans (SIP's), conformity analyses, and project-level analyses. MOVES2009 will eventually replace MOBILE6. The most established micro-simulation emission model is CMEM. MOBILE6 and EMFAC2007 are not appropriate for use in project-level analysis except with the availability of key local factors such as average speed, truck age distribution, and miles travelled by each truck type. Due to the lack of collected local data, the national defaults are often used instead of local factors, which is considered a source of substantial uncertainty. In the model on the other hand, MOBILE6 and EMFAC2007 are ill-suited to accurately incorporate congestion effects as they use speed correction curves to estimate emissions by average speed. Another problem is the use of Vehicle Inventory and Use Survey (VIUS) data for the characteristics of truck population. The last version of VIUS was published in 2002, so there are concerns about how outdated these data are becoming. Add to this the missing temporal distribution of emissions in the models, which are critical for air quality analysis. Table 1 lists the most important input parameters used in emissions calculations. Their importance is based on the impact on emissions and the level of uncertainty in the parameter estimates. It is obvious that the vehicle 
miles travelled (VMT), and the driving cycle have the highest impact on emissions, but at the same time have the most highly uncertain estimates.

Table 1: List of Truck Parameters (Façanha et al., 2010)

\begin{tabular}{|c|c|c|c|c|}
\hline Parameter & Methods/Models & $\begin{array}{l}\text { Geographic } \\
\text { Scale }\end{array}$ & $\begin{array}{l}\text { Impact on } \\
\text { Emissions }\end{array}$ & Uncertainty \\
\hline Truck VMT & All & All & High & Medium/High \\
\hline $\begin{array}{l}\text { VMT Share by Truck } \\
\text { Type }\end{array}$ & All & All & Medium/High & Medium/High \\
\hline $\begin{array}{l}\text { VMT Share by Time } \\
\text { of Day }\end{array}$ & All & Regional/Local & Low/ Medium & Medium/High \\
\hline $\begin{array}{l}\text { Truck Age } \\
\text { Distribution }\end{array}$ & All & All & Medium/High & Medium \\
\hline $\begin{array}{l}\text { Mileage } \\
\text { Accumulation }\end{array}$ & All & All & Medium & Medium \\
\hline $\begin{array}{l}\text { Distribution of } \\
\text { Emission Control } \\
\text { Technology }\end{array}$ & All & All & Low/ Medium & Medium \\
\hline $\begin{array}{l}\text { Truck Fuel Type } \\
\text { Distribution }\end{array}$ & All & All & Medium & Low/ Medium \\
\hline Average Speed & $\begin{array}{l}\text { MOBILE6, } \\
\text { EMFAC2007 }\end{array}$ & Regional/Local & Medium & Medium \\
\hline Driving Cycles & CMEM & Local & Medium/High & High \\
\hline Emission Factors & All & All & High & High \\
\hline $\begin{array}{l}\text { Classification of } \\
\text { Truck Types }\end{array}$ & All & All & Medium & Medium \\
\hline Road Grade & CMEM & Local & Low/ Medium & Low \\
\hline Empty Miles & All & All & Medium & High \\
\hline
\end{tabular}

Dreher and Harley (1998) found that the potential reason for uncertainty in using MOBILE and EMFAC models to predict heavy-duty truck 
emissions is the need to convert from gram per brake horsepower units to mass emission rates per unit distance travelled. The reason of this uncertainty is that there is a wide range of diesel engine sizes and gross vehicle weights for heavy-duty trucks, and the variation in emission factors normalized to work output would be less than those estimated on distance-travelled basis. Where the fuel-based models used to estimate heavy-duty truck emissions have the advantages that the fuel-use data are available from tax records, and the emission factors normalized to fuel consumption have less variability over the full range of driving conditions than travel-normalized emission factors. Yoon et al. (2004) states that another problem of using MOBILE is that this model deals with the heavy heavy-duty diesel vehicles (HHDDV's) as a single vehicle type, and uses national default parameters for their engine and weight characteristics.

Brodrick et al. (2002) compared nitrogen oxide $\left(\mathrm{NO}_{x}\right)$ idling emissions of Class 8 trucks obtained from laboratory tests with those obtained from the EMFAC2000 and MOBILE5b emissions inventory models. The results showed that both models underestimated the $\mathrm{NO}_{x}$ emissions in all of the idling conditions. 
Dreher and Harley (1998) applied a fuel-based model to estimate the heavy-duty diesel truck emissions of the San Francisco Bay Area. It was found that the nitrogen oxide $\left(\mathrm{NO}_{\mathrm{x}}\right)$ emissions were $110 \times 10^{3} \mathrm{~kg} /$ day, and the black carbon $(\mathrm{BC})$ emissions are $3.7 \times 10^{3} \mathrm{~kg} / \mathrm{day}$. These values were 2.3 and 4.5 times higher, respectively, than the corresponding estimates of California's motor vehicle emission inventory model, MVEI 7G.

Singh et al. (2003) developed a microscale emission factor model, called MicroFacPM, to estimate site-specific real-time vehicle particulate matter (PM), which was more essential for human exposure studies. The motivation was that they found that the contemporaneously used PM emission models were only suitable for county-scale modelling and emission inventories. The model's inputs included information on the characteristics of the on-road realtime fleet, average vehicle speed, time and day of year, ambient temperature, and relative humidity. It predicts PM emission rates for both light- and heavyduty vehicles. One of the study results was that despite the small percentage (less than $2 \%$ ) of diesel vehicles in the tested fleet, they contributed the most significant percentage (62\%) of all $\mathrm{PM}_{2.5}$ emissions. 


\subsection{Summary of Findings}

The findings from the literature review are summarized in Table 2, which tabulates the descriptions of the influencing factors, their parameters, and the relation to emission rates.

For the factors affecting emissions mentioned in Table 2, an estimate of how much every factor affects emissions rate was identified (Clark et al., 2002). The results are shown in Figure 4 and Figure 5, where each bar represents the amount a factor could change the emissions of particulate matter $(\mathrm{PM})$ and nitrogen oxide $\left(\mathrm{NO}_{\mathrm{x}}\right)$, because these are the emissions of the most interest in case of heavy-duty diesel vehicles. It was concluded that the driving mode had the largest effect on both the PM and $\mathrm{NO}_{\mathrm{x}}$ emissions. 
Table 2: Relation Between Influencing Characteristics and Emission Rates

\begin{tabular}{|c|c|c|c|c|}
\hline Characteristics & Parameters & $\begin{array}{l}\text { Pollutants } \\
\text { Studied }\end{array}$ & $\begin{array}{l}\text { Influence on Emission } \\
\text { rates }\end{array}$ & References \\
\hline \multirow[t]{3}{*}{ Vehicle } & Class and Weight & $\mathrm{NO}_{x}$ and $\mathrm{PM}$ & $\begin{array}{ll}\begin{array}{l}\text { Increase in } \\
\text { consumption }\end{array} & \text { and } \\
\text { emissions } & \end{array}$ & $\begin{array}{l}(4,7,8,9, \\
13,15,16, \\
23,24,30, \\
31)\end{array}$ \\
\hline & Vehicle Age & NOx and PM & $\begin{array}{l}\text { Older vehicles cause } \\
\text { higher emissions }\end{array}$ & $\begin{array}{l}(8,21,29, \\
31)\end{array}$ \\
\hline & $\begin{array}{l}\text { Engine } \\
\text { Aftertreatment }\end{array}$ & $\begin{array}{l}\mathrm{NO}_{x}, \mathrm{PM} \text {, and } \\
\mathrm{CO}\end{array}$ & Reduces emissions & $(8)$ \\
\hline Travel & $\begin{array}{l}\text { Speed and } \\
\text { Operating Mode }\end{array}$ & $\begin{array}{l}\mathrm{NO}_{x}, \mathrm{PM}, \mathrm{CO}_{2}, \\
\mathrm{HC}, \mathrm{CO} \text {, and } \\
\mathrm{NO}\end{array}$ & $\begin{array}{l}\text { Changing rate of speed } \\
\text { defines driving mode. } \\
\text { Rapid acceleration and } \\
\text { deceleration emits } \\
\text { more emission than } \\
\text { cruising followed by } \\
\text { idling }\end{array}$ & $\begin{array}{l}(1,4,5,7 \\
8,12,13 \\
17,19,21 \\
24,26,31)\end{array}$ \\
\hline Driver & Driving Style & $\begin{array}{l}\mathrm{NO}_{x}, \mathrm{PM} \text {, and } \\
\mathrm{CO}\end{array}$ & $\begin{array}{l}\text { Aggressive driving } \\
\text { generates more } \\
\text { emissions and causes } \\
\text { poorer fuel economy }\end{array}$ & $\begin{array}{l}(1,4,5,7 \\
8,12,13 \\
17,19,21 \\
24,26,31)\end{array}$ \\
\hline Fuel & Fuel Type & $\begin{array}{l}\mathrm{NO}_{x}, \mathrm{PM}, \mathrm{CO}_{2}, \\
\mathrm{HC}, \mathrm{CO} \text {, and } \\
\mathrm{NO}\end{array}$ & $\begin{array}{l}\text { Biodiesel fuel has the } \\
\text { potential to reduce } \\
\text { engine emissions }\end{array}$ & $\begin{array}{l}(8,13,14, \\
31)\end{array}$ \\
\hline Roadway & Road Grade & $\begin{array}{l}\mathrm{NO}_{x}, \mathrm{CO}_{2}, \mathrm{CO} \text {, } \\
\text { and } \mathrm{HC}\end{array}$ & $\begin{array}{l}\text { Upgrade has positive } \\
\text { effect on emissions }\end{array}$ & $\begin{array}{l}(2,8,20, \\
22,24)\end{array}$ \\
\hline \multirow[t]{3}{*}{ Environmental } & Altitude & $\begin{array}{l}\mathrm{CO}, \mathrm{NO} \text {, and } \\
\mathrm{HC}\end{array}$ & $\begin{array}{l}\text { Slight increase in } \\
\text { emissions at higher } \\
\text { altitudes }\end{array}$ & (6) \\
\hline & $\begin{array}{l}\text { Ambient } \\
\text { Temperature }\end{array}$ & $\mathrm{NO}_{x}$, and $\mathrm{HC}$ & $\begin{array}{l}\text { Less ambient temp. } \\
\text { and rapid vehicle } \\
\text { cooling affect ignition } \\
\text { temp. and decreases } \\
\text { emissions }\end{array}$ & $(1,21,28)$ \\
\hline & Humidity & $\mathrm{NO}_{x}$ & $\begin{array}{l}\text { Higher ambient } \\
\text { humidity reduces } \\
\text { emissions }\end{array}$ & $(18,27,28)$ \\
\hline
\end{tabular}




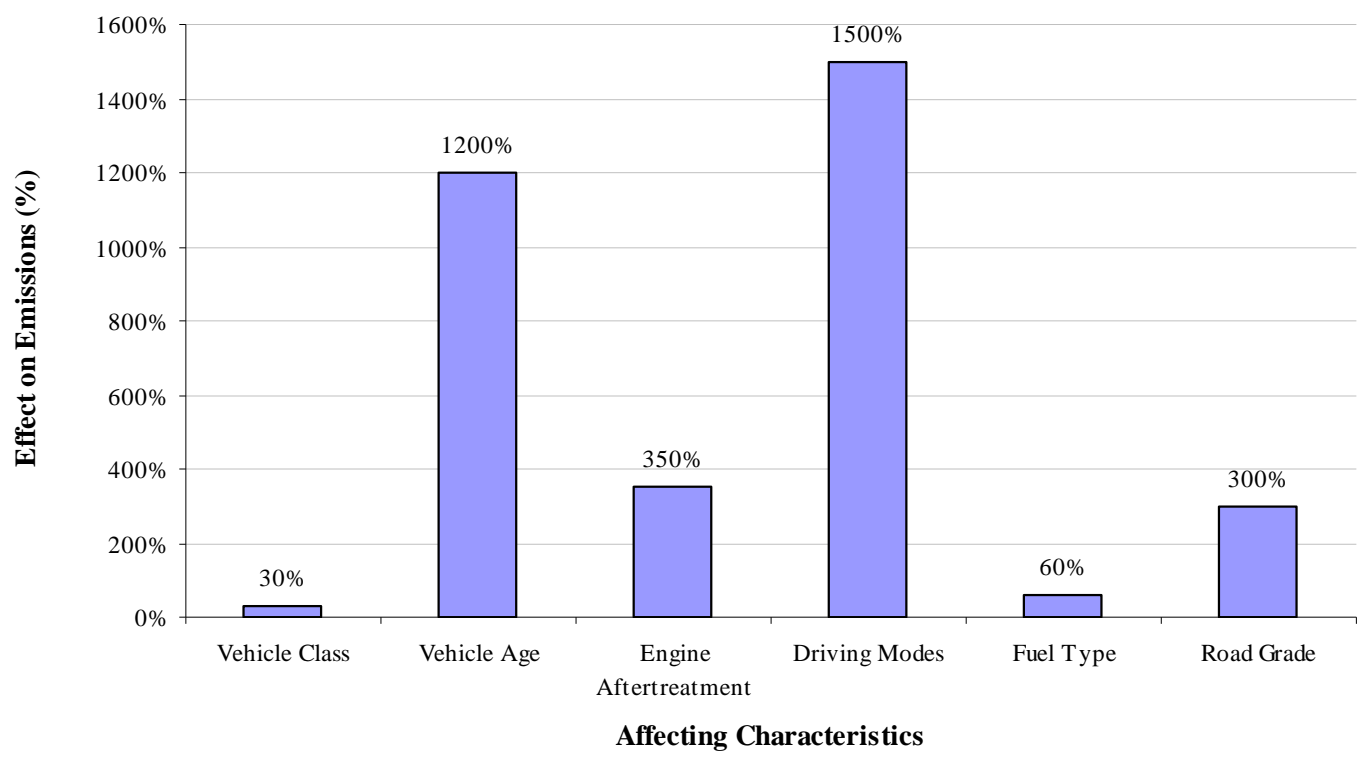

Figure 4: Effect of Various Factors on PM Emissions (Clark et al., 2002)

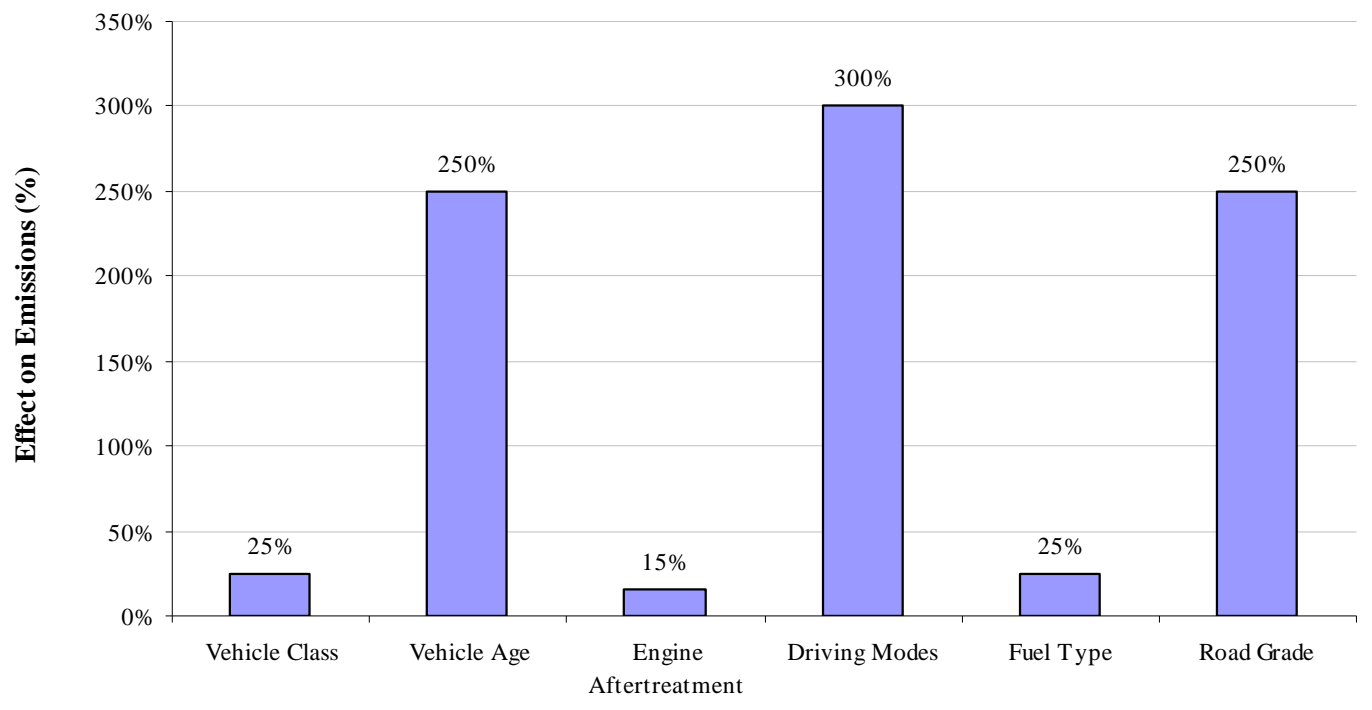

Affecting Characteristics

Figure 5: Effect of Various Factors on $\mathrm{NO}_{x}$ Emissions (Clark et al., 2002) 


\subsection{Conclusions and Recommendations}

Heavy-duty diesel vehicles continue to play an increasingly important role in the overall emissions inventory. Concerns about this source of emissions require greater understanding and evaluation of the factors that most affect them. In this literature review a survey of the factors that impact heavy-duty vehicle emissions has been conducted, along with quantification of each factor's significance. Most studies have concentrated on limited parameters of the characteristics such as driving speed and driving modes. Few studies critically accounted for and assessed the impacts of other parameters, which are hard to quantify because of their high expenses like vehicle weight and road grade for example. These studies suggested that these factors have a significant effect on heavy-duty diesel vehicle emissions. However, the lack of proper methodology in estimating emissions which incorporates all significant parameters has slowed down the advancement in heavy-duty vehicles' emission modelling.

Critical gaps were found to exist within current literature and emissions modeling. These gaps include: 
- Although the effects of vehicle weight and road grade were found to be most pronounced for the emissions of heavy-duty vehicles, they have not been studied in detail.

- There is little reported literature on the effects of altitude on compression ignition engine emissions.

- Current modelling practices estimate heavy-duty vehicle travel as a fixed percentage of predicted traffic volumes. However, heavy-duty truck travel does not have the same spatial and temporal trends as light-duty vehicle travel. Consequently, the activity estimates of heavy-duty vehicle used in the models should not be based upon light-duty vehicle travel patterns.

- Fleet characteristics used in developing the emissions models are derived from the VIUS (Vehicle Inventory and Use Survey) dataset representing the 2002 fleet. These data may not be reflective for the present actual on-road fleet.

- Truck emissions at high driving speed are not well documented, which could result in inaccuracy of on-road mobile inventories in terms of emission factors and could therefore mislead the design of countermeasures to control vehicle emissions from these sources. 
- Idling time is hard to quantify, although it presents a significant percentage (up to $50 \%$ ) of the total operating time. As a result of the lack of idling time data, they are not taken in account when predicting emissions.

- There is a lack of real-world data to be used as actual input for the emissions models. This results in using the national defaults instead of actual data.

In summary, there are key features that can enhance the current emissions prediction models. Models should take into account most of the heavy-duty vehicles' characteristics that have proved to significantly affect emissions such as vehicle weight, vehicle age, engine type, fuel type, and road grade. Future work should focus on filling the identified gaps to increase the accuracy of the emissions estimates obtained from the models. The work done in this thesis combined key factors (gross vehicle weight, road grade, and vehicle speed) in estimating link-based emission factors. Results obtained could be used to improve the accuracy models used to estimate the emission factors of heavy-duty vehicles.

Better understanding and assessment of the impact of the different factors presented in this review of literature that affect the emissions of heavyduty diesel vehicles and improving the accuracy of the models used to 
estimate the real-world emissions is essential for developing successful regional air quality management plans and to evaluate different technologies and strategies of emission control measures.

This chapter reviewed the literature that studied the most significant factors affecting heavy-duty emissions. The models typically used to predict the emissions factors, together with their areas of strength, weakness, and potential improvements were discussed. The final section summarized the key findings, and provided the conclusions and recommendations. The next chapter will present the data used in this research, discuss the methodologies and assumptions for estimating link-based heavy-duty vehicle emissions, and describe the chosen case study. 


\subsection{METHODOLOGY}

In this chapter, the data, methodologies, and the chosen case study are described. The first section gives a brief overview of Oregon's Weigh-InMotion (WIM) data. A summary of the algorithm developed in previous research for filtering the through trucks between stations is presented in the second section. In the third section, the methodology and assumptions for estimating link-based nitrogen oxide $\left(\mathrm{NO}_{\mathrm{x}}\right)$ and carbon dioxide $\left(\mathrm{CO}_{2}\right)$ emissions are discussed. Finally, in the last section, a description of the case study used to apply the methodology is introduced.

\subsection{Weigh-In-Motion (WIM) Data}

In 1995, the Green Light Program was initiated in Oregon using the existing intelligent transportation systems (ITS) infrastructure for commercial trucking weight and safety enforcement as a weigh station preclearance program (Monsere et al., 2009). In addition, the program aimed to improve the performance of roadside weigh station facilities without the need to expand them. Presently, there are 22 equipped weigh stations on the Oregon highway system as shown in Figure 6. Sensors at each of the fixed weigh-in-motion (WIM) sites check the vehicle's weight, height and class (from the number and spacing of the axles), while the automatic vehicle identification (AVI) systems 
check vehicle's registration, tax status, and safety status. According to these checks, the driver is signaled with a device inside the vehicle cab as to whether report to the station or to bypass (green light). The data recorded at each observation also include the vehicles speed, a timestamp, lane (at locations with multiple lanes), and vehicle length. Data have been gathered every month starting in July 2005.

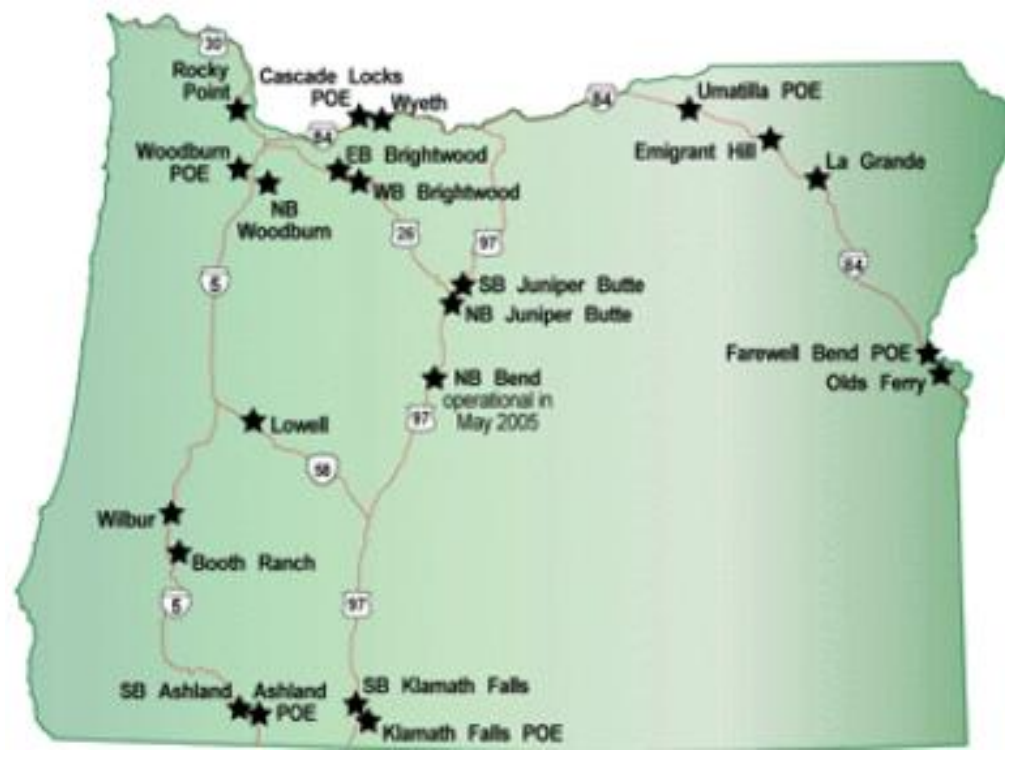

Figure 6: Oregon Green-Light Locations

This vast amount of WIM data are archived under the Portland Oregon Regional Transportation Archive Listing (PORTAL) at Portland State University's (PSU) Intelligent Transportation Systems Lab (ITS Lab). Monthly data were sent in the form of comma-separated files to PSU from the Oregon Department of Transportation (ODOT) Motor Carrier through the ODOT FTP 
website. Data were extracted and four main tables were created in the archive. The primary table is called wimdata and contains the truck-level observations. Information about each weigh station is loaded in the stations table. In previous research conducted by researchers in the ITS Lab at Portland State University (Monsere et al., 2009), methods and algorithms were developed to create two additional tables. The table stationmap provides a list of all possible routes or links (i.e. station pairs), free flow travel time, distance, and a parameter called upper time (which is the travel time at 50-mph speed). The last table, linktraveltime, contains all matched tags between upstream and downstream stations, station numbers, tag numbers, and timestamps.

\subsection{Through-Truck Filter}

This section summarizes the algorithm developed by (Monsere et al., 2009) to estimate through trucks' link-based travel time. Identifying only the through trucks traveling between two stations took place in two steps. First, all matched tags at the upstream and downstream stations of each link that have a travel time within a specified time window of $0.75^{*}$ free flow time to $2^{*}$ free

flow time are identified. The free flow time is the time taken to traverse the link at $55 \mathrm{mph}$. The second step was to filter only the through trucks. 
In order to apply the tag-matching algorithm, it was needed to determine all the possible downstream stations that a truck can go to from a certain upstream station. For simplicity, it was assumed that the trucks used the fastest available route. The distance of each path (in miles) was measured using Google Earth, and assuming the trucks traveled at the posted speed limit (55 mph), the free flow travel time for each link was determined.

To accurately estimate link travel time, only through trucks (trucks traveling between upstream and downstream stations without stopping) are the vehicles of interest. The long distances between stations introduced some uncertainty to the through-trucks filtering algorithm. Under normal conditions, trucks were expected to traverse the link within a small time window. Trucks that exceeded this time window would have stopped for other activities (e.g. driver rest, delivery, or pick-up). On the other hand, if a delay-causing event occurred (e.g. weather, construction, or incident) on the highway, it was normal to expect longer travel time than the expected time window. For that reason, the through-trucks filtering algorithm assumed that if a number of consecutive trucks had nearly the same long travel times, then a delay-causing event should have occurred. 
The through-trucks filtering algorithm was validated using periods of known delay on highway segments for which data were available. The chosen types of delay were incident and weather-induced delays. The incident delays were obtained from the Oregon State Police statewide dispatch database for the year 2007. To examine the weather-induced delays, weather data were taken from Road Weather Information Systems (RWIS) automatic weather stations with supplementary data from the National Oceanic and Atmospheric Administration (NOAA) at Pendleton, Oregon. The inspection of several links suggested that the filter did a reasonable job of identifying through trucks that had faced some delay.

For this study, the archived WIM data for the year 2007 will be used. Monthly data with high quality for links on Oregon's key freight corridors (I-5 and I-84) will be chosen. Data of the most dominant truck class on the studied links (Class 9, or five-axle truck) for January 2007 will be analyzed. More details will be explained in the section of the case study. It should be noted that the majority of the literature reviewed in the previous chapter identified the five-axle truck as Class 8. 


\subsection{Estimating Link-Based Heavy-Vehicle Emissions}

As mentioned above, the archived weigh-in-motion (WIM) database provides information about the gross vehicle weight (GVW), vehicle class, and the through trucks identified using the algorithm described in section 3.2. The link average speed for observed trucks can be calculated knowing the travel time (by subtracting dwn_timstamp from up_timestamp) and the approximate link distance. In addition, because trucks can be uniquely identified between WIM stations they can be associated with link properties such as grade.

The effect of the truck weight and the road grade on emissions has not been studied in detail. The objective of this case study is to explore the possibility of using vehicle weight and average speed from the archived WIM database, together with the link grade to estimate link-based emissions for one of Oregon's main freight corridors. The proposed methodology develops emission factors from published research and applies them to the WIM data set.

\subsubsection{Extracting Vehicle Weight and Speed from WIM Database} As mentioned before, Interstate 5 (I-5) and Interstate 84 (I-84) are highly significant freight corridors in Oregon, as they connect major population centers and transportation infrastructure in the north-south and east-west 
directions, respectively. As a result, this study will focus on a link that lies on one of these two main corridors. The links' numbers, names of the upstream and downstream stations, link distance, and free flow travel times are listed in Table 3.

Table 3: I-5 and I-84 Links

\begin{tabular}{|c|c|c|c|c|c|c|}
\hline Hwy & Link ID & Upstream Station & $\begin{array}{l}\text { Downstream } \\
\text { Station }\end{array}$ & $\begin{array}{l}\text { Link } \\
\text { Distance } \\
\text { (mi) } \\
\end{array}$ & $\begin{array}{l}\text { Free } \\
\text { Travel } \\
\text { (hrs) } \\
\end{array}$ & $\begin{array}{l}\text { Flow } \\
\text { Time }\end{array}$ \\
\hline \multirow[t]{2}{*}{$\mathrm{I}-5$} & 211 & $\begin{array}{l}\text { Ashland Port Of } \\
\text { Entry (POE) (NB, } \\
\text { MP 18.08) }\end{array}$ & $\begin{array}{l}\text { Booth Ranch (NB, } \\
\text { MP 111.07) }\end{array}$ & 93.4 & 1.70 & \\
\hline & 214 & $\begin{array}{l}\text { Booth Ranch (NB, } \\
\text { MP 111.07) }\end{array}$ & $\begin{array}{l}\text { Woodburn } \\
\text { MP 274.15) }\end{array}$ & 165.0 & 3.00 & \\
\hline \multirow[t]{4}{*}{ I-84 } & 201 & $\begin{array}{l}\text { Farewell Bend Port } \\
\text { Of Entry (POE) } \\
\text { (WB, MP 353.31) }\end{array}$ & $\begin{array}{l}\text { Emigrant Hill } \\
\text { (WB, MP 226.95) }\end{array}$ & 126.4 & 2.30 & \\
\hline & 202 & $\begin{array}{l}\text { Emigrant Hill (WB, } \\
\text { MP 226.95) }\end{array}$ & $\begin{array}{l}\text { Wyeth (WB, MP } \\
54.3)\end{array}$ & 172.7 & 3.14 & \\
\hline & 208 & $\begin{array}{l}\text { Cascade Locks Port } \\
\text { Of Entry (POE) (EB, } \\
\text { MP 44.93) }\end{array}$ & $\begin{array}{l}\text { LaGrande (EB, MP } \\
\text { 258.52) }\end{array}$ & 214.0 & 3.89 & \\
\hline & 210 & $\begin{array}{l}\text { LaGrande (EB, MP } \\
258.52)\end{array}$ & $\begin{array}{l}\text { Olds Ferry } \\
\text { MP } 354.38)\end{array}$ & 96.1 & 1.75 & \\
\hline $\begin{array}{l}\mathrm{I}-5 \& \\
\mathrm{I}-84\end{array}$ & 205 & $\begin{array}{l}\text { Wyeth (WB, MP } \\
54.3)\end{array}$ & $\begin{array}{l}\text { Woodburn POE } \\
\text { (SB, MP 274.18) }\end{array}$ & 78.9 & 1.43 & \\
\hline
\end{tabular}

The needed data for any link are found in the WIM data archive and will be extracted from a table called link_traveltime_all. This table contains all 
upstream and downstream information about each observed truck, such as: link number, stations, tag numbers, timestamps, truck type, used lane, average speed, gross vehicle weight, truck length, number of axles, axle spacing, and whether it is a through truck or not. From the difference between the downstream and upstream timestamps, the trip travel time can be calculated.

For each link, only certain observations are selected for the analysis. The selected records are based on the following criteria:

1. Chosen records should be for filtered through trucks to correctly estimate the actual link emissions.

2. Emissions will be estimated for the most dominant type of trucks on the studied highways. It was found that the five-axle trucks had the highest counts. In the WIM database the five-axle truck is type 11 (an internal ODOT code) which is the Federal Highway Administration's (FHWA) classification type 9 .

3. Since the intended goal is to study the emissions of heavy-duty vehicles, then only trucks with weight more than or equal 8,500 lbs are taken.

4. Observed trucks with speeds less than $40 \mathrm{mph}$ are neglected, as these are assumed to be outliers. The reason is that they would not be considered as 
through trucks traveling on a highway with such low speed unless there was a certain event that caused trucks to slow down.

5. To study the effect of weight on the emissions, the gross vehicle weights were divided into three categories: empty, medium, and full. Yoon et al. (2004) investigated vehicle weight through a screen-line cordon survey in the 21-county Atlanta metropolitan area. It was found that although the U.S. Department of Transportation (USDOT) truck size and weight study in 2000 suggested that a heavy heavy-duty vehicle weight of 30,500 lbs would be an empty load, the survey reported $33,000 \mathrm{lb}$ as an empty load. Therefore, according to (Yoon et al., 2004), MOBILE6 Vehicle Classifications, and the FHWA Freight Management and Operations, three weight bins were selected as follows: empty $(8,500-33,000 \mathrm{lbs})$, medium (33,000-60,000 lbs), and full (60,000 lbs-Above). The minimum weight for empty trucks is taken at $(8,500 \mathrm{lbs})$ although it is known that Class 9 (fiveaxle) trucks weigh more than that. The reason was to get an idea about the percentage of trucks misclassified as Class 9 in the studied case study (more details in section 4.1.4). The truck load is assumed to be the same over the whole trip. 


\subsubsection{Effect of Grade on Heavy-Duty Vehicle Speeds}

Recently, due to the increases in trucking movement and the use of larger and heavier trucks on the majority of highways, it has become of an increasing need and importance to take into consideration the speed gain or loss resulting from gross vehicle weights on downgrades and upgrades, and consequently in estimating the emissions.

The American Association of State Highway and Transportation Officials (AASHTO) Policy on Geometric Design (2001) provides a single set of truck speed profile charts (speed drop/gain versus distance) derived using the design standard of the weight-to-power ratio (W/P) equal to $120 \mathrm{~kg} / \mathrm{kW}$ (200 lb/hp). These charts have some limitations. Although the design standard used to develop the charts is representative of the average trucking activities in the U.S., the single set of speed profiles might not be universal or suitable for all locations (e.g. those locations with a significant mix of larger and heavier trucks with more axial loads). However, AASHTO does not suggest a computational procedure or information for such cases. In addition, AASHTO assumes that trucks with the same $\mathrm{W} / \mathrm{P}$ ratio have similar performance and operating characteristics. This assumption may be valid if the grade resistance dictates the overall resistance. Another limitation in the AASHTO method is 
that the chart requires that the initial entering speed is less than $110 \mathrm{~km} / \mathrm{hr}(70$ $\mathrm{mph}$ ) and the final speed is less than $90 \mathrm{~km} / \mathrm{hr}$ (55 mph).

In order to overcome the AASHTO curves limitations, Lan and Menendez (2003) proposed a well-defined approach and formulation to obtain truck speed profiles based on nominal dynamic, kinematic, and operating characteristics of trucks on grades. The approach considered not only the W/P and the grade, but also the design engine power of trucks. The study provided a speed-profile model, then the results were calculated by numerical integration and the values that reflect different design standards for critical length were represented using a series of tables and figures. For practical application, an approximation model for calculation by hand is presented. This approximation model is used in this study. The model equation and a list of the definitions of coefficients with the recommended values are as follows:

$$
x=\frac{u_{i}-u_{f}}{\beta}+\frac{\alpha}{\beta^{2}} \ln \left(\frac{u_{i}-\alpha / \beta}{u_{f}-\alpha / \beta}\right)
$$

where

$x=$ travel distance on grade $(\mathrm{ft})$,

$u_{i}=$ initial (entering) speed $(\mathrm{ft} / \mathrm{sec})$,

$u_{f}=$ final speed $(\mathrm{ft} / \mathrm{sec})$, 


$$
\begin{gathered}
\alpha=\frac{a_{\circ} u_{x}-a_{x} u_{\circ}}{u_{x}-u_{\circ}} \\
\beta=\frac{a_{\circ}-a_{x}}{u_{x}-u_{\circ}}
\end{gathered}
$$

where

$\alpha=\operatorname{coefficient}\left(\mathrm{ft} / \mathrm{sec}^{2}\right)$,

$\beta=\operatorname{coefficient}\left(\sec ^{-1}\right)$,

$u_{\circ}=$ cut-off speed $(\mathrm{ft} / \mathrm{sec})-$ it is the speed producing an interruption or cessation of a power or fuel supply (the best estimate was found to be 65 $\mathrm{km} / \mathrm{h}$ or $40 \mathrm{mph}$ ),

$u_{x}=$ higher speed data point $(\mathrm{ft} / \mathrm{sec})$ - the best estimate was found to be 105 $\mathrm{km} / \mathrm{h}$ or $65 \mathrm{mph})$,

Note: $u_{0}$ and $u_{x}$ are values used to define the linear portion of the acceleration curve between ao and $a_{x}$.

$$
\begin{aligned}
& a_{\circ}=\left(1.02-\frac{4.76}{u_{\circ}}\right) *\left\lfloor\frac{550 r / u_{\circ}}{W / P}\left(k_{r}+k_{s} u_{\circ}\right)-\frac{k_{a} u_{\circ}{ }^{2}}{W}-G\right\rfloor g \\
& a_{x}=\left(1.02-\frac{4.76}{u_{x}}\right) *\left\lfloor\frac{550 r / u_{x}}{W / P}\left(k_{r}+k_{s} u_{x}\right)-\frac{k_{a} u_{x}^{2}}{W}-G\right\rfloor g
\end{aligned}
$$

where $a_{\circ}, a_{x}=$ acceleration/deceleration rates at $u_{o}$ and $u_{x}$, respectively $\left(\mathrm{ft} / \mathrm{sec}^{2}\right)$, 
$r=$ engine efficiency factor, taken $=0.92$ (assuming trucks operate at higher gear most of the time),

$W=$ vehicle weight $(\mathrm{lb})$,

$P=$ vehicle horsepower $(\mathrm{hp})$,

$k_{r}, k_{s}=$ basic coefficients of speed effect on rolling resistance, taken: $k_{r}=0.01$

and $k_{s}=1 / 14,667$ (for all speeds less than $80 \mathrm{mph}$ ),

$k_{a}=\frac{\rho}{2 g} C_{a} A=0.0764$,

$G=$ road grade, and

$g=$ gravity constant $=32.17 \mathrm{ft} / \mathrm{sec}^{2}$.

Equation 3.1 is only applicable for $u_{i}$ and $u_{f}$ greater than or equal 40 $\mathrm{mph}$. All the equations are valid for all possible ranges of $W(=30-140 \mathrm{kips}), P$ $(=275-650 \mathrm{hp})$, and $G(=-5-9 \%)$.

Equation 3.1 was used to predict the speed loss (by knowing $u_{f}$ ) on link upgrades for all observed truck speeds. The speed gain on link downgrades was neglected and the speeds were assumed to remain constant. The travel distance was assumed to be $2,000 \mathrm{ft}$ because as the speed profile charts developed by Lan and Menendez (2003) suggest, the most significant change in speeds took place over that distance (i.e. the vehicle maintain a constant 
speed after that). It is worth to mention that the distances of all the segments of link 211 are longer than 2,000 ft. According to the horsepower ranges of Class 9 heavy-duty vehicles $(400-450 \mathrm{hp})$ suggested in the study made by Ahanotu (1999) and with reference to the valued calculated by equation 3.7 (in next section), the horsepower used for estimating the speed loss was chosen to be $400 \mathrm{hp}$. This constant horsepower was used with the three weight bins studied and mentioned before (empty, medium, full), as the aim was to study the performance of the same vehicle (i.e. same heavy-duty vehicle's class) under increasing weights. This horsepower value gave reasonable weight-topower ratios $(\mathrm{W} / \mathrm{P})$ for the three weight bins. This step would enable the estimation of hypothetical trajectories for each observed truck. By using this equation, it was possible to apply the effect of both vehicle weight and road grade on the speed and eventually the truck emissions.

The grade profiles for all links were established using ODOT Integrated Transportation Information System (ITIS). In addition, these grades are checked using Google Earth. These detailed grades might be approximated to upgrades or downgrades of longer distances as will be explained in more details in the case study. 


\subsubsection{Estimating Link-Based $\mathrm{NO}_{x}$ Emissions}

There are several studies that provided equations to estimate the nitrogen oxide $\left(\mathrm{NO}_{\mathrm{x}}\right)$ emissions. Most of these equations require information about the studied trucks that are not available in the WIM data archive (e.g. instantaneous speeds, accelerations, axle horsepower, power needed for accessories, engine displacement, etc.).

Gajendran and Clark (2003) studied the real effects of truck operating weight on emissions. The paper presented a collection of experimental data and examined weight corrections from a theoretical point of view. Data were collected using the West Virginia University Transportable Heavy Duty Emissions Testing Laboratories (TransLab). A theoretical approach was applied to test the effect of vehicle weight by combining predictions of vehicle power with existing $\mathrm{NO}_{x}$ correlations. The analysis came up with a relationship between $\mathrm{NO}_{x}$ emissions (in grams per second) and rear axle power (in units of hp):

$$
N O_{x}=0.00122 A H P+0.0294
$$

This equation was found to have an $R^{2}$ value of 0.93 . The rear axle power can be calculated from the following equation: 


$$
A H P=M v(d v / d t)+0.5 C_{D} \rho A v^{3}+\mu M g v
$$

where

$A H P=$ rear axle power $(\mathrm{Watt})$,

$M=$ mass of the vehicle $(\mathrm{kg})$,

$v=$ vehicle velocity $(\mathrm{m} / \mathrm{sec})$,

$C_{D}=$ aerodynamic drag coefficient of the vehicle (taken $\left.=0.76\right)$,

$\rho=$ density of the air $\left(\mathrm{kg} / \mathrm{m}^{3}\right)\left(\operatorname{taken}=1.207 \mathrm{~kg} / \mathrm{m}^{3}\right)$,

$A=$ frontal area of the vehicle $\left(\mathrm{m}^{2}\right)\left(\right.$ taken $\left.=8.32 \mathrm{~m}^{2}\right)$,

$\mu=$ tire rolling resistance coefficient $(\operatorname{taken}=0.00938)$,

$g=$ acceleration due to gravity $\left(\mathrm{m} / \mathrm{s}^{2}\right)\left(\right.$ taken $\left.=9.81 \mathrm{~m} / \mathrm{s}^{2}\right)$,

Although the paper mentioned that the rear axle power $(A H P)$ calculated from equation 3.7 is in units of horsepower, this was found to be incorrect. Checking the units of the equation variables at the beginning of the research calculations revealed this error. The equation calculates the $A H P$ in the units of $\left(\mathrm{kg} \mathrm{m}^{2} \mathrm{~s}^{-3}\right)$ which is the same units of (Watt). To convert AHP from (Watt) to (hp) to be used in equation 3.6 it should be divided by (746).

Using equation 3.6 to estimate the link-based $\mathrm{NO}_{\mathrm{x}}$ emissions has several advantages. First, it takes into account the effect of vehicle weight $(M)$, which 
is seen in calculating the rear axle power. Second, the vehicle speed used in equation 3.7 is the actual speed experienced on the road grades and estimated using the method described in section 3.3.2. All other factors in equation 3.7 are estimated (as listed above) and generalized for all the vehicles of Class 9 for the WIM data. Moreover, the types of vehicles and test cycle used to develop the equation for estimating the $\mathrm{NO}_{x}$ emissions were similar to the truck type studied and the freeway driving conditions. The $\mathrm{NO}_{x}$ emissions are calculated for the three weight bins: empty $(8,500-33,000 \mathrm{lbs})$, medium $(33,000-$ 60,000 lbs), and full (60,000 lbs-Above) and for all the speeds observed. Knowing the distance of each link and the vehicle's speed, the travel time (in seconds) can be calculated. Multiplying travel time (sec) by the $\mathrm{NO}_{x}$ emissions $(\mathrm{g} / \mathrm{sec})$ gives the emissions in grams per link. The only disadvantage of using equation 3.7 is that the term $(d v / d t)$, which is the truck acceleration, is not available in the WIM data archive. Many researchers studied the acceleration values of heavy-duty vehicles. For example, Harwood (2003) found that the acceleration is approximately between $0.2-0.5 \mathrm{~m} / \mathrm{s}^{2}$, while Frey et al. (2008) gave the heavy-duty vehicle's acceleration a range of $0.2-0.8 \mathrm{~m} / \mathrm{s}^{2}$. In addition, Grant (1998) predicted models of heavy- duty vehicle activity using acceleration range of $0.2-0.4 \mathrm{~m} / \mathrm{s}^{2}$. Accordingly, the $A H P$ was computed 
assuming that $(d v / d t=0.3)$. This assumption is reasonable for Class 9 truck weights.

\subsubsection{Estimating Link-Based $\mathrm{CO}_{2}$ Emissions}

So far, most of the efforts to reduce the green house gas (GHG) emissions have been focused on improving engine technology and changing to a less carbonintensive fuel (e.g. biodiesel) (Scora et al., 2010). Reducing the vehicle miles traveled (VMT) in the freight industry was found to be difficult to apply because goods movement will continue to increase in the future. However, improving transportation operational efficiencies such as vehicle speed and acceleration patterns across different roadway types, traffic congestion, road grade, and vehicle weight has received little attention.

Scora et al. (2010) studied the effect of operational variability of heavyduty diesel truck use on fuel use and $\mathrm{CO}_{2}$ emissions. The researchers used the University of California-Riverside's Mobile Emissions Laboratory (MEL) to quantify the effect of vehicle weight, road grade, facility type, and congestion on $\mathrm{CO}_{2}$ emissions and fuel economy. The analysis of gathered data helped develop the Comprehensive Modal Emission Model (CMEM). This model covered all types of vehicles found on the road today (about 30 vehicle/technology categories from light-duty vehicles to Class 8 heavy-duty 
trucks). Using the CMEM, the road grade effect on $\mathrm{CO}_{2}$ emissions was examined and regression analysis was developed. The resulting regression lines, equations, and goodness of fit for the $\mathrm{CO}_{2}$ emissions at various speeds and grades are shown in Figure 7. The resulting $\mathrm{CO}_{2}$ emissions are in units of grams per mile. The $\mathrm{CO}_{2}$ emissions are calculated for the three weight bins: empty $(8,500-33,000 \mathrm{lbs})$, medium $(33,000-60,000 \mathrm{lbs})$, and full $(60,000 \mathrm{lbs}-$ Above) and for all the speeds observed. For each part with a certain grade of the link, the resulting emission value $(\mathrm{g} / \mathrm{mi})$ would be multiplied by the grade distance (mi) and summed to get the overall link $\mathrm{CO}_{2}$ emissions in grams.

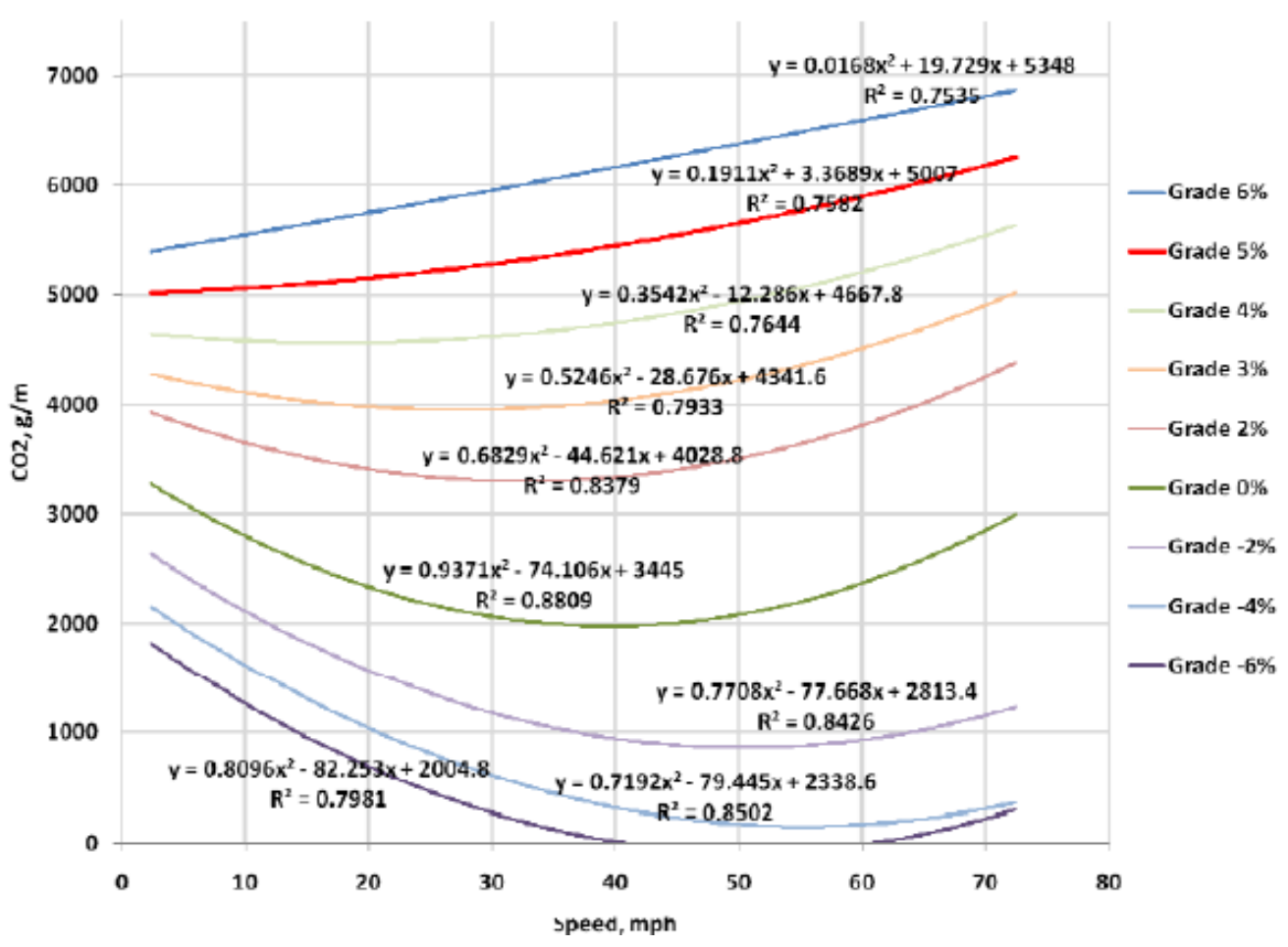

Figure 7: CMEM Modelled $\mathrm{CO}_{2}$ Emissions as a Function of Speed for Various Grades (Scora et al., 2010) 
The benefit from using these regression equations using the CMEM is that they only need the vehicle's speed and the road grade. The vehicle speed used in these equations is the actual speed experienced by the vehicle on the specified grade resulting from analysis explained in section 3.3.2. Therefore, the actual speed, vehicle weight, and road grade are taken into consideration when estimating the link-based $\mathrm{CO}_{2}$ emissions.

\subsection{Description of Case Study}

Link 211 (from Table 3) on Interstate five (I-5) was chosen as a case study for estimating the link-based $\mathrm{NO}_{x}$ and $\mathrm{CO}_{2}$ emissions on Oregon's Highways. The link distance is 93.4 miles and is bounded by the Ashland POE (NB, MP 18.08) and Booth Ranch (NB, MP 111.07) as shown in, Figure 8. This link was chosen because it is a part of a key freight corridor and known for its hilly terrain. Weigh-in-motion (WIM) data for January 2007 are extracted as the records are complete and there are minimal errors in the data. The goodness of this dataset is attributed to the following reasons: (1) In 2007, Link 211 was found to have the highest number of matched trucks with approximately 190,000 observations (Monsere et al., 2009). (2) There were no missing data for any day during January 2007. (3) Low standard deviation of travel time ( 0.2 hours) (Monsere et al., 2009). (4) In January 2007, about 75 percent (9,669 records) of 
transponder-equipped (Class 9) trucks are through trucks. (5) Only two percent from the total number of through-truck records had average speeds less than $40 \mathrm{mph}$ (which is considered a very low speed for traveling on a highway) and were excluded.

The grade profile of link 211 was developed using the ODOT Integrated Transportation Information System (ITIS) and was also checked using the elevations from Google Earth. For simplicity, the grades were approximated to longer segments of upgrades and downgrades as shown in Figure 9. The approximated grades with their distances are listed in Table 4.

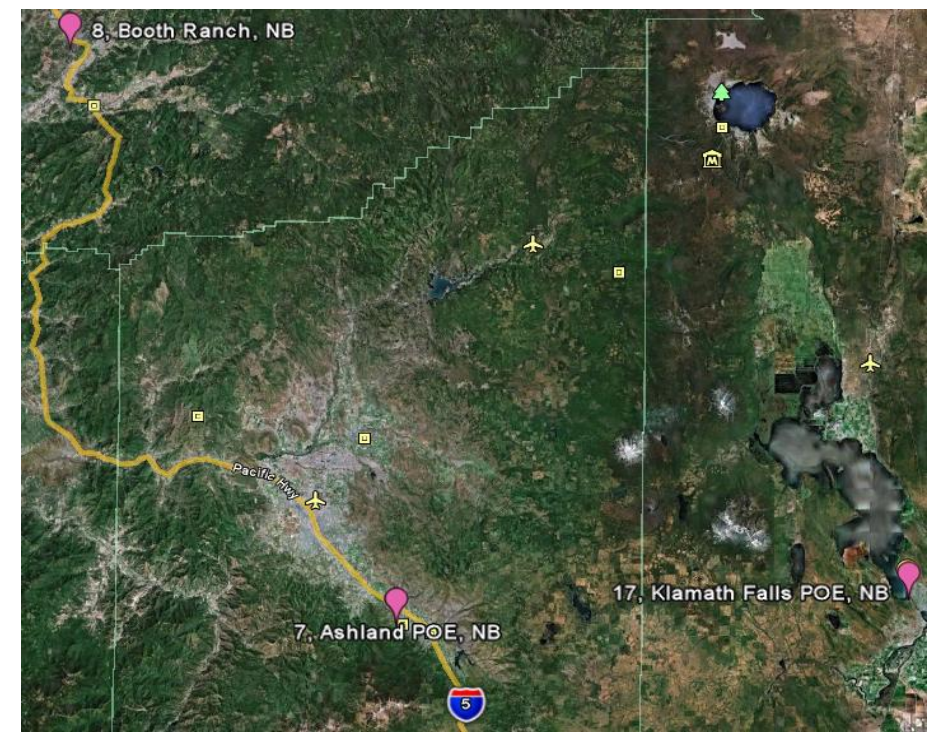

Figure 8: Link 211 on I-5 by Google Earth 


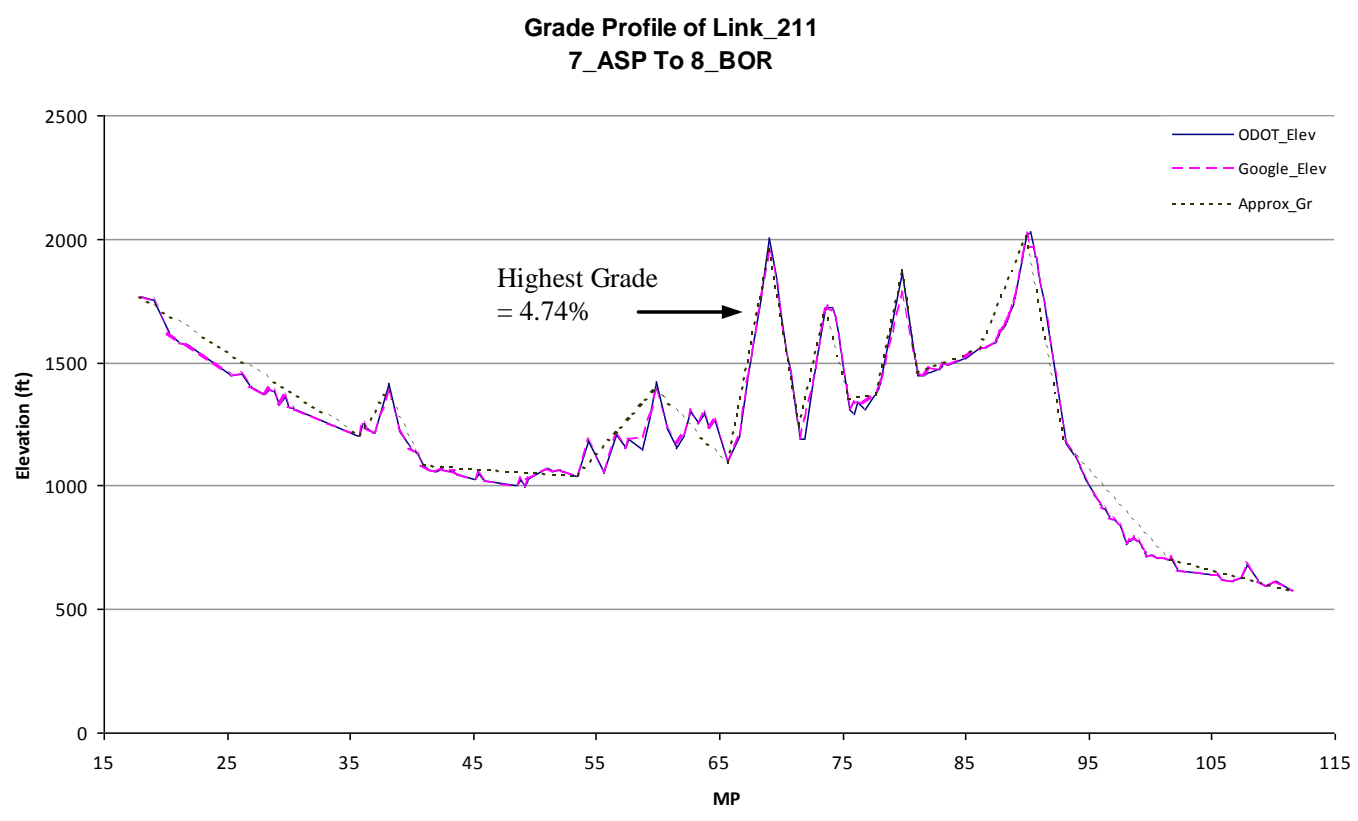

Figure 9: Grade Profile for Link 211

\subsection{Conclusions}

This section presented a brief summary of the weigh-in-motion (WIM) data, and the algorithm for identifying through trucks. The methods used for estimating link-based carbon dioxide $\left(\mathrm{CO}_{2}\right)$ and nitrogen oxide $(\mathrm{NO} \times)$ emissions for heavy-duty vehicles were discussed in detail. The section ended with a description for the case study that will focus on the mentioned emissions. The next chapter will present the performed data analysis, discuss the study results, and summarizes a list of the key findings. 
Table 4: Approximated Grade Segments for Link 211

\begin{tabular}{llll}
\hline \multicolumn{1}{c}{ MP } & Elevation $(\mathbf{f t})$ & Distance $(\mathbf{m i})$ & Grade (\%) \\
\hline 18.02 & 1767.51 & & \\
35.69 & 1204.94 & 17.67 & -0.60 \\
38.07 & 1377 & 2.38 & 1.37 \\
40.89 & 1083.93 & 2.82 & -1.97 \\
53.4 & 1037.91 & 12.51 & -0.07 \\
59.89 & 1384 & 6.49 & 1.01 \\
65.64 & 1096 & 5.75 & -0.95 \\
69.08 & 1957 & 3.44 & 4.74 \\
71.43 & 1239.63 & 2.35 & -5.78 \\
73.56 & 1711.22 & 2.13 & 4.19 \\
75.47 & 1351.35 & 1.91 & 3.57 \\
77.71 & 1369.17 & 2.24 & 0.15 \\
79.81 & 1867.09 & 2.10 & 4.49 \\
81.13 & 1459 & 1.32 & -5.86 \\
86.13 & 1556.7 & 5.00 & 0.37 \\
89.9 & 2007.04 & 3.77 & 2.26 \\
93.02 & 1170.94 & 3.12 & -5.08 \\
101.6 & 700.88 & 8.58 & -1.04 \\
111.66 & 578.4 & 10.06 & -0.23 \\
\hline & & &
\end{tabular}




\subsection{ANALYSIS AND RESULTS}

This chapter presents the results of the data analysis. The first section provides some performance measures for the chosen case study. A sensitivity analysis is then carried out to test the effect of the gross vehicle weight and terrain upgrade on the truck speed and to test how the change in speed affects emissions. The third section will show the results of estimating link-based heavy-vehicle emissions using the archived weigh-in-motion (WIM) data, and will be followed by a discussion of the results. Finally, a summary of the key findings will conclude the chapter.

\subsection{Link-Based Performance Metrics}

The archived weigh-in-motion (WIM) data offer the opportunity to develop link-based performance measures for heavy-duty vehicles. As mentioned before, the research is focused on the trucks that traveled directly without stopping between the upstream and downstream stations of the link under study (i.e. through trucks). The five-axle trucks (or Class 9 trucks) are the most dominant truck type on the Oregon highways. As a result, the analysis will highlight the performance measures for five-axle through trucks in each weight bin (empty: 8,500-33,000 lbs, medium: 33,000-60,000 lbs, and full: 60,000 lbs-Above) for link_211 on January 2007. These metrics include counts, 
percentage of the total traffic, travel times, speed of trucks, and weight frequencies. The following sections will discuss through truck performance measures in detail.

\subsubsection{Counts of Trucks}

Figure 10 presents the frequency of transponder-equipped and through-truck counts in each weight bin for Link-211 on January 2007. The results show that weight bin 2 (medium-weighed trucks between 33,000 lbs and 60,000 lbs) has the highest frequency followed by weight bin 3 (full-weighed trucks above 60,000 lbs). Significantly fewer trucks lie in weight bin 1 (empty trucks weighed between 8,500 lbs and 33,000 lbs). This shows that on Link 211 during January 2007, nearly 95\% of transponder-equipped trucks were medium (50\%) or full (45\%) trucks while only 5\% traveled empty. It is also clear from Figure 10 that the number of through trucks in each weight bin is proportional to the number of transponder-equipped trucks and this proportion is relatively high (75\% on average).

Figure 11 and Figure 12 show the number of through, non-through trucks, and their percentages from the number of transponder-equipped trucks in each weight bin. Although there are clear variations in the number of 
trucks with transponder in each weight bin, the percentage of through trucks is almost the same in the three weight bins ( $75 \%$ on average).

\subsubsection{Travel Time}

The case study presented in this work is for Link_211 on Interstate-5 (I-5) between Ashland POE (NB, MP 18.08) and Booth Ranch (NB, MP 111.07). The distance of this corridor is nearly 93.4 miles and the free flow travel time is estimated to be 1.70 hours (1:42:00) assuming free flow (i.e. posted limit) speed $55 \mathrm{mph}$.

As seen in Figure 13, trucks in weight bin 2 have the highest frequency as mentioned in the previous section. For weight bin 1 the peak is at $1.63 \mathrm{hrs}$ (1:38:00), where it is at $1.67 \mathrm{hrs}$ (1:40:00) for weight bin 2, and the peak for weight bin 3 is at $1.70 \mathrm{hrs}(1: 42: 00)$. This is intuitive, as the travel time is expected to increase (lower speeds) with higher gross vehicle weight. Frequencies for all weight bins are skewed to the left, which means that the majority of through trucks travel at the free-flow travel time. The flat nature of the curve of weight bin 1 indicates the higher variability in trucks' travel times than that of weight bins 2 and 3. 
Count of Transponder-Equipped Trucks - Link_211 on Jan 2007

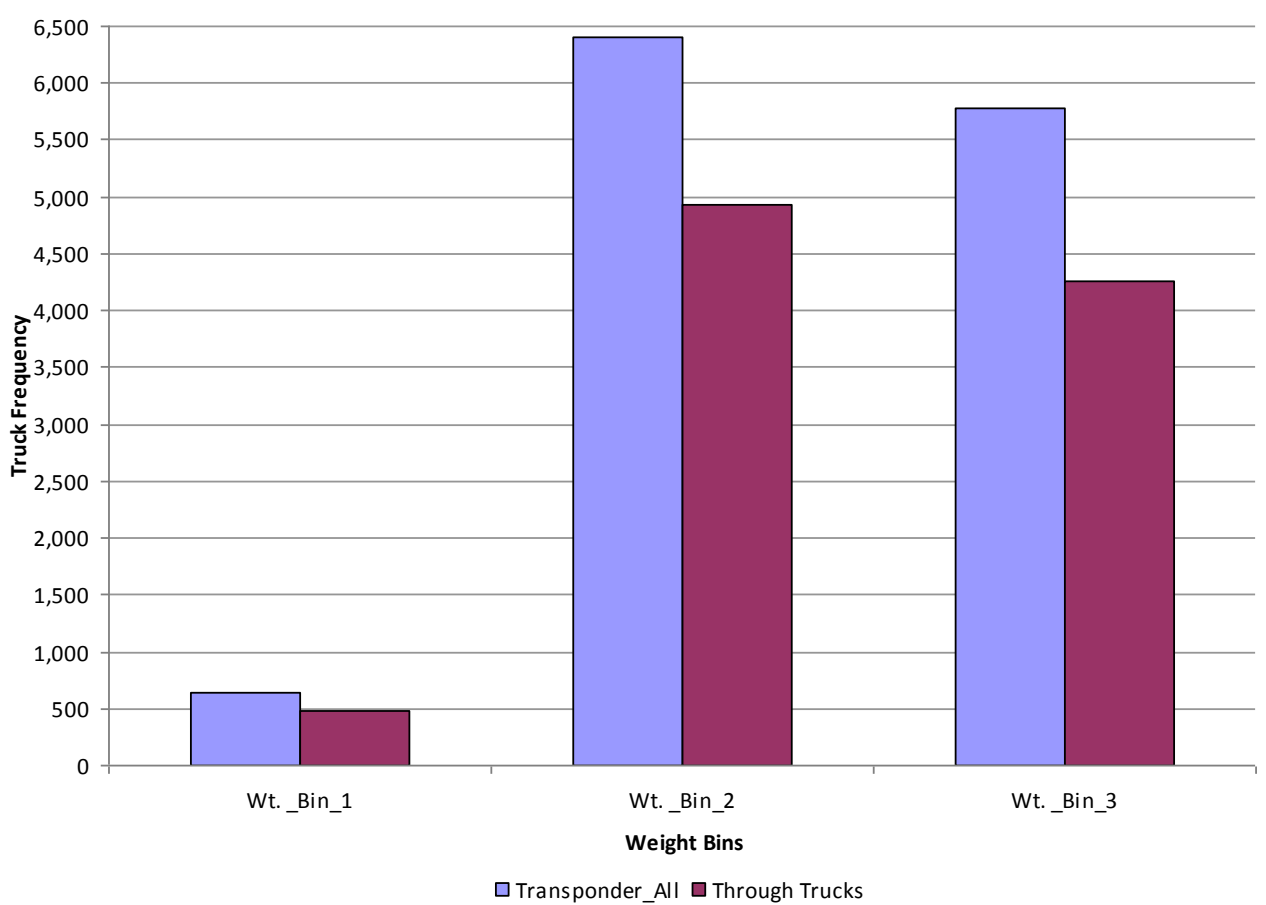

Figure 10: Counts of Transponder-Equipped and Through Trucks - Link 211, Jan_07

Through and Non-Through Truck Count - Link_211 - Jan 07

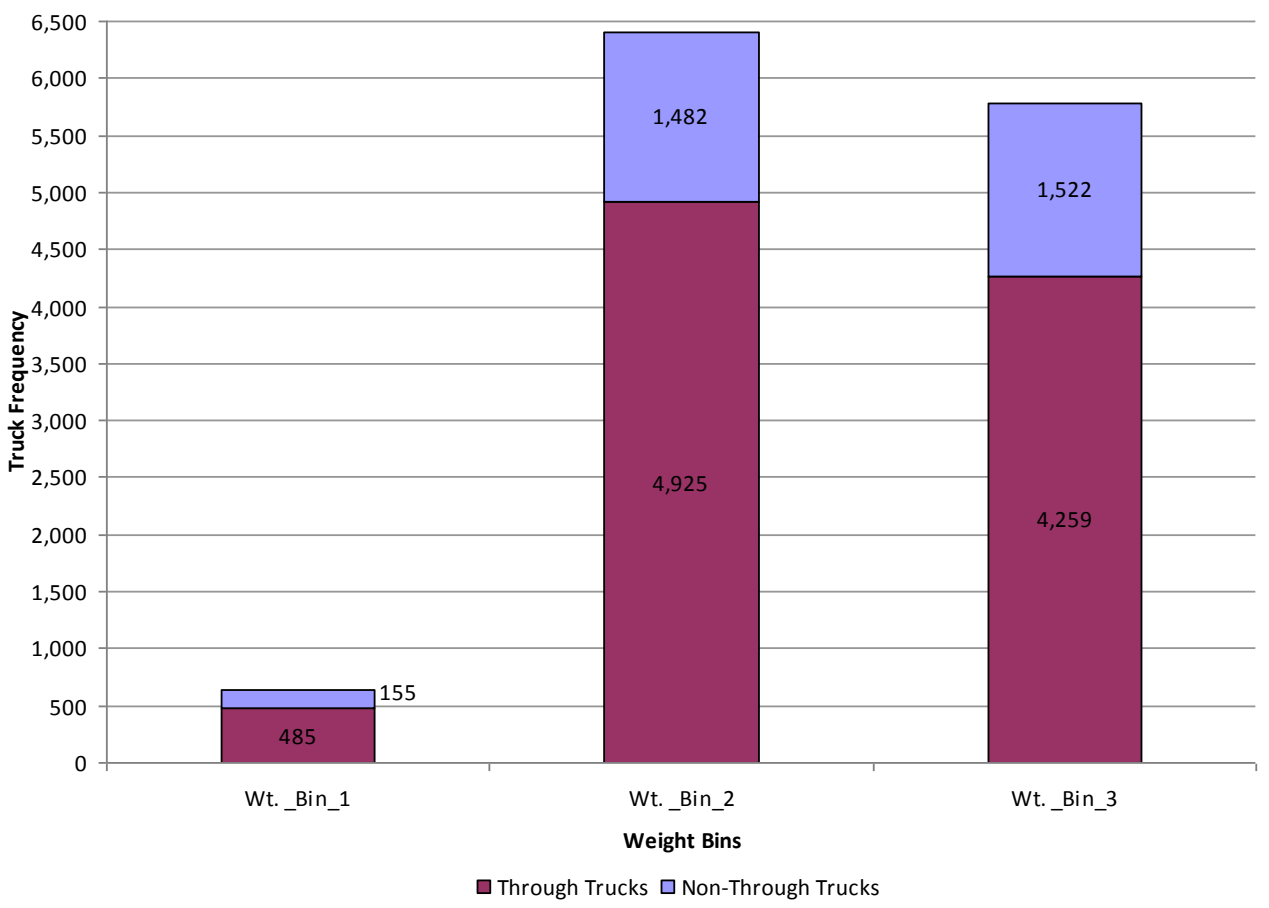

Figure 11: Counts of Through and Non-Through Trucks - Link 211, Jan_07 


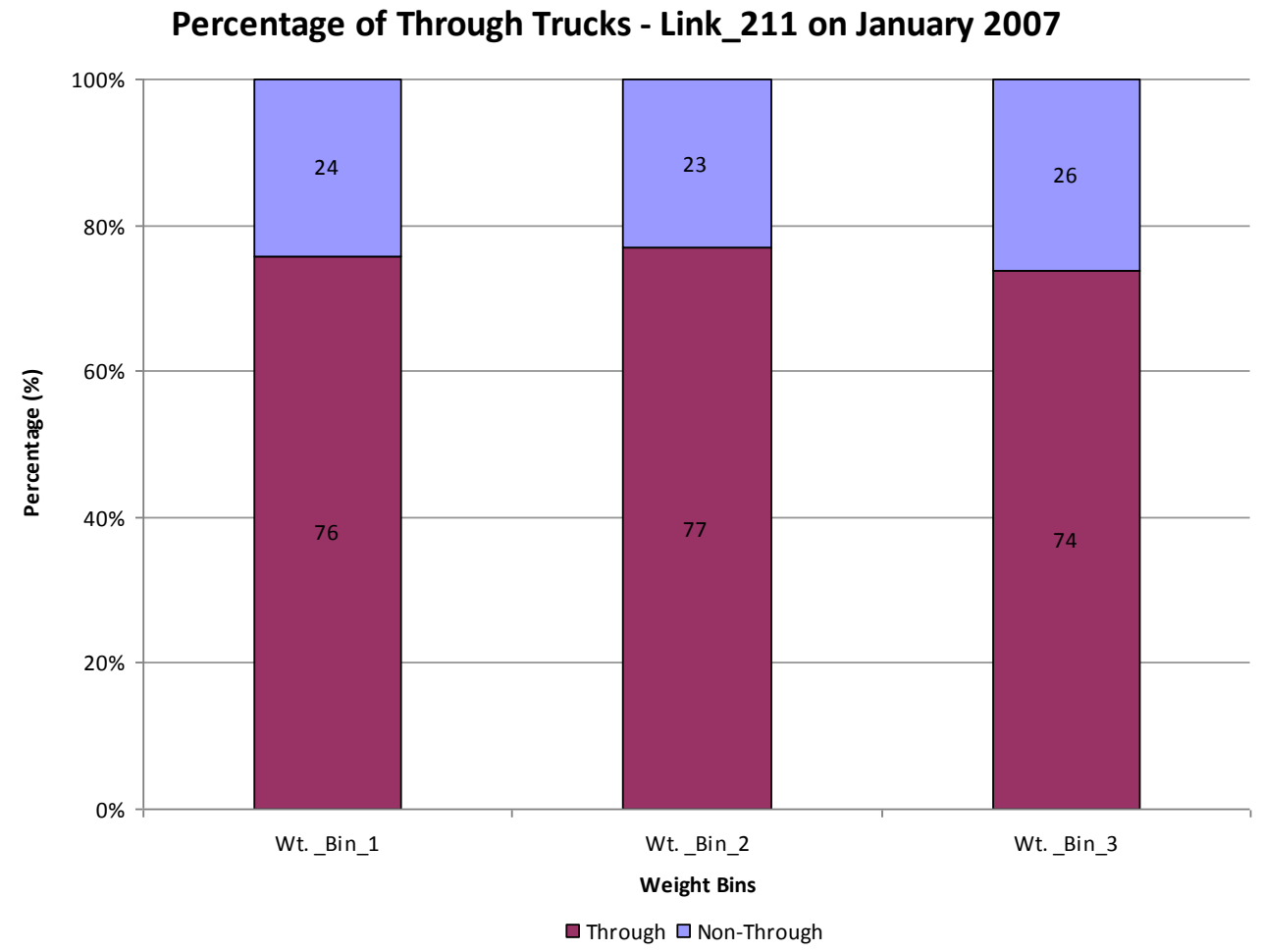

Figure 12: Percentage of Through Trucks on Link 211 - Link 211, Jan_07

Travel Times for Chosen Weight Bins

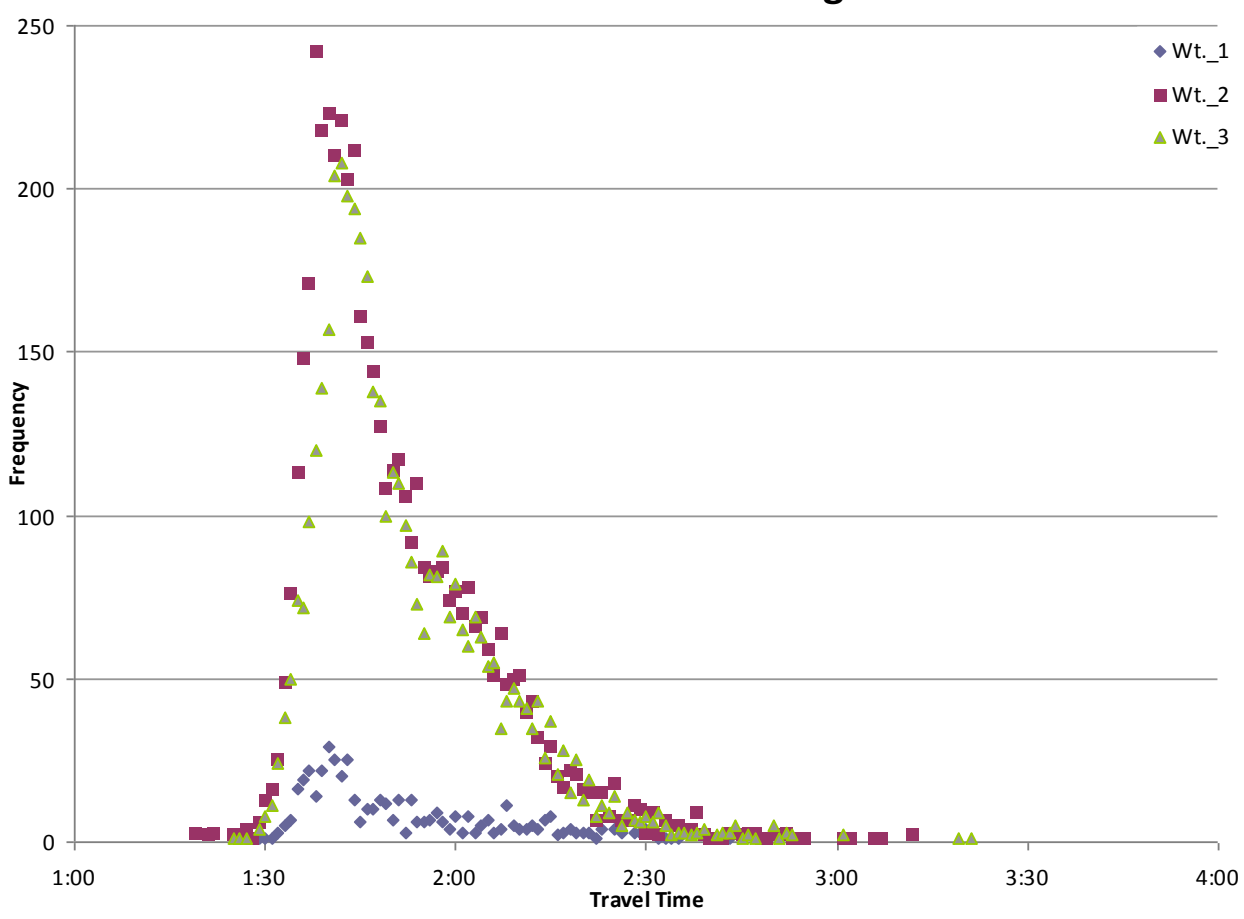

Figure 13: Travel Time Frequency for Link 211 on January_07 


\subsubsection{Truck Speed}

The weigh-in-motion (WIM) data provide upstream and downstream timestamps from which the trip travel time is calculated. Knowing the approximate link distance, the average traveling speed can be calculated. Figure 14 shows the frequency of average speeds on Link_211 for five-axle (Class 9) through trucks in each weight bin. It could be seen that the highest speed frequency for all weight bins is nearly at $55 \mathrm{mph}$ (posted speed limit). For empty and full trucks (i.e. weight bins 1 and 3 respectively), the majority of trucks traveled with speeds at or near the speed limit, while the biggest number of medium-weighed trucks (i.e. weight bin 1) tended to drive a little faster. Numbers of trucks driving at speeds above $60 \mathrm{mph}$ were minimal.

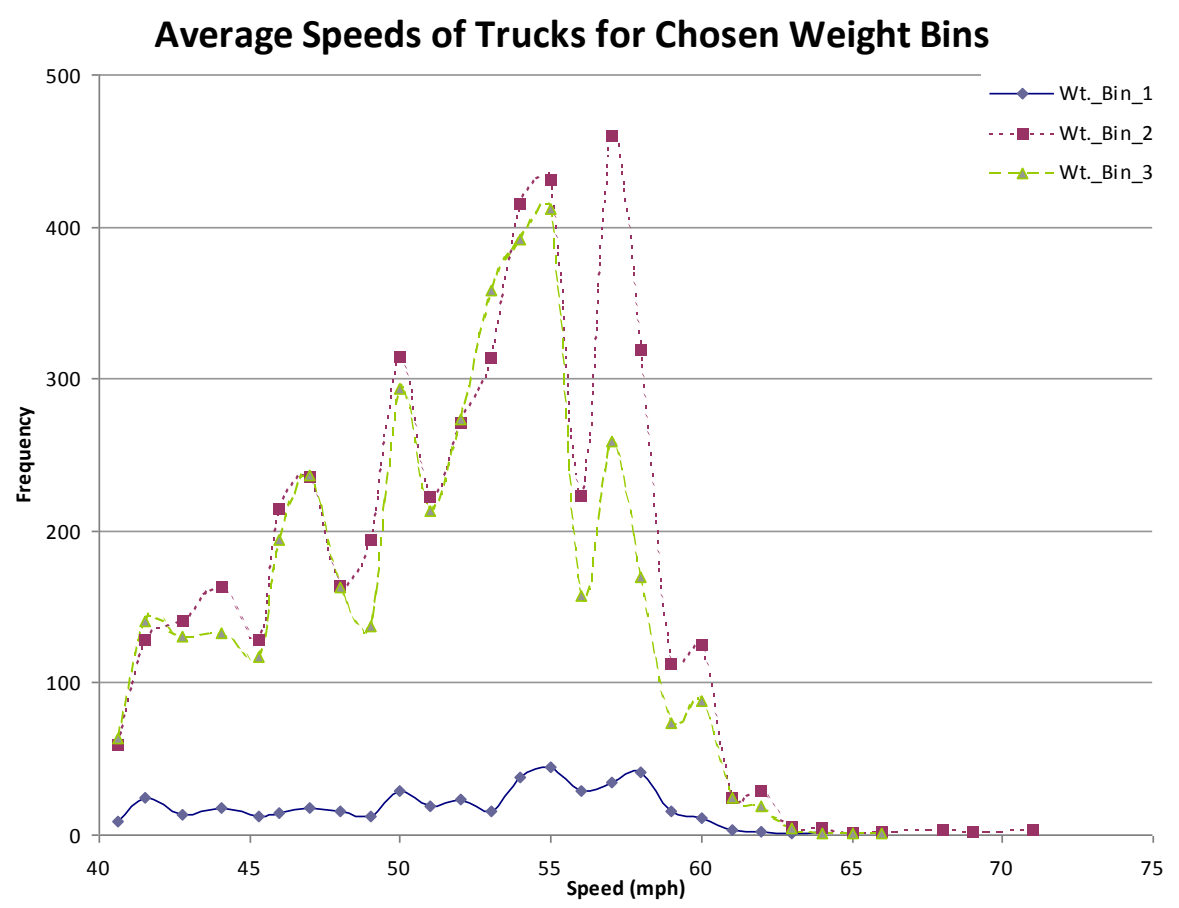

Figure 14: Speed Frequency for Link 211 on January_07 


\subsubsection{Gross Vehicle Weight}

The gross vehicle weight is also one of the available metrics provided by the weigh-in-motion (WIM) data. The counts of Class 9 truck in each weight bin are presented in Figures 15 to 17. Figure 15 presents the frequency of gross vehicle weight for empty trucks (i.e. weight bin 1). It is clear that very few trucks travel with weights less than $23,000 \mathrm{lbs}$. In addition, the count of trucks increases with higher weights. While for medium trucks (i.e. weight bin 2), Figure 16, no apparent variation (increase/decrease) is seen with increasing gross vehicle weights as the counts fluctuate within almost the same range (20-30 trucks). The highest frequency of trucks lies in weight bin 3 (i.e. full trucks) for vehicles weighed between 65 and 70 kips, Figure 17. It can be seen that trucks with weights above 80 kips are rare. 
Weight Frequency of Weight Bin_1 - Link_211 on January 2007

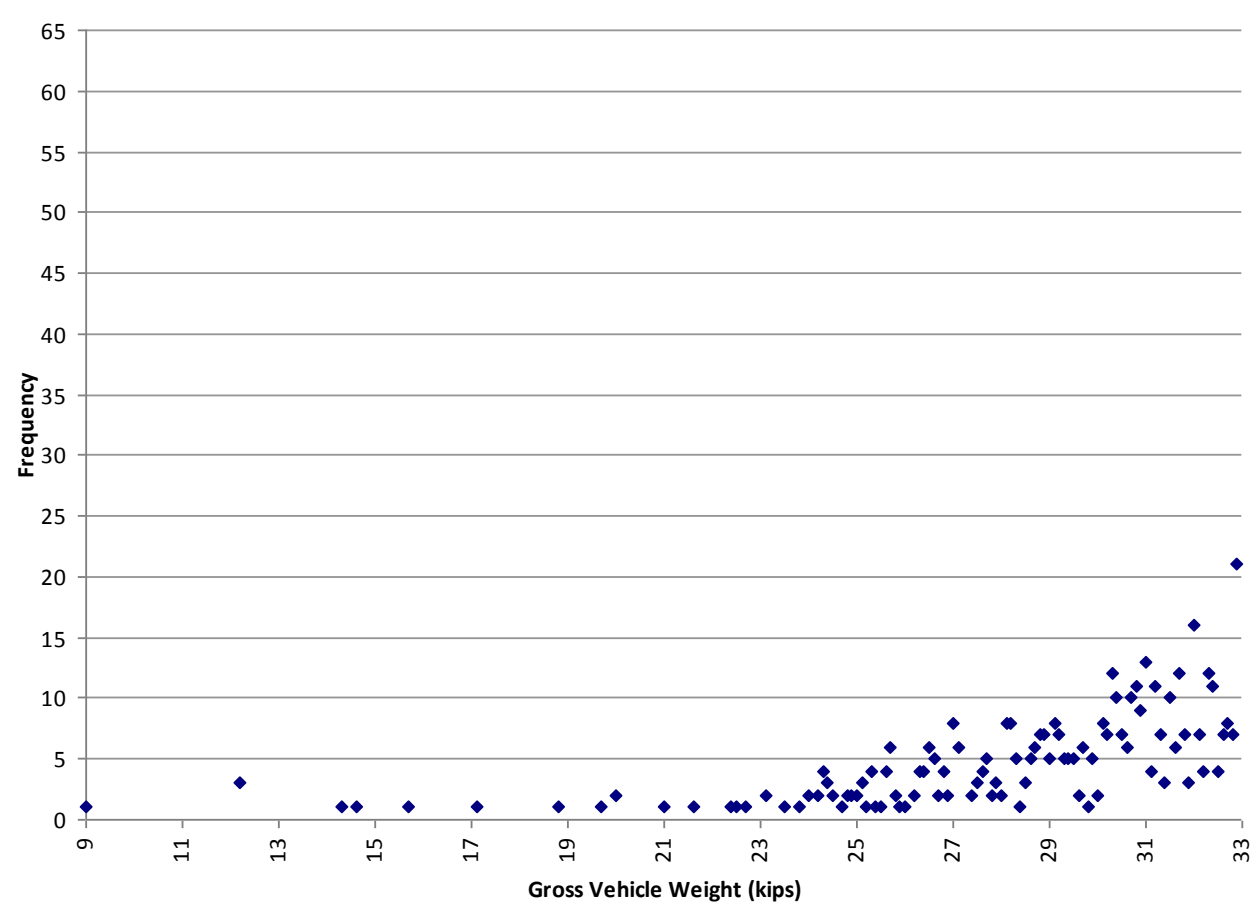

Figure 15: Frequency of Gross Vehicle Weight in Bin_1 - Link 211, Jan_07

Weight Frequency of Weight Bin_2 - Link_211 on January 2007

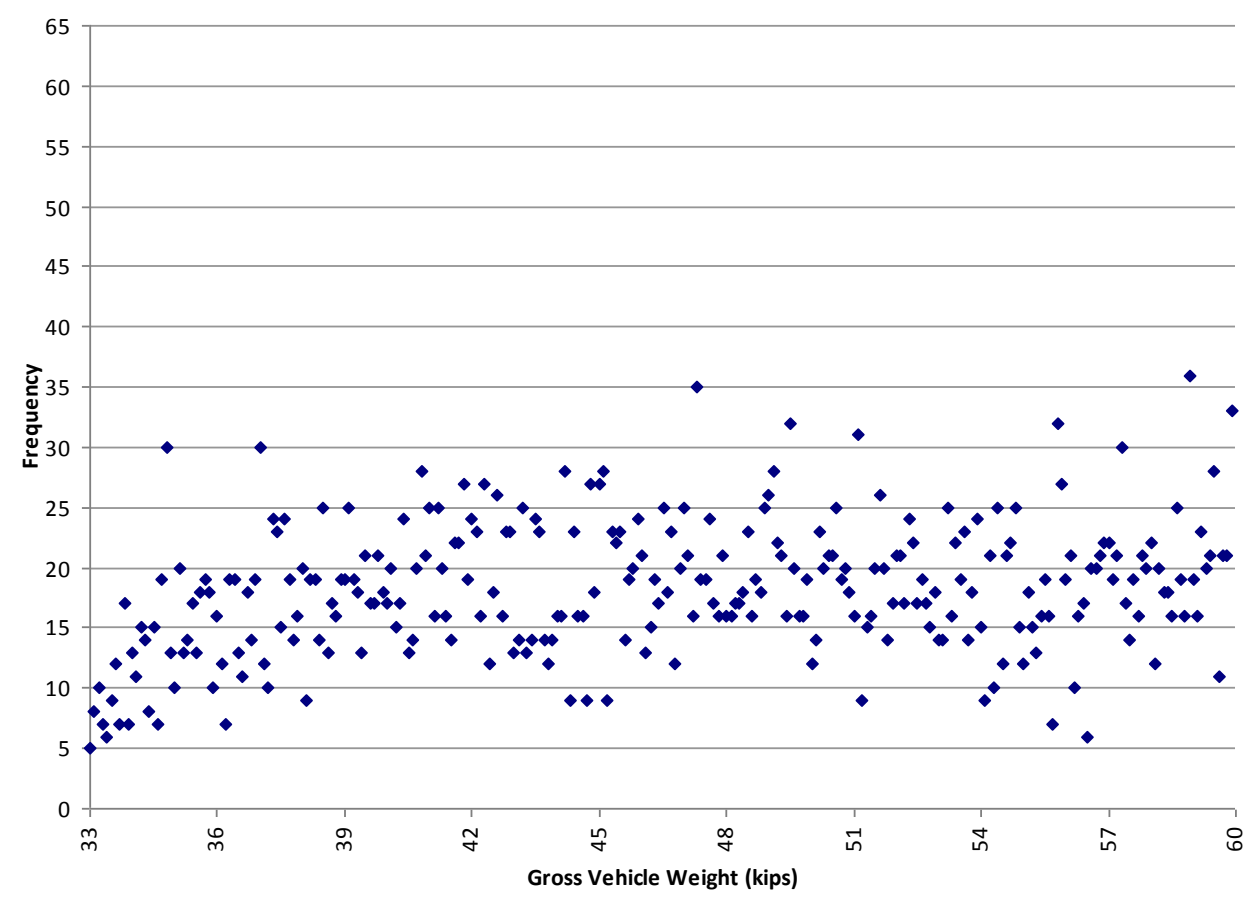

Figure 16: Frequency of Gross Vehicle Weight in Bin_2 - Link 211, Jan_07 
Weight Frequency of Weight Bin_3 - Link_211 on January 2007

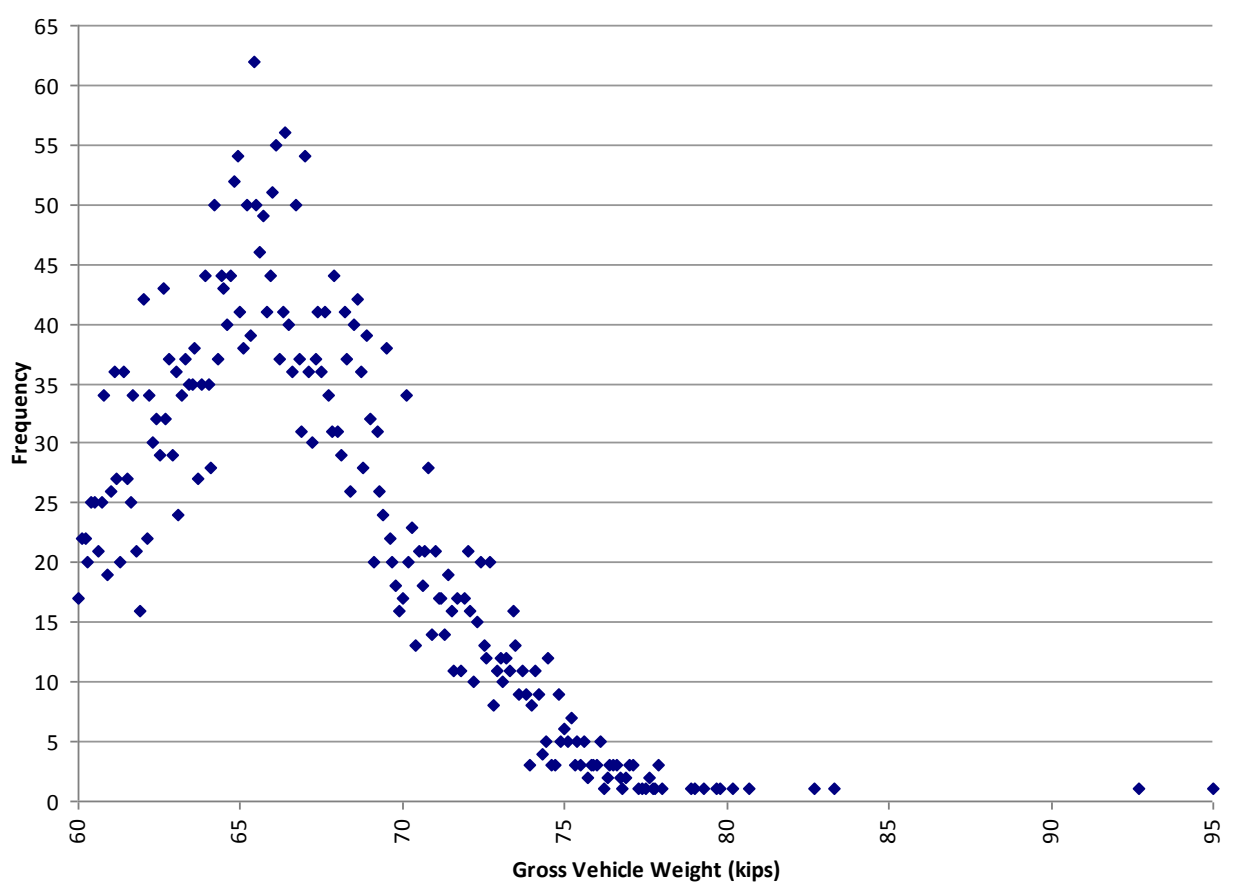

Figure 17: Frequency of Gross Vehicle Weight in Bin_3 - Link 211, Jan_07 


\subsection{Sensitivity Analysis}

This section will explore how the variation of parameters like terrain grade and gross vehicle weight affect speed and consequently the emissions. This section begins with testing the sensitivity of the empty, medium, and fulltruck speed to the road grade. Then the following section will analyze the amount of change in carbon dioxide $\left(\mathrm{CO}_{2}\right)$ and nitrogen oxide $\left(\mathrm{NO}_{\mathrm{x}}\right)$ emissions with vehicle speed in the three weight bins.

\subsubsection{Sensitivity of Speed to Road Grade}

The traveling trucks experience drop in speed when driving uphill. To determine the effect of highway grade on the speed of heavy-duty vehicles (with different weights), equation 3.1 mentioned previously is used. The variation (decrease) in speed is studied using speeds estimated on a segmentby-segment basis (i.e. the link route was divided to segments depending on the prevailing grade - see section 3.4). Data recorded at the upstream weigh station include the timestamp, gross vehicle weight, and speed. This upstream speed (i.e. entering/initial speed, $u_{i}$ ) is used in equation 3.1 to calculate the final speed $\left(u_{f}\right)$ at the end of the first segment of the link. The final speed is considered the entering speed for the next segment, and so on. The truckexiting speed is calculated on each link segment for all truck weights in the 
dataset. Equation 3.1 is used to calculate the exiting speeds for segments with uphill grade. Speeds on leveled terrain or segments with downgrades are assumed to remain unchanged. It should be mentioned that to estimate the emissions on each segment, the final speed is used which results in the lower bound emission values.

The data used in the study are for the through trucks of Link_211 (I-5 between Ashland POE and Booth Ranch) on January 2007. Figure 18 presents the percentage of variation between the entering and exiting speeds for empty trucks (in weight bin 1 ) on roadway grades from $1 \%$ to $5 \%$. The lengths of approximated grade segments of Link_211 are listed in Table 4. It makes sense that the speed drop increases with higher speeds and on more steep grades. The empty trucks did not experience any change in speed (i.e. variation percentage $=0$ ) on segments with grade $1 \%$. It can be seen that the drop starts at approximately $50 \mathrm{mph}$, where no change in speed occurred for slower trucks. The relation between the entering speed and the percentage of speed drop is almost linear. Table 5 lists the ranges of speed-variation percentages for all through trucks (empty, medium, and full) in the data set of the case study. 
Percentage of Speed Variation on Grades - Weight Bin_1 -

Link_211 on January 2007

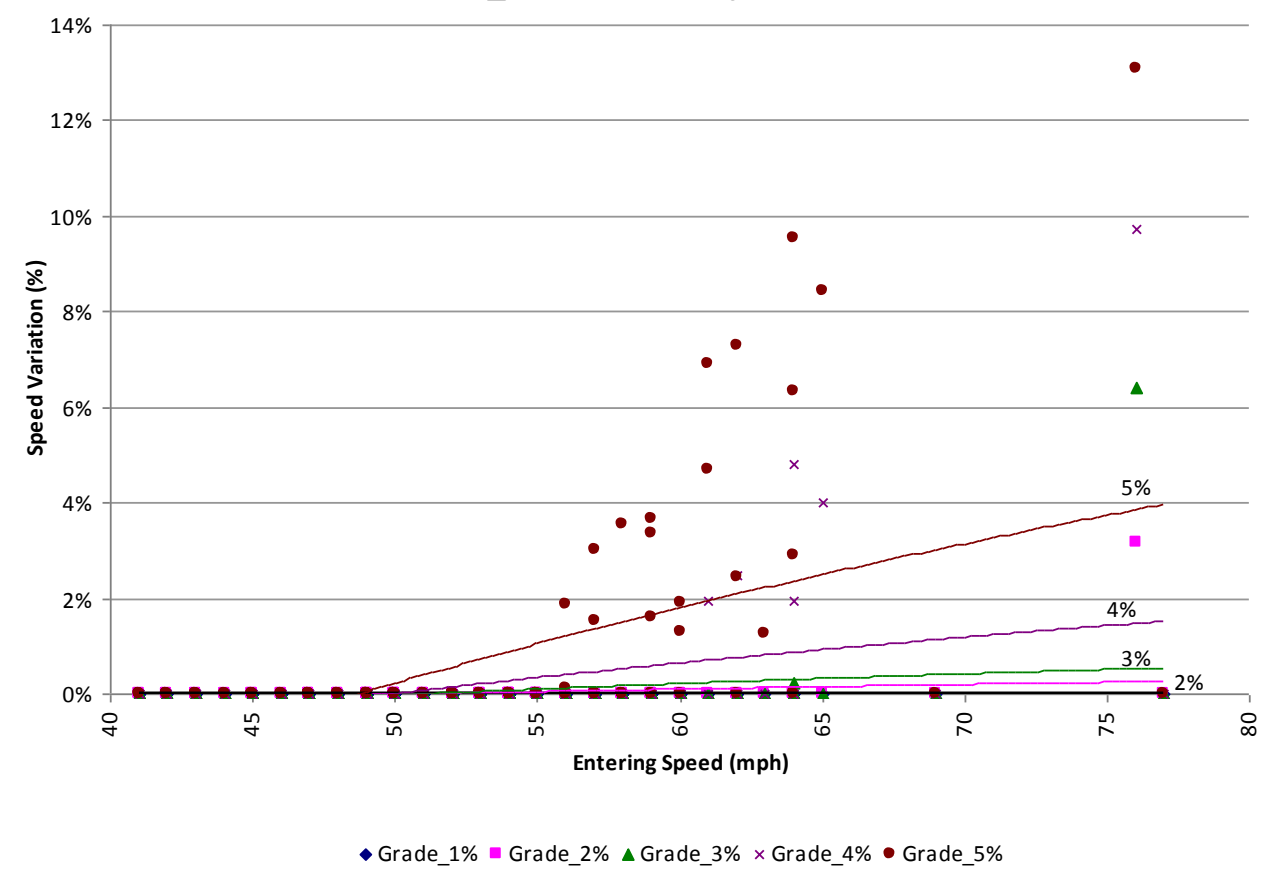

Figure 18: Percentage of Speed Change on Grades - Empty Trucks - Link 211, Jan_07

The sensitivity of medium truck speed (in weight bin 2) to road grade is shown in Figure 19. As in the case of empty heavy-duty vehicles, speed of medium weighed trucks is not affected by uphill grade of $1 \%$. The percentage of speed drop is almost linear on roads with grade $2 \%-5 \%$. The variation in speed on uphill roads increases with increase in the vehicle's entering speed and grade. Figure 19 also shows that the range of variation in speeds increases with steeper grades. 
Percentage of Speed Variation on Grades - Weight Bin_2 -

Link_211 on January 2007

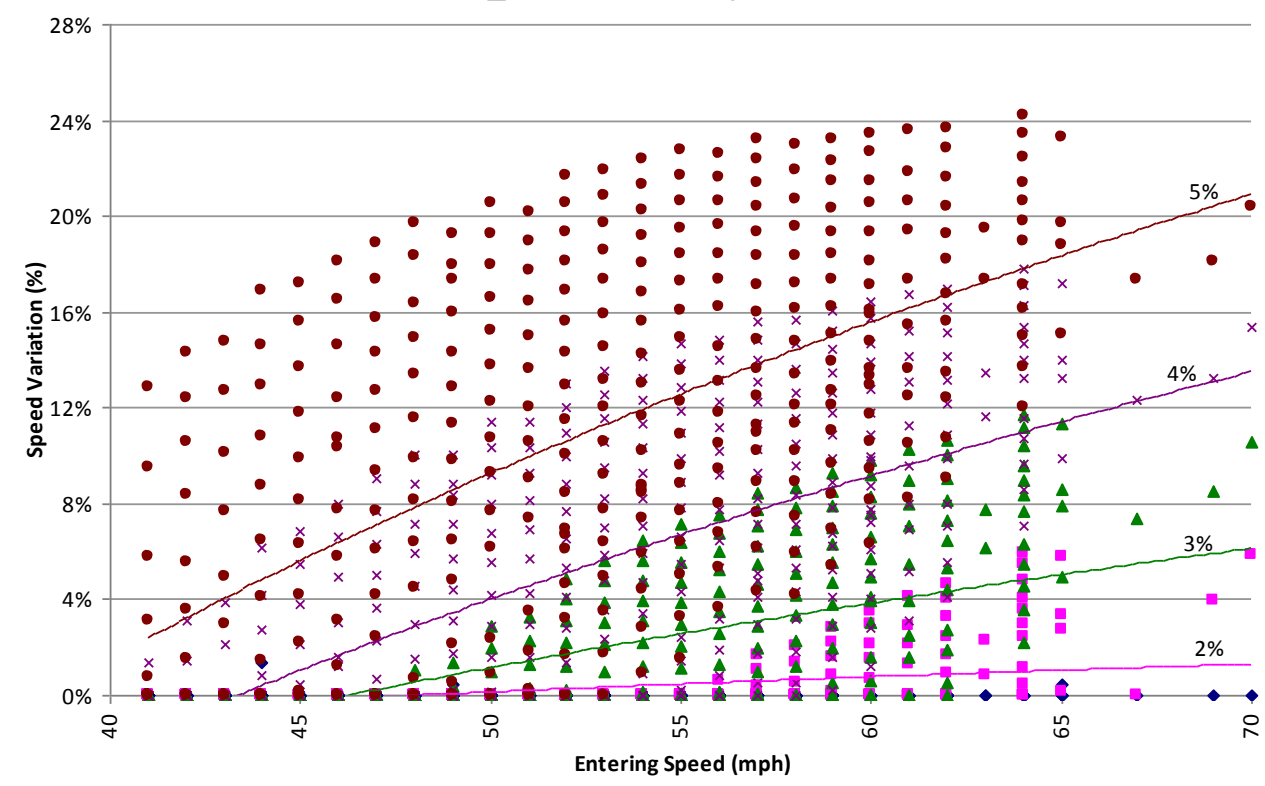

$\bullet$ Grade_1\% $\bullet$ Grade_2\% $\Delta$ Grade_3\% x Grade_4\% • Grade_5\%

Figure 19: Percentage of Speed Change on Grades - Medium Trucks - Link 211, Jan_07

For full trucks (weight bin 3), Figure 20 shows that the percentage of variation in speed increases with the increasing entering speed and at higher grades. On grade $1 \%$, the trucks experience low difference in the traveling speed. The relatively steep slope of curves for grades $3 \%$ and $4 \%$ means that the drop in speed is higher that that occurring on grades $2 \%$ and $5 \%$ (which have curves with mild slope). In addition, it can be seen that the variation curves are apart at speed $40 \mathrm{mph}$ and get closer with increase in entering speed. This implies that for full heavy-duty vehicles, the decrease in speed on different grades varies more at lower speeds and becomes less when traveling 
faster. The maximum and minimum values of speed variation percentages for empty, medium, and full heavy-duty vehicles are presented in Table 5. From the numbers in the table, it is also noticed that the speed decreases with increase of vehicle weight. This drop is almost linear for grades $1 \%$ and $2 \%$, while for grades between 3\% and 5\% speed significantly falls for weights up to 80

Percentage of Speed Variation on Grades - Weight Bin_3 -

hts. Link_211 on January 2007

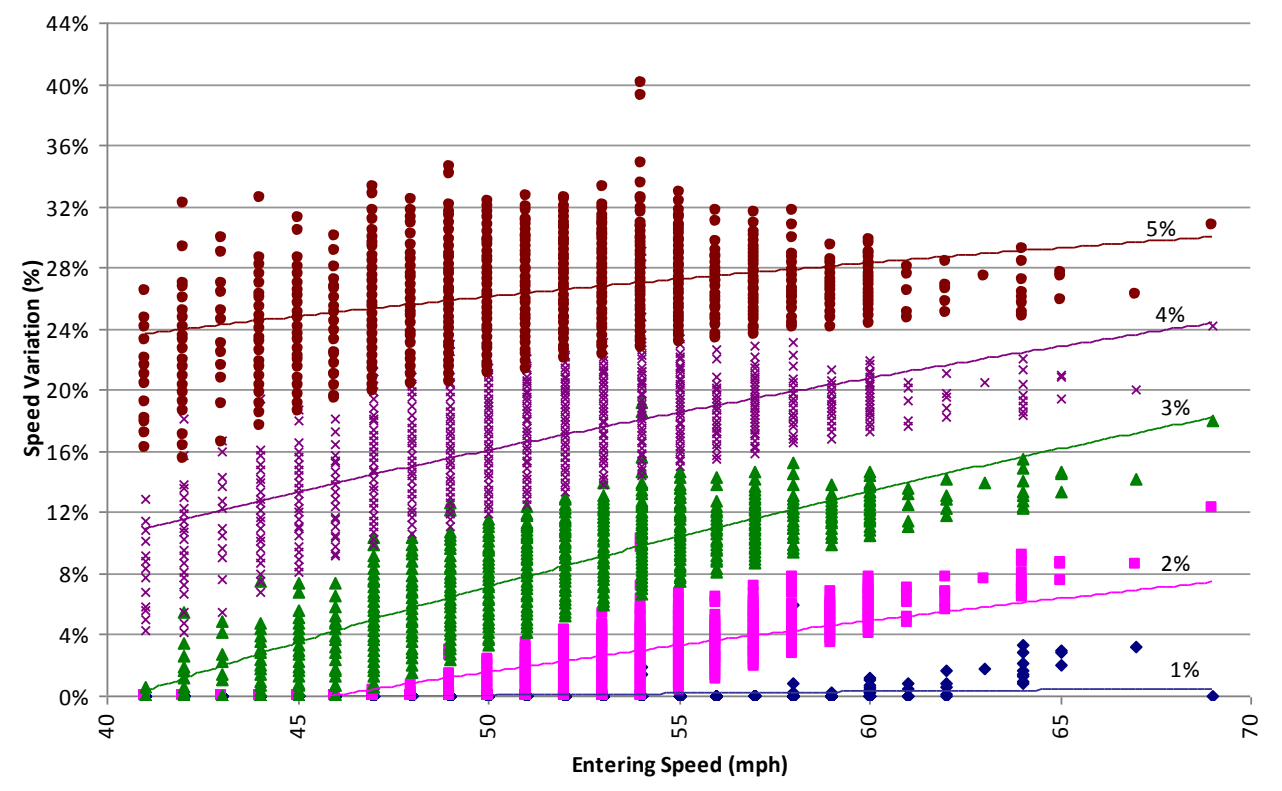

- Grade_1\% - Grade_2\% \ Grade_3\% x Grade_4\% • Grade_5\%

Figure 20: Percentage of Speed Change on Grades - Full Trucks - Link 211, Jan_07 
Table 5: Minimum and Maximum Values of Speed-Variation Percentages on Link 211

\begin{tabular}{cccc}
\hline Grade (\%) & $\begin{array}{c}\text { Weight Bin_1 } \\
\text { (Empty) }\end{array}$ & $\begin{array}{c}\text { Weight Bin_2 } \\
\text { (Medium) }\end{array}$ & $\begin{array}{c}\text { Weight Bin_3 } \\
\text { (Full) }\end{array}$ \\
\hline 1 & $0 \%$ & $0 \%-1 \%$ & $0 \%-6 \%$ \\
2 & $0 \%-3 \%$ & $0 \%-6 \%$ & $0 \%-12 \%$ \\
3 & $0 \%-6 \%$ & $0 \%-12 \%$ & $0 \%-19 \%$ \\
4 & $0 \%-10 \%$ & $0 \%-18 \%$ & $4 \%-29 \%$ \\
5 & $0 \%-13 \%$ & $0 \%-24 \%$ & $16 \%-40 \%$ \\
\hline
\end{tabular}

\subsubsection{Sensitivity of Emissions to Speed}

Figure 21 shows the effect of changing the speed on the amount of carbon dioxide $\left(\mathrm{CO}_{2}\right)$ emissions for Link 211 during January 2007. It can be seen that at certain speed value, the value of $\mathrm{CO}_{2}$ emissions is highest for weight bin 1 (empty trucks), followed by weight bin 2 (medium trucks), while the fullloaded vehicles (weight bin 3) have the lowest amount of emissions. However, in each specific weight bin and for the same speed value, the $\mathrm{CO}_{2}$ emissions decrease with the increase in gross vehicle weight. This was not the expected result and the reason will be discussed in detail in later section. The same trend of variation in $\mathrm{CO}_{2}$ emissions with speed is seen for through empty, medium, and full vehicles (weight bins 1, 2, and 3 respectively). The amount of emissions goes up with higher speeds. This increase is low for speed range between $40 \mathrm{mph}$ and $55 \mathrm{mph}$, and then becomes rapid for higher speeds. The 
graph shows that for an increase of speed from $40 \mathrm{mph}$ to $70 \mathrm{mph}$, the $\mathrm{CO}_{2}$ emission rates increased by approximately 1.5 times.

Figure 22 presents the results of sensitivity of nitrogen oxide $\left(\mathrm{NO}_{x}\right)$ emissions to speed. For same speed, the $\mathrm{NO}_{x}$ emissions are higher for heavier gross vehicle weight (i.e. emissions from full truck is higher than that from medium one). This is also the case in each weight bin for a specific speed (i.e. $\mathrm{NO}_{x}$ emissions goes up with the increase in weight at same speed). In general, the variation in $\mathrm{NO}_{x}$ emissions has the same trend for all weight bins, where the emissions are found to increase for speeds up to $55 \mathrm{mph}$ and decrease for high

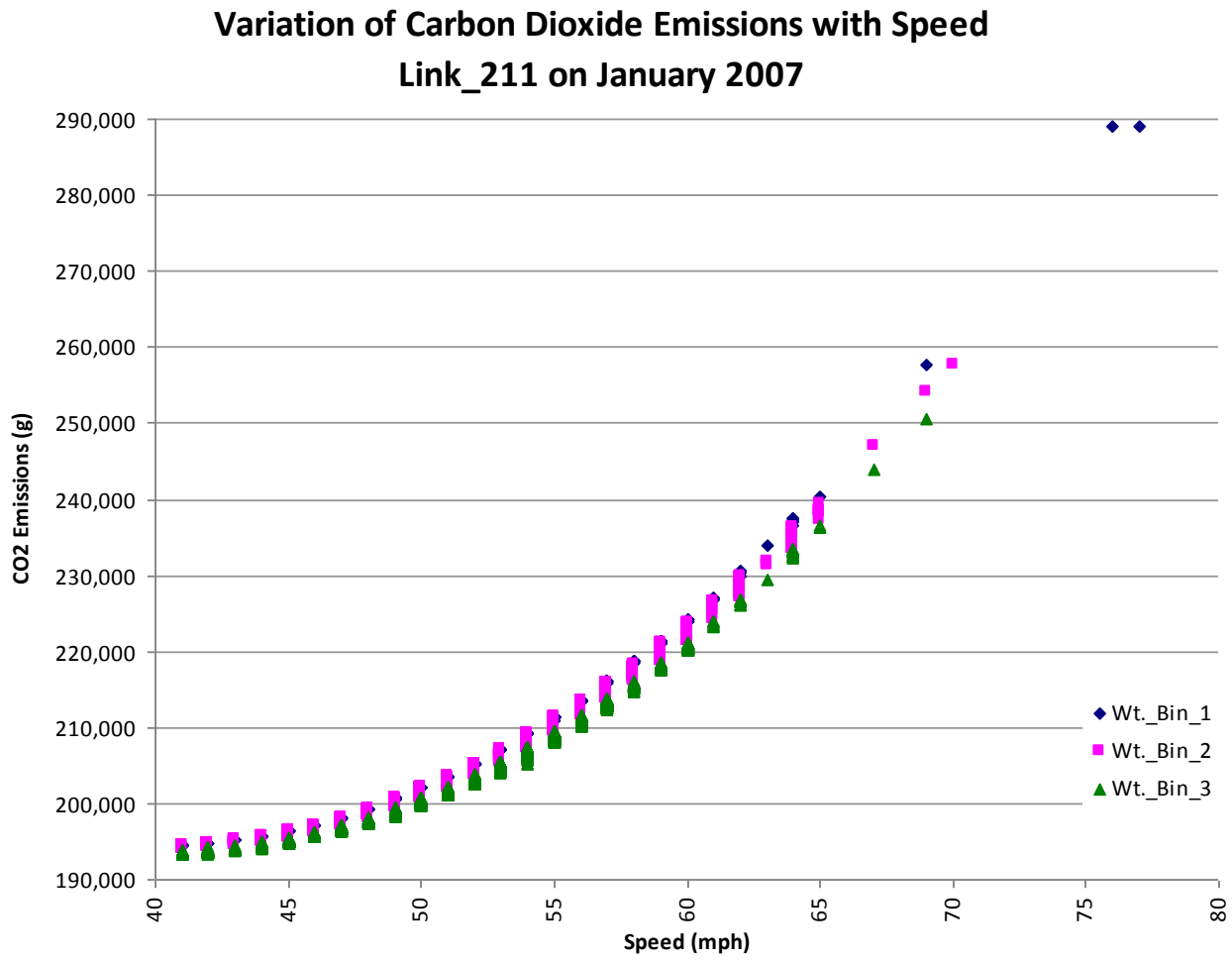

Figure 21: Variation of $\mathrm{CO}_{2}$ Emissions with Speed - Link 211 on January_07 


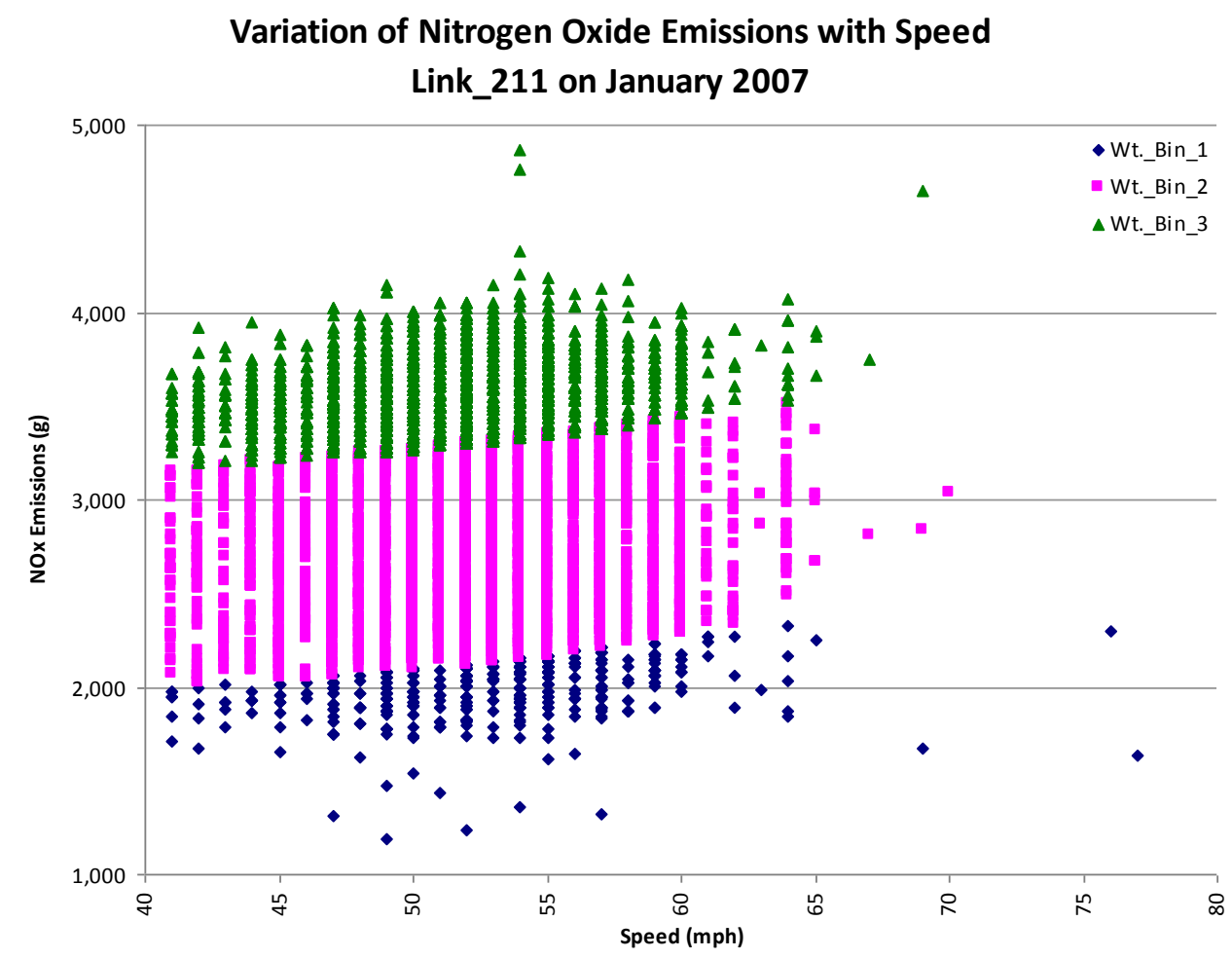

Figure 22: Variation of NOx Emissions with Speed - Link 211 on January_07

\subsection{Link-Based Emissions Estimation}

The amounts (in grams) of carbon dioxide $\left(\mathrm{CO}_{2}\right)$ and nitrogen oxide $\left(\mathrm{NO}_{\mathrm{x}}\right)$ emissions for Link 211 on northbound I-5 were estimated using empirical equations from other researchers. These equations and the used variables are listed in chapter 3 in detail. January 2007 was the sample month chosen for analysis as it had high data quality for Link 211. A data set of 9,669 records for five-axle (Class 9) through trucks is used to estimate the emissions. Please refer to Appendix A for a step-by-step explanation for methods and 
assumptions made to estimate the emissions for the studied corridor in January 2007.

A plot of Class 9 through-truck counts on Link 211 versus time of day for January 2007 is shown in Figure 23. It is found that the highest truck frequency (curve peaks) occurs during the midday between 12:00 PM and 2:00 PM. The highest truck activity on the corridor was on January $4^{\text {th }}$ at 2:00 PM. The trucks count did not show differences between weekdays and weekends.

\subsubsection{Carbon Dioxide $\left(\mathrm{CO}_{2}\right)$ Emissions}

Figure 24 shows the continuous carbon dioxide $\left(\mathrm{CO}_{2}\right)$ emissions (in grams) of five-axle through trucks traveled on Link 211 versus time of day for the whole month of January 2007. Comparing the profile of $\mathrm{CO}_{2}$ emissions and that of the through-trucks count, it can be easily seen that the peaks of both graphs occur at the same time (i.e. a rise in the number of trucks is accompanied by increasing emissions). This correlation suggests that this increase in emissions is due to larger number of trucks traveling on the corridor at that time interval, not because the trucks are driving at higher speeds. 
Through-Truck Count for Link_211 on January 2007

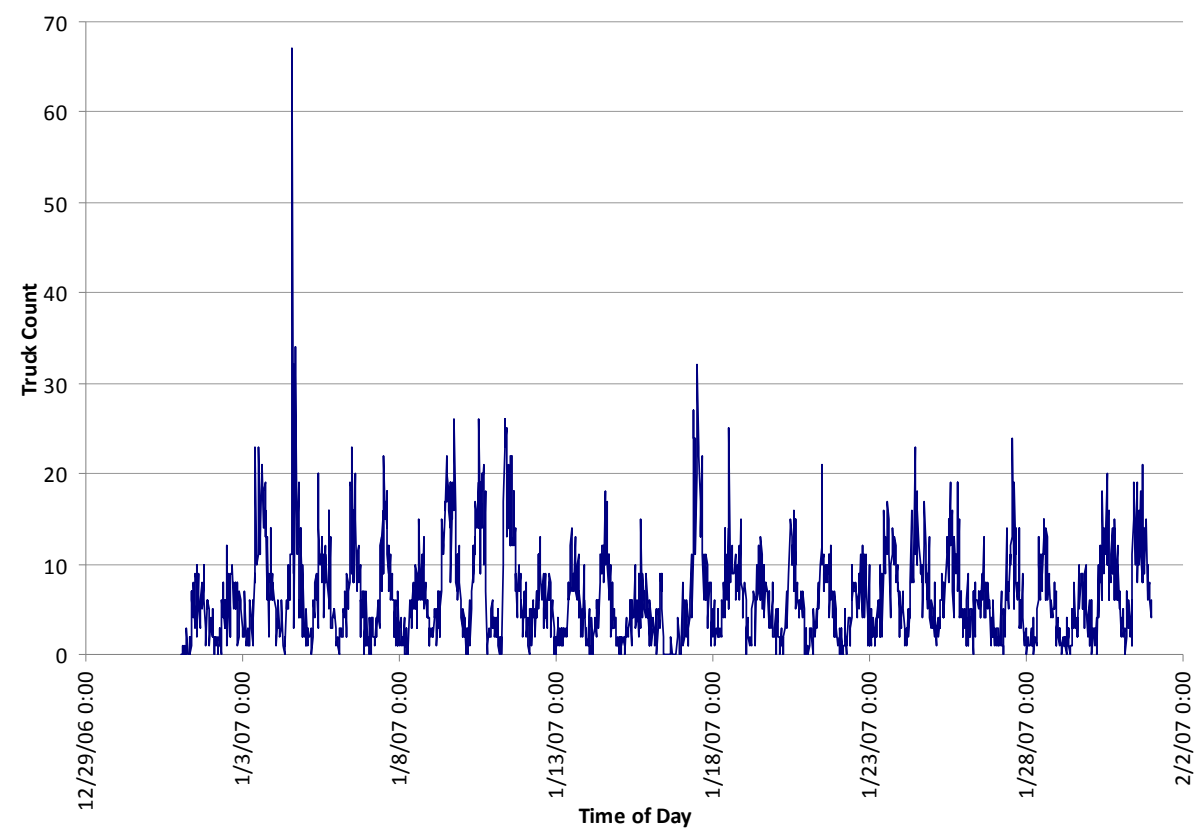

Figure 23: Through-Truck Count by Time of Day for Link 211 on January_07

$\mathrm{CO}_{2}$ Emissions for Through Trucks - Link_211 - January 07

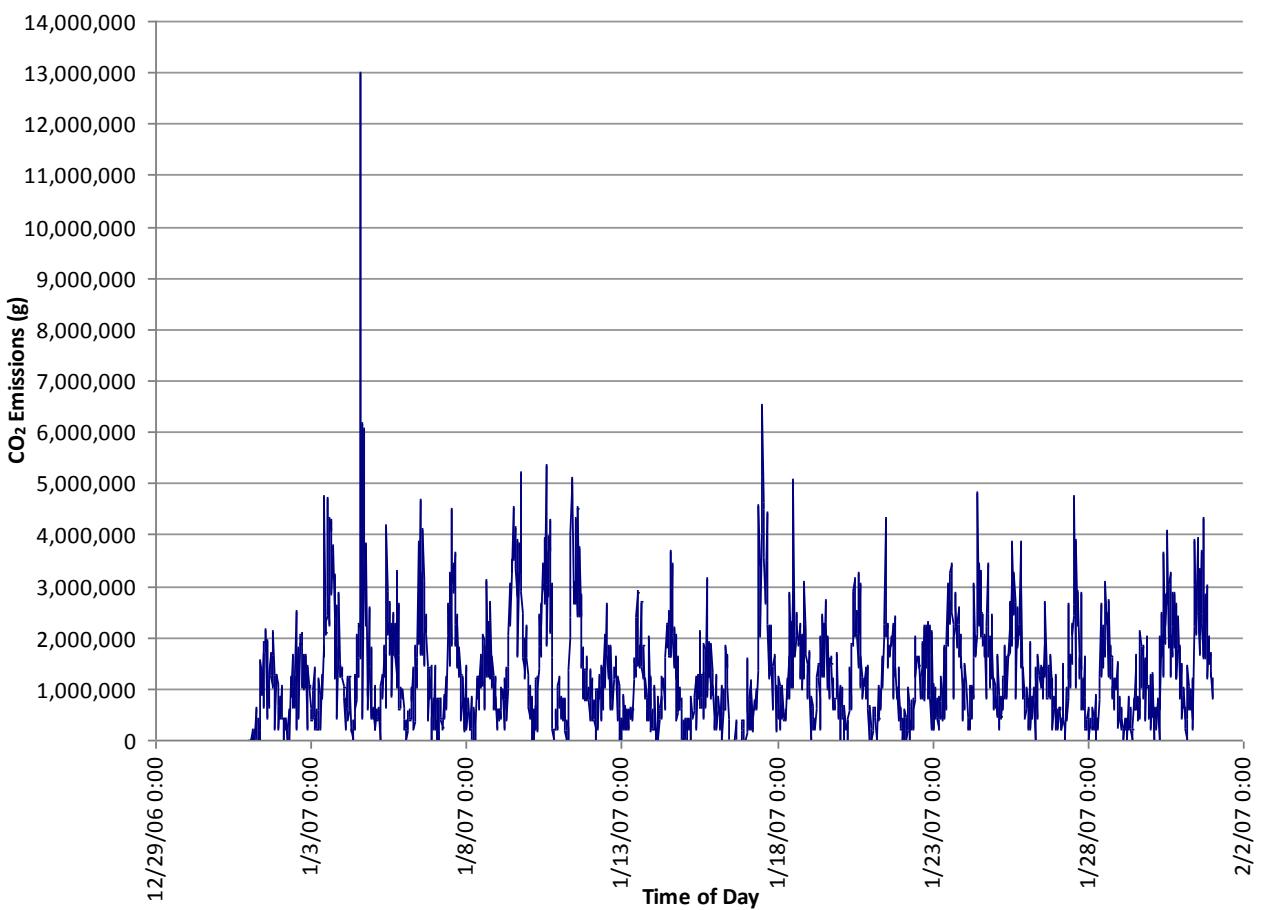

Figure 24: Through-Truck Carbon Dioxide Emissions - Link 211, Jan_07 
The average $\mathrm{CO}_{2}$ emission rates per truck for empty, medium, and full trucks at eight speed ranges (from 40 to $80 \mathrm{mph}$ in 5-mph increments) are presented in Table 6. It can be seen that the emission rates at high speeds are generally larger than those at low speeds for all truck weights. There is an exception for empty trucks (weight bin 1) for speed range between 65 and 80 mph but this is attributed to small sample sizes. The results also indicate that heavier trucks emit less $\mathrm{CO}_{2}$ emissions compared with empty or mediumloaded trucks for a given speed level. Again, because of few truck records for speeds above $65 \mathrm{mph}$ in the three weight bins, it was difficult to check the same trend at high speeds.

Table 6: Average $\mathrm{CO}_{2}$ Emission Rates (in Grams) for Heavy-Duty Trucks - Link 211

\begin{tabular}{c|cc|cc|cc}
\hline \multirow{2}{*}{$\begin{array}{c}\text { Speed } \\
\text { (mph) }\end{array}$} & \multicolumn{2}{|c|}{ Weight Bin_1 (Empty) } & \multicolumn{2}{|c|}{ Weight Bin_2 (Medium) } & \multicolumn{2}{|c}{ Weight Bin_3 (Full) } \\
\cline { 2 - 7 } & $\begin{array}{c}\text { Sample } \\
\text { Size }\end{array}$ & $\begin{array}{c}\text { Average } \\
\text { Emissions } \\
\mathbf{( g )}\end{array}$ & $\begin{array}{c}\text { Sample } \\
\text { Size }\end{array}$ & $\begin{array}{c}\text { Average } \\
\text { Emissions } \\
\mathbf{( g )}\end{array}$ & $\begin{array}{c}\text { Sample } \\
\text { Size }\end{array}$ & $\begin{array}{c}\text { Average } \\
\text { Emissions } \\
\text { (g) }\end{array}$ \\
\hline $40-45$ & 20 & 194,990 & 223 & 194,944 & 241 & 194,147 \\
$45-50$ & 89 & 199,184 & 892 & 198,509 & 912 & 197,550 \\
$50-55$ & 198 & 206,022 & 2,290 & 205,103 & 2,061 & 203,691 \\
$55-60$ & 142 & 215,193 & 1,182 & 213,796 & 841 & 211,566 \\
$60-65$ & 22 & 228,869 & 229 & 226,043 & 93 & 223,276 \\
$65-70$ & 2 & 166,048 & 9 & 241,057 & 5 & 240,718 \\
$70-75$ & 0 & N/A & 1 & 257,757 & 0 & N/A \\
$75-80$ & 2 & 192,774 & 0 & N/A & 0 & N/A \\
\hline
\end{tabular}


The percent difference in $\mathrm{CO}_{2}$ emissions between every two consequent speed ranges is calculated for the three weight bins. The percent of increase is found to be higher as the speed goes up and approximately the same for all truck weights. In other words, an increase in average speed from 40 versus 45 mph results in nearly $1.7 \%$ higher $\mathrm{CO}_{2}$ emissions, while this increase is $5.5 \%$ when going from 60 versus $65 \mathrm{mph}$.

Observing the change in average emission rates with respect to gross vehicle weight (GVW), it is found that the $\mathrm{CO}_{2}$ emissions are lower for heavier truck weights at a given speed. This reduction is minimal and ranges between $0.3 \%$ and $0.9 \%$. The reason for this trend is because the GVW was only used in calculating the actual vehicle speed on uphill grades, but the equations used to estimate the $\mathrm{CO}_{2}$ emissions (mentioned in section 3.3.4) did not encounter the truck weight as a variable. Speed and roadway grade were the variables used in these equations, which explains the decrease in emissions with increase in GVW (because the speed decreases with higher GVW). It should be noted that this result does not agree with other researchers and what was expected from the study. This limitation may have been overcome if an equation that takes the vehicle weight as a variable was available. 
In order to highlight the variability in emission rates for the three studied weight bins, the ratio of maximum to minimum emission rates of carbon dioxide $\left(\mathrm{CO}_{2}\right)$ and nitrogen oxide $(\mathrm{NO} \times)$ (which will be discussed in the next section) are given in Table 7. In general, the $\mathrm{CO}_{2}$ ratios show that the variation in emission rates for full, medium, and empty heavy-duty vehicles ranges approximately between $30 \%$ and $50 \%$. This variation is found to become smaller when the truck weight goes up.

Table 7: Ratios of Maximum to Minimum Link Emission Rates - Link 211

\begin{tabular}{cccc}
\hline Pollutant Type & $\begin{array}{c}\text { Weight Bin_1 } \\
\text { (Empty) }\end{array}$ & $\begin{array}{c}\text { Weight Bin_2 } \\
\text { (Medium) }\end{array}$ & $\begin{array}{c}\text { Weight Bin_3 } \\
\text { (Full) }\end{array}$ \\
\hline $\mathrm{CO}_{2}$ & 1.49 & 1.33 & 1.30 \\
$\mathrm{NO}_{\mathbf{x}}$ & 1.96 & 1.74 & 1.52 \\
\hline
\end{tabular}

To estimate the total carbon dioxide $\left(\mathrm{CO}_{2}\right)$ emissions of Link 211 on Interstate 5 (I-5) between Ashland POE (NB, MP 18.08) and Booth Ranch (NB, MP 111.07), the emission rates calculated above for through empty, medium, and full trucks will be multiplied by their percentage from total truck count. It was decided that the multiplication by a factor was possible after comparing the profile of the monthly counts for total, empty (weight bin 1), medium (weight bin 2), and full (weight bin 3) trucks, Figure 25. All profiles show similar trend with same peaks. As previously presented in Figure 11, empty 
trucks are approximately $5 \%$ from the total fleet, while medium and full trucks are $50 \%$ and $45 \%$ respectively. The count of the through trucks used to estimate the emissions represents nearly $75 \%$ of the total number of trucks that traveled on the studied corridor on January 2007. The total link-based carbon dioxide emissions (in grams) resulting from five-axle (Class 9) heavy-duty vehicles are shown in Figure 26.

Transponder-Truck Count for Link_211 on January 2007

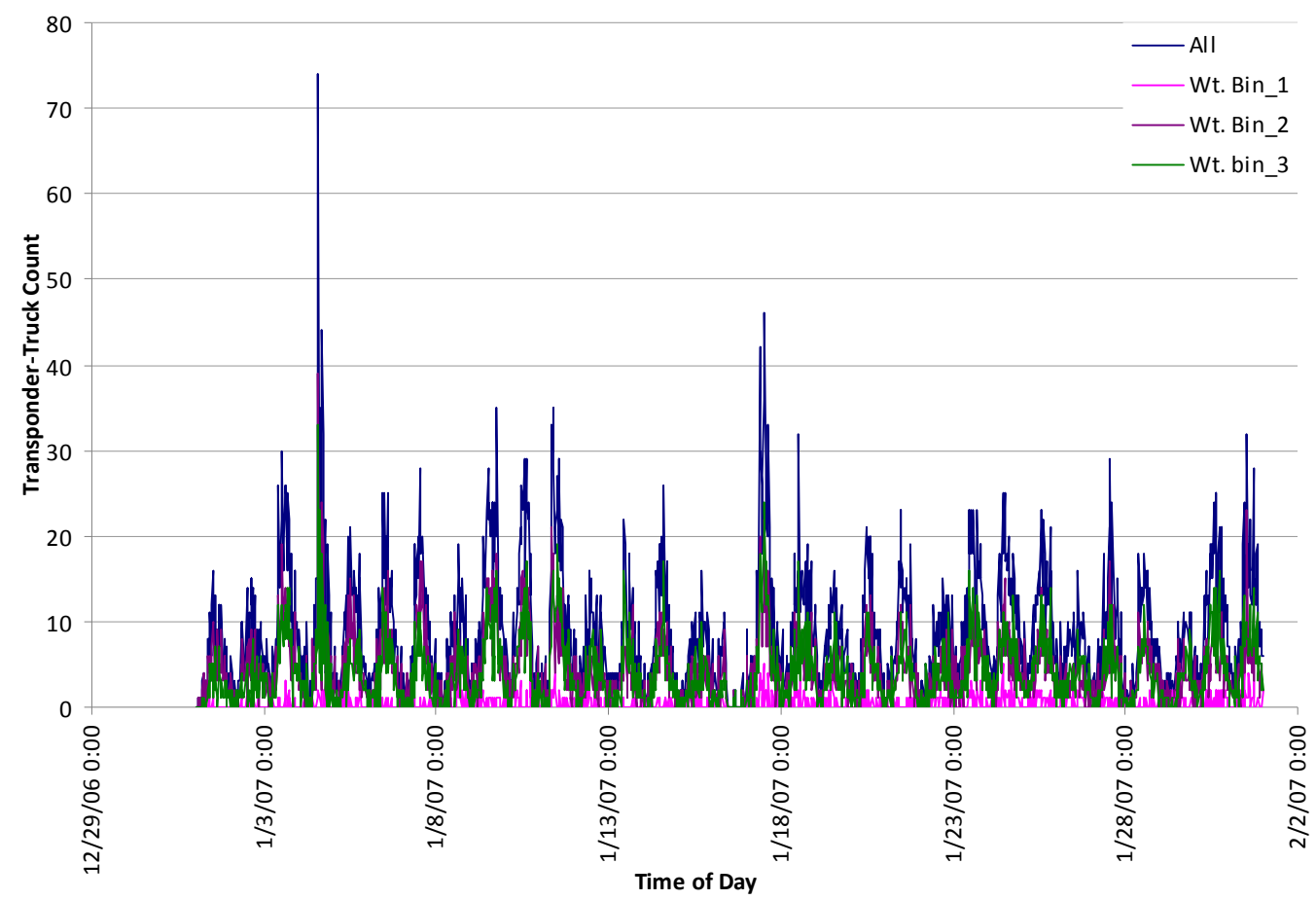

Figure 25: Counts of Transponder-Equipped Trucks - Link 211, Jan_07

From the total link-based emissions plot, Figure 26, it can be seen that the highest daily values of emissions occurred between 12 PM and 2 PM. This is the time interval that encountered the highest activity of trucks during the 
day. The mass of daily carbon dioxide $\left(\mathrm{CO}_{2}\right)$ emissions for the whole month ranged approximately between 252,570 and 17,180,927 grams with an average of 1,830,000 grams. On a monthly basis, nearly $2.569 \times 10^{9}$ grams of $\mathrm{CO}_{2}$ are

Total $\mathrm{CO}_{2}$ Emissions for Link_211 on January 07

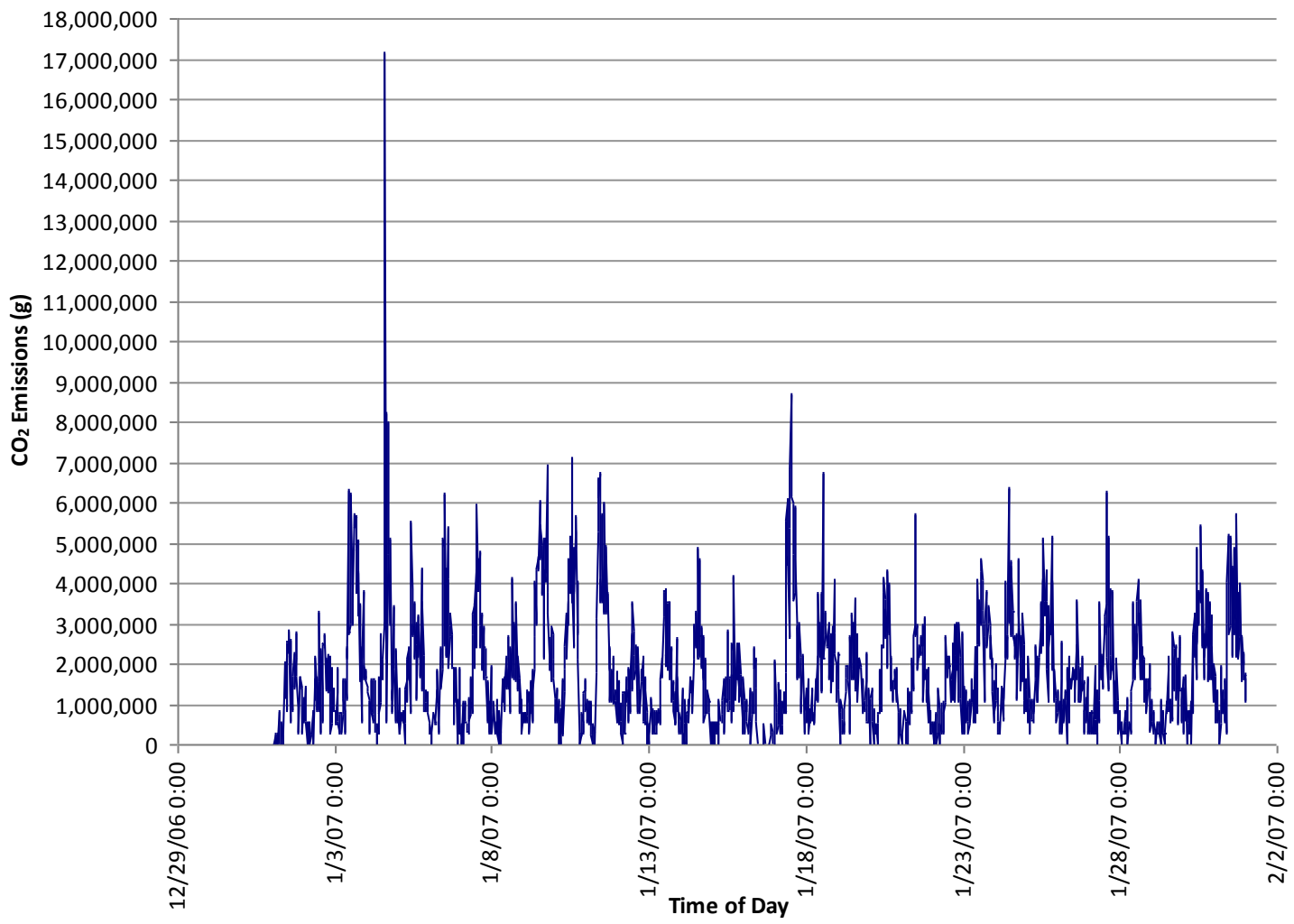

Figure 26: Total Carbon Dioxide Emissions for Link 211 on January_07 


\subsubsection{Nitrogen Oxide $\left(\mathrm{NO}_{x}\right)$ Emissions}

The nitrogen oxide $\left(\mathrm{NO}_{\mathrm{x}}\right)$ emissions (in grams) for through five-axle heavyduty vehicles on Link 211 versus time of day for the whole month of January 2007 are presented in Figure 27. Strong correlation is observed between the $\mathrm{NO}_{x}$ emissions profile and the through-truck count plotted in Figure 23. Increases in the $\mathrm{NO}_{x}$ emissions are found to happen with spikes in the truckcount curve, while the emissions fall when the count decreases. This implies that the rise in emissions is resulting from higher number of vehicles passing on the corridor at that time not because higher speeds of those trucks.

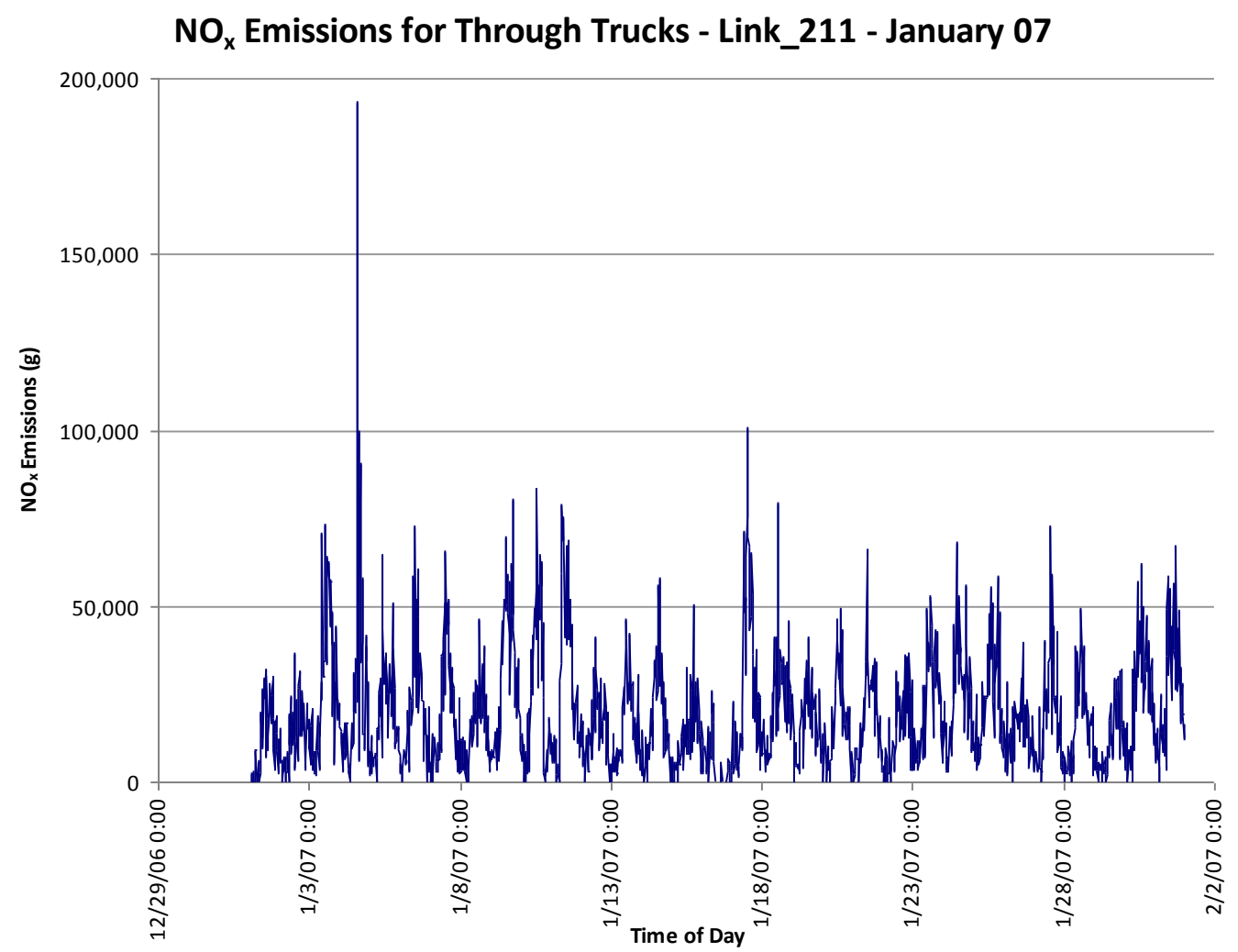

Figure 27: Through-Truck Nitrogen Oxide Emissions - Link 211, Jan_07 
Table 8 lists the average values of $\mathrm{NO}_{x}$ emissions per truck at eight speed ranges between 40 and $80 \mathrm{mph}$ (in 5-mph increments) for through trucks in the three studied weight categories (empty, medium, and full). In general, the average $\mathrm{NO}_{x}$ emission rates tend to increase with higher speed. Some values are affected by the small sample sizes. For the same gross vehicle weight (GVW), the emission rate rises by nearly $2 \%$ for every $5 \mathrm{mph}$ increase in traveling speed.

Table 8: Average NOx Emission Rates (in Grams) for Heavy-Duty Trucks - Link 211

\begin{tabular}{c|cc|cc|cc}
\hline \multirow{2}{*}{$\begin{array}{c}\text { Speed } \\
\text { (mph) }\end{array}$} & \multicolumn{2}{|c|}{ Weight Bin_1 (Empty) } & \multicolumn{2}{|c|}{ Weight Bin_2 (Medium) } & \multicolumn{2}{|c}{ Weight Bin_3 (Full) } \\
\cline { 2 - 7 } & $\begin{array}{c}\text { Sample } \\
\text { Size }\end{array}$ & $\begin{array}{c}\text { Average } \\
\text { Emissions } \\
\mathbf{( g )}\end{array}$ & $\begin{array}{c}\text { Sample } \\
\text { Size }\end{array}$ & $\begin{array}{c}\text { Average } \\
\text { Emissions } \\
\mathbf{( g )}\end{array}$ & $\begin{array}{c}\text { Sample } \\
\text { Size }\end{array}$ & $\begin{array}{c}\text { Average } \\
\text { Emissions } \\
\text { (g) }\end{array}$ \\
\hline $40-45$ & 20 & 1,898 & 223 & 2,650 & 241 & 3,477 \\
$45-50$ & 89 & 1,917 & 892 & 2,682 & 912 & 3,522 \\
$50-55$ & 198 & 1,975 & 2,290 & 2,757 & 2,061 & 3,592 \\
$55-60$ & 142 & 2,043 & 1,182 & 2,793 & 841 & 3,636 \\
$60-65$ & 22 & 2,104 & 229 & 2,860 & 93 & 3,694 \\
$65-70$ & 2 & 1,308 & 9 & 2,897 & 5 & 3,966 \\
$70-75$ & 0 & N/A & 1 & 3,040 & 0 & N/A \\
$75-80$ & 2 & 1,313 & 0 & N/A & 0 & N/A \\
\hline
\end{tabular}

The results in Table 8 also indicate that the emission rates for $\mathrm{NO}_{\mathrm{x}}$ tend to increase with the GVW. For example, an increase in the weight of heavyduty vehicle from $30,000 \mathrm{lbs}$ to $60,000 \mathrm{lbs}$ resulted in approximately $45 \%$ 
higher mass (in grams) of $\mathrm{NO}_{x}$ emissions for same speed (taken $55 \mathrm{mph}$ because it is the posted speed limit and the most typical speed, see Figure 14). Increasing the GVW from $60,000 \mathrm{lbs}$ to $80,000 \mathrm{lbs}$ caused approximately $23 \%$ higher $\mathrm{NO}_{\mathrm{x}}$ emissions (in grams). In addition, $\mathrm{NO}_{\mathrm{x}}$ emissions were found to have a linear relationship with vehicle weight as shown in Figure 28. This is primarilv due to the used eauation.

Effect of GVW on Nitrogen Oxide Emissions

Link_211 on January 2007

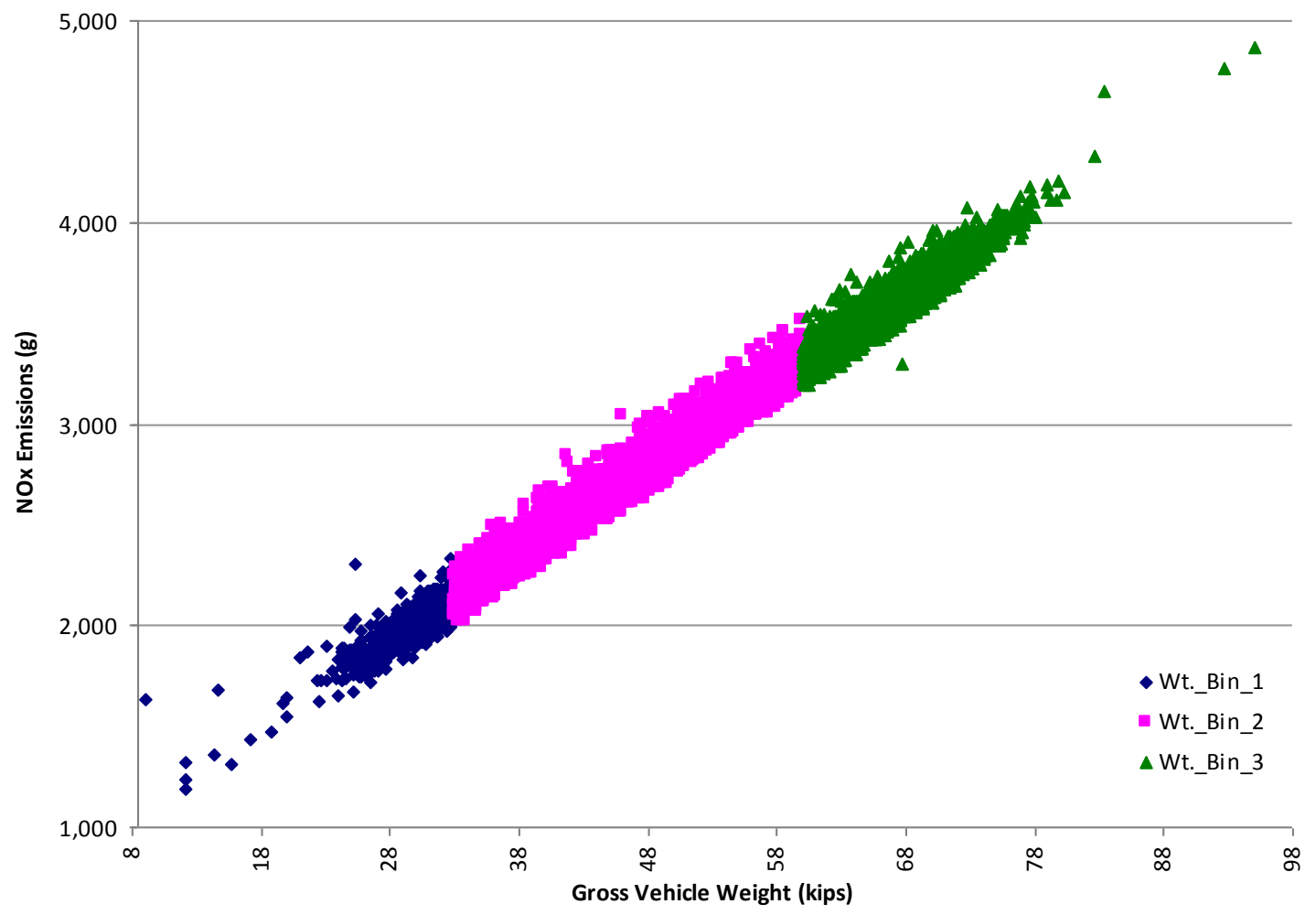

Figure 28: Relationship between Nitrogen Oxide Emissions and GVW - Link 211, Jan_07 
Table 7 presents the ratios of maximum to minimum emission rates of nitrogen oxide $\left(\mathrm{NO}_{\mathrm{x}}\right)$ for through empty, medium, and full trucks. The ratios indicate that a significant amount of variability in emissions is being captured for all weight categories. This variability tends to decrease as the truck gets heavier (i.e. minimum ratio for full trucks). Variation in the emitted $\mathrm{NO}_{\mathrm{x}}$ is nearly the double for empty and medium truck, while for full trucks the emissions are nearly 1.5 times more.

The total link-based nitrogen oxide (NOx) emissions (in grams) of Link 211 on Interstate 5 (I-5) between Ashland POE (NB, MP 18.08) and Booth Ranch (NB, MP 111.07) in January 2007 are estimated by multiplying the emission rates calculated for through trucks by their percentage $(\sim 75 \%)$ from the total amount of trucks on the link. This assumption appears valid because after inspecting the count profiles for total, empty (weight bin 1), medium (weight bin 2), and full (weight bin 3) trucks, it was found that rises and falls in counts occur at same time for all profiles, Figure 25. In addition, an additional assumption was made that the non-through trucks have the same count behavior over time through the whole month as that of through trucks in each weight category. This is a reasonable assumption though there are no ground truth data available to validate. The total link-based nitrogen oxide 
emissions (in grams) resulting from five-axle (Class 9) heavy-duty vehicles are shown in Figure 29.

From the total link-based emissions plot, it can be seen that the highest daily values of emissions occurred between $12 \mathrm{PM}$ and $2 \mathrm{PM}$. This is the time interval that encountered the highest activity of trucks during the day. The mass of daily nitrogen oxide $\left(\mathrm{NO}_{\mathrm{x}}\right)$ emissions for the whole month ranged between 2,199 and 255,742 grams with an average of 65,600 grams. On a monthly basis, nearly $38,600,500$ grams of $\mathrm{NO}_{x}$ are emitted from five-axle trucks traveling on Link 211 on January 2007.

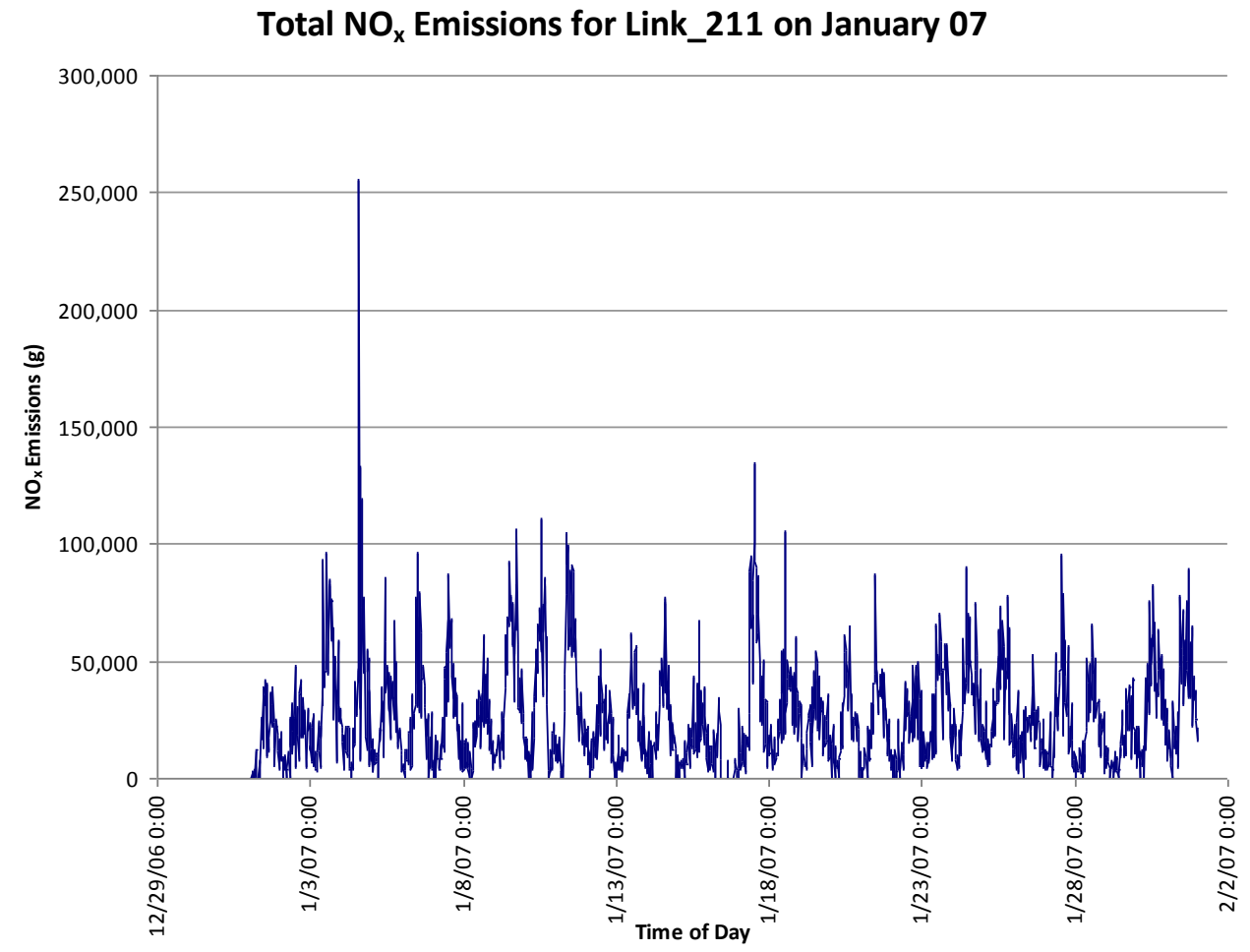

Figure 29: Total Nitrogen Oxide Emissions for Link 211 on January_07 


\subsection{Summary of Key Findings}

\subsubsection{Truck Data Characteristics}

- 50\% of transponder-equipped trucks on Link 211 were full, while $45 \%$ were medium weighed, and only $5 \%$ empty.

- Through trucks were found to represent $\sim 75 \%$ of the total transponder-equipped heavy-duty vehicles.

- The majority of through trucks were found to adhere to the posted speed (55 mph) (over the distance) with gross vehicle weight (GVW) between 65 and 70 kips.

\subsubsection{Effects of Grade on Speed}

- For empty trucks, the variation percentage of speed drop increased with increase in speed and uphill grade. The variation ranged between $0 \%$ and $13 \%$ for grades between $1 \%$ and $5 \%$.

- For medium weight trucks, the percentage of speed drop increased with increase in speed for grades $1 \%$ to $5 \%$. The variation range of speed drop increased as the grade gets more steep. The speed variation ranged between $0 \%$ and $24 \%$ for grades between $1 \%$ and $5 \%$. 
- With increase in speed of full trucks, the percent decrease in speed was minimal for grade $1 \%$. For grades $3 \%$ and $4 \%$, the rate of drop in speed was higher than that on grades $2 \%$ and $5 \%$. The speed variation ranged between $0 \%$ and $40 \%$ for grades between $1 \%$ and $5 \%$.

\subsubsection{Carbon Dioxide $\left(\mathrm{CO}_{2}\right)$ Emissions}

- Carbon dioxide $\left(\mathrm{CO}_{2}\right)$ emissions were found to increase as speed increased for all truck weights. Emissions resulting from traveling at $70 \mathrm{mph}$ are approximately 1.5 times higher than those emitted when driving at $40 \mathrm{mph}$.

- $\mathrm{CO}_{2}$ emissions were found to increase with speed. For example, incremental change in speed from 40 to $45 \mathrm{mph}$ resulted in $1.7 \%$ higher emissions, while the increment from 60 to $65 \mathrm{mph}$ increased the emissions by $5.5 \%$.

- The equation used to estimate the carbon dioxide $\left(\mathrm{CO}_{2}\right)$ emissions was not able to accurately capture the effect of gross vehicle weight on the emissions.

- A daily average of $1,830,000$ grams of carbon dioxide $\left(\mathrm{CO}_{2}\right)$ emissions were emitted from five-axle trucks traveled on Link 211 
during January 2007, while the total month emissions were $2.568 \times 10^{9}$ grams.

- Increases in $\mathrm{CO}_{2}$ emissions on Link 211 was found to be due to higher truck counts and not related to higher heavy-duty vehicle speed.

\subsubsection{Nitrogen Oxide $\left(\mathrm{NO}_{x}\right)$ Emissions}

- Nitrogen oxide $(\mathrm{NO} \times)$ emissions were found to increase as speed increased. For same truck weight, the emissions increased by nearly $2 \%$ for every $5 \mathrm{mph}$ increase in traveling speed.

- The nitrogen oxide $\left(\mathrm{NO}_{x}\right)$ emissions increased with gross vehicle weight (GVW). For the same speed, doubling the heavy-duty vehicle weight resulted in approximately $45 \%$ higher emissions.

- The relationship between nitrogen oxide $\left(\mathrm{NO}_{x}\right)$ emissions and gross vehicle weight was found to be linear for empty, medium, and full trucks.

- Increases in $\mathrm{NO}_{x}$ emissions on Link 211 were found to be due to higher truck counts and not related to higher speeds.

- A daily average of 27,500 grams of nitrogen oxide ( $\mathrm{NO} \times$ ) emissions were emitted from five-axle trucks traveled on Link 211 during 
January 2007, while the total month emissions were $38,600,500$ grams.

This chapter started with an analysis of some performance measures for heavy vehicles traveling on Link 211 in January 2007. The results from the sensitivity analysis of speed to vehicle weight and road grade were then discussed. This was followed by an estimation of the link-based heavy-duty vehicle emissions of carbon dioxide $\left(\mathrm{CO}_{2}\right)$ and nitrogen oxide $\left(\mathrm{NO}_{x}\right)$. Finally, the chapter was concluded by a summary of the key findings. The research conclusions and suggestions for possible future work are the focus of the following chapter. 


\subsection{CONCLUSIONS}

This final chapter is a summary of the main findings. The findings are put in context of what contribution this research makes to the state of the knowledge. The second section gives recommendations for possible future work.

\subsection{Summary of Findings}

The objective of this study was to explore the possibility of using the archived weigh-in-motion (WIM) data to estimate link-based emission factors for Oregon in key freight corridors. This research successfully met the objective, and found that by knowing the truck type and the gross vehicle weight (GVW) and with a set of assumptions, it is possible to estimate emissions for Oregon's highway corridors using the WIM data archive.

The work presented in this report combined the truck speed, roadway grade and the heavy-duty gross vehicle weight to estimate the link-based carbon dioxide $\left(\mathrm{CO}_{2}\right)$ and nitrogen oxide $\left(\mathrm{NO}_{\mathrm{x}}\right)$ emissions. In addition, the impact of these factors on estimated emissions was examined. The combination of these effects is important as it has received little attention in previous emission research related to freight vehicles.

Findings show that, in general, $\mathrm{CO}_{2}$ and $\mathrm{NO}_{x}$ emissions increase as the average speed, gross vehicle weight, and uphill grade increase. The $\mathrm{CO}_{2}$ 
emissions are 1.5 times greater when the speed is from $70 \mathrm{mph}$ versus $40 \mathrm{mph}$, while the $\mathrm{NO}_{x}$ emissions rise by $1 \%$ for every speed increase of $5 \mathrm{mph} . \mathrm{NO}_{x}$ emissions has linear relationship with vehicle weight, and emissions increase by $45 \%$ with a doubling of weight.

The total estimated link-based emissions for Link 211 on Interstate 5 during January 2007 are $2.5 \times 10^{9}$ grams of carbon dioxide $\left(\mathrm{CO}_{2}\right)$ and $38,600,500$ grams of nitrogen oxide $(\mathrm{NO} \times)$. Identifying the mass of emissions on key highway corridors will be helpful information in potentially setting new measures to reduce emissions from heavy-duty vehicles.

Road uphill grade was estimated to produce a significant fall in the traveling speed. Percent variation in speed drop differs depending on the grade value. The range of speed decrease for grades between $1 \%$ and $5 \%$ is $0 \%-13 \%$ for empty trucks, $0 \%-24 \%$ for medium trucks, and is $0 \%-40 \%$ for full trucks.

Another contribution of this research is the utilization of the additional information provided by weigh-in-motion (WIM) data for estimating linkbased heavy-duty vehicle emissions, where these data have been mainly used in the past to estimate truck counts and in pavement design. 


\subsection{Future Work}

While using weigh-in-motion (WIM) data offers the opportunity to estimate link-based emissions, the limitations of the data must be understood. The most important issue is that the available speed is the average speed at the station location. Future work should focus on increasing the accuracy of the emission estimates by obtaining more information about the speed profile along the studied corridor. This could be obtained from installing additional sensors to read transponders and detect speed as recommended in a previous research (Monsere et al., 2009) or most likely the use of GPS equipped fleet vehicles to determine speed profiles. Work in urban areas by Wheeler and Figliozzi (2011) has shown the usefulness of these data. Another refinement to the emission estimates will be through using models or equations that contain speed, vehicle weight, and road grade together as variables.

The next step in this research would be to estimate the link-based emissions for all links and pollutants on Oregon highways using empirical equations or models. In addition, emissions estimation for all truck classes is needed to develop more comprehensive fleet-based estimates. This information will enable the creation of an emissions inventory archive. The results could be presented in graphical or tabular form. To achieve this, a 
program or module is to be written to calculate the emissions on a truck-bytruck basis. 


\subsection{REFERENCES}

1. AGUDELO, J., AGUDELO, A. \& PEREZ, J. (2009) Energy and Exergy Analysis of a Light-Duty Diesel Engine Operating at Different Altitudes. Review School of Engineering, University of Antioquia, No. 48, pp. $45-54$.

2. AHANOTU, D.N. (1999) Heavy-Duty Vehicle Weight and Horsepower Distributions: Measurement of Class-Specific Temporal and Spatial Variability. Dissertation, Georgia Institute of Technology.

3. BIGAZZI, A.Y. \& BERTINI, R.L. (2009) Adding Green Performance Metrics to a Transportation Data Archive. Transportation Research Record: Journal of the Transportation Research Board, No. 2121, pp. 30-40.

4. BORIBOONSOMSIN, K. \& BARTH, M. (2009) Impacts of Road Grade on Fuel Consumption and Carbon Dioxide Emissions Evidenced by Use of Advanced Navigation Systems. Transportation Research Record: Journal of the Transportation Research Board, No. 2139, pp. 21-30.

5. BARTH, M., SCORA, G. \& YOUNGLOVE, T. (2004) Modal Emissions Model for Heavy-Duty Diesel Vehicles. Transportation Research Record: Journal of the Transportation Research Board, No. 1880, pp. 10-20.

6. BRODRICK, C.J., LACA, E.A., BURKE, A.F., FARSHCHI, M., LI, L. \& DEATON, M. (2004) Effect of Vehicle Operation, Weight, and Accessory Use on Emissions from a Modern Heavy-Duty Diesel Truck. Transportation Research Record: Journal of the Transportation Research Board, No. 1880, pp. 119-125.

7. BRODRICK, C.J., DWYER, H.A., FARSHCHI, M., HARRIS, D.B. \& KING, F.G. (2002) Effects of Engine Speed and Accessory Load on Idling Emissions from Heavy-Duty Diesel Truck Engines. Journal of the Air \& Waste Management Association, Volume 52, pp. 1026-1031. 
8. BISHOP, G.A., MORRIS, J.A., STEDMAN, D.H., COHEN, L.H., COUNTESS, R.J., COUNTESS, S.J., MALY, P. \& SCHEREER, S. (2001) The Effects of Altitude on Heavy-Duty Diesel Truck On-Road Emissions. Environmental Science \& Technology, Volume 35, No. 8, pp. 1574-1578.

9. CLARK, N.N. \& GAJENDRAN, P. (2003) A Predictive Tool for Emissions from Heavy-Duty Diesel Vehicles. Environmental Science \& Technology, Volume 37, pp. 7-15.

10. CLARK, N.N., KERN, J.M., ATKINSON, C.M. \& NINE, R.D. (2002) Factors Affecting Heavy-Duty Diesel Vehicle Emissions. Journal of the Air \& Waste Management Association, Volume 52, pp. 84-94.

11. DURBIN, T.D., NORBECK, J.M., WILSON, R.D. \& GALDAMEZ, N.A. (2000) Effect of Payload on Exhaust Emissions from Light Heavy-Duty Diesel and Gasoline Trucks. Environmental Science \& Technology, Volume 34, No. 22, pp. 4708-4713.

12. DREHER, D.B. \& HARLEY, R.A. (1998) A Fuel-Based Inventory for Heavy-Duty Diesel Truck Emissions. Journal of the Air $\mathcal{E}$ Waste Management Association, Volume 48, pp. 352-358.

13. FACANHA, C., BROWNING, L., ANG-OLSON, J., HARTLEY, S., PAPSON, A. \& CARR, E. (2010) Evaluation of Methods, Models, and Parameters to Represent Freight in Air Quality and Greenhouse Gas Models. 89th Annual Meeting of Transportation Research Board Compendium of Papers CD-ROM.

14. FIGLIOZZI, M. (2010) Vehicle Routing Problem for Emissions Minimization. Transportation Research Record: Journal of the Transportation Research Board, No. 2197, pp. 1-7.

15. FREY, H.C., ROUPHAIL, N.M. \& ZHAI, H. (2008) Link-Based Emission Factors for Heavy-Duty Diesel Trucks Based on Real-World Data. Transportation Research Record: Journal of the Transportation Research Board, No. 2058, pp. 23-32. 
16. FREY, H.C. \& KIM, K. (2006) Comparison of Real-World Fuel Use and Emissions for Dump Trucks Fueled with B20 Biodiesel Versus Petroleum Diesel. Transportation Research Record: Journal of the Transportation Research Board, No. 1987, pp. 110-117.

17. FENG, C., YOON, S. \& GUENSLER, R. (2005) Data Needs for a Proposed Modal Heavy-Duty Diesel Vehicle Emission Model. 98 AWMA Meeting - Paper \# 1072.

18. GAJENDRAN, P. \& CLARK, N.N. (2003) Effect of Truck Operating Weight on Heavy-Duty Diesel Emissions. Environmental Science $\mathcal{E}$ Technology, Volume 37, No. 18, pp. 4309-4317.

19. GRANT, C.D. (1998) Representative Vehicle Operating Mode Frequencies: Measurement and Prediction of Vehicle Specific Freeway Modal Activity. Dissertation, Georgia Institute of Technology.

20. HAO, Y., YU, L., SONG, G., XU, Y. \& WANG, H. (2010) Analysis of Driving Behavior and Emission Characteristics for Diesel Transit Buses Using PEMS' Measurements. 89th Annual Meeting of Transportation Research Board - Compendium of Papers CD-ROM.

21. HEARNE, J. (2004) School Bus Idling and Mobile Diesel Emissions Testing: Effect of Fuel Type and Development of a Mobile Test Cycle. Thesis, College of Engineering Rowan University.

22. HARWOOD, D.W. (2003) Highway/Heavy Vehicle Interaction: A Synthesis of Safety Practice. National Research Council (U.S.), Transportation Research Board, Commercial Truck and Bus Safety Synthesis Program, Synthesis 3.

23. HOLMEN, B.A. \& NIEMEIER, D.A. (1998) Characterizing the Effects of Driver Variability on Real-World Vehicle. Transportation Research Part D: Transport and Environment, Volume 3, Issue 2, pp. 117-128. 
24. KEAN, A.J., HARLEY, R.A. \& KENDALL, G.R. (2003) Effects of Vehicle Speed and Engine Load on Motor Vehicle Emissions. Environmental Science \& Technology, Volume 37, No. 17, pp. 3739-3746.

25. LAN, C.J. \& MENENDEZ, M. (2003) Truck Speed Profile Models for Critical Length of Grade. Journal of Transportation Engineering, ASCE, Volume 129, No. 4, pp. 408-419.

26. MONSERE, C.M., WOLFE, M., ALWAKIEL, H. \& STEPHENS, M. (2009) Developing Corridor-Level Truck Travel Time Estimates and Other Freight Performance Measures from Archived ITS Data. Oregon Department of Transportation (ODOT) and Oregon Transportation Research and Education Consortium (OTREC, Final Report, SPR 304-361, 07-01).

27. PANDIAN, S., GOKHALE, S. \& GHOSHAL, A.K. (2009) Evaluating Effects of Traffic and Vehicle Characteristics on Vehicular Emissions Near Traffic Intersections. Transportation Research Part D: Transport and Environment, Volume 14, Issue 3, pp. 180-196.

28. PIERSON, W.R., GERTLER, A.W., ROBINSON, N.F., SAGEBIEL, J.C., ZEILINSKA, B., BISHOP, G.A., STEDMAN, D.H., ZWEIDINGER, R.B. \& RAY, W.D. (1996) Real-World Automotive Emissions - Summary of Studies in the Fort McHenry and Tuscarora Mountain Tunnels. Atmospheric Environment Volume 30, No. 12, pp. 2233-2256.

29. QU, T., LEE, C.E. \& HUANG, L. (1997) Traffic Load Forecasting Using Weigh-In-Motion Data. Center for Transportation Research, Bureau of Engineering Research, University of Texas at Austin (Research Report 987$6)$.

30. RAMAMURTHY, R. \& CLARK, N.N. (1999) Atmospheric Emissions Inventory Data for Heavy-Duty Vehicles. Environmental Science $\mathcal{E}$ Technology, Volume 33, pp. 55-62.

31. SCORA, G., BORIBOONSOMSIN, K. \& BARTH, M. (2010) Effects of Operational Variability on Heavy-Duty Truck Greenhouse Gas 
Emissions. 89th Annual Meeting of Transportation Research Board Compendium of Papers CD-ROM.

32. SCHMITT, R., SPRUNG, M., KIM, S. \& SEDOR, J. Freight Management and Operations: Freight Facts and Figures. Publication FHWA-HOP-08052. FHWA, U.S. Department of Transportation, November 2008.

33. SADLER, S. Inventory and Forecast of Oregon's Greenhouse Gas Emissions. Revision and Update of the Oregon Greenhouse Gas Inventory first published in the Oregon Strategy for Greenhouse Gas Reductions in December 2004. Pre-Publication Draft, October 31, 2007. http://www.oregon.gov/ENERGY/GBLWRM/docs/Oregon_GhG_Inven tory_1990_2004_Report_PrePub_Draft_31Oct2007.pdf?ga=t. Accessed April 6, 2011.

34. SINHA, K.C. \& LABI, S. Transportation Decision Making: Principles of Project Evaluation and Programming. Published by John Wiley \& Sons, Inc., Hoboken, New Jersey, 2007.

35. SINGH, R.B., HUBER, A.H. \& BRADDOCK, J.N. (2003) Development of a Microscale Emission Factor Model for Particulate Matter for Predicting Real-Time Motor Vehicle Emissions. Journal of the Air $\mathcal{E}$ Waste Management Association, Volume 53, pp. 1204-1217.

36. SwRL Project (2003) Humidity and Temperature Correction Factors for Development of $\mathrm{NO}_{x}$ Emissions from Spark Ignited Engines. Prepared for ENVIRON International Corporation Southwest Research Institute.

37. U.S. Environmental Protection Agency (EPA), Air Quality Management Online Portal. Emissions Inventory. June 2009. http://www.epa.gov/air/aqmportal/management/emissions_inventory/ Accessed May 9, 2011.

38. U.S. Department of Transportation, Research and Innovative Technology Administration, Bureau of Transportation Statistics. Freight in America - A New National Picture. January 2006. 
http://www.bts.gov/publications/freight_in_america/pdf/entire.pdf. Accessed April 5, 2011.

39. WHEELER, N. \& FIGLIOZZI, M. (2011) Multi-Criteria Trucking Freeway Performance Measures in Congested Corridors. 90 th Annual Meeting of the Transportation Research Board. Forthcoming 2011 Transportation Research Record.

40. WENZEL, T., SINGER, B.C. \& SLOTT, R. (2000) Some Issues in the Statistical Analysis of Vehicle Emissions. Journal of Transportation and Statistics, Volume 2, pp. 1-14.

41. YOON, S., RODGERS, M.O., PEARSON, J.R. \& GUENSLER, R.L. (2004) Engine and Weight Characteristics of Heavy Heavy-Duty Diesel Vehicles and Improved On-Road Mobile Source Emissions Inventories: Engine Model Year and Horsepower and Vehicle Weight. Transportation Research Record: Journal of the Transportation Research Board, No. 1880, pp. 99-107.

42. YANOWITZ, J., GRABOSKI, M.S. \& MCCORMICK, R.L. (2002) Prediction of In-Use Emissions of Heavy-Duty Diesel Vehicles from Engine Testing. Environmental Science \& Technology, Volume 36, No. 2, pp. 270-275.

43. YANOWITZ, J., GRABOSKI, M.S., RYAN, L.B.A., ALLEMAN, T.L. \& MCCORMICK, R.L. (1999) Chassis Dynamometer Study of Emissions from $21 \mathrm{In}-$ Use Heavy-Duty Diesel Vehicles. Environmental Science $\mathcal{E}$ Technology, Volume 33, No. 2, pp. 209-216. 


\section{Appendix A: Steps for Estimating Link-Based Nitrogen Oxide $\left(\mathrm{NO}_{\mathrm{x}}\right)$ and Carbon Dioxide $\left(\mathrm{CO}_{2}\right)$ Emissions}

This section presents the assumptions and the detailed procedure used for estimating link-based nitrogen oxide $(\mathrm{NO} \times)$ and carbon dioxide $\left(\mathrm{CO}_{2}\right)$ emissions. This section begins with the query used for retrieving Weigh-InMotion (WIM) data, then the method used for approximating the link grades, followed by the steps for estimating actual speed on grades, and finally the calculation of the nitrogen oxide $\left(\mathrm{NO}_{x}\right)$ and carbon dioxide $\left(\mathrm{CO}_{2}\right)$ emissions. Where applicable, the assumptions used will be provided.

\section{Weigh-In-Motion (WIM) Link Data}

The Weigh-In-Motion (WIM) data are archived under the Portland Oregon

Regional Transportation Archive Listing (PORTAL) found at (http://portal.its.pdx.edu/phpPgAdmin/), which requires a username and password. The path for the data is (bottleneck.research.pdx.edu - portals wim). Knowing the upstream and downstream stations for each link, the linkid is determined from the stationmap table. The WIM data are retrieved using postgreSQL query. The following SQL is an example for the query used to extract WIM data for link 211 through trucks on January 2007. Link 211 is between Ashland POE (NB, MP 18.08) and Booth Ranch (NB, MP 111.07). 


\section{SELECT *}

FROM wim.link_traveltime_all

WHERE linkid $=211$

AND up_timestamp $>=$ '2007-01-01' AND up_timestamp $<$ '2007-02-01'

Only certain observations are kept for the analysis. These are the records of through trucks $($ thru_truck $=\mathrm{t})$, type 11 for five-axle trucks $($ up_type $=$ 11), heavy-duty vehicles (up_gvw > 8.5), with average speed higher than 40 mph (up_speed $>40)$. These records are compiled into three bins: empty $(8.5<$ up_gvw<32.9), medium $\left(33<u p \_g v w<59.9\right)$, and full $\left(u p \_g v w>60\right)$. The travel time for each truck is the difference between the up_timestamp and dwn_ timestamp.

\section{Approximation of Link's Grade Profile}

The link's grade profile is developed using the ODOT Integrated Transportation Information System (ITIS). The $\mathrm{x}$-axis of the grade profile is the link milepost (BEG_MP_NO), while the $y$-axis is the elevation at each milepost (VPI_MEAS_1). The elevations of the grade profile are then checked using Google Earth. . For simplicity, the grade profile is approximated to longer segments of upgrades and downgrades. An example of grade approximation for Link 211 is shown in Figure 9. Table 4 lists the mileposts, elevations, 
approximated grades, and the lengths of the new approximated segments. These approximated grades will be used later to estimate $\mathrm{NO}_{x}$ and $\mathrm{CO}_{2}$ emissions.

\section{Estimating Actual Speed on Grades}

For the estimation of actual speed of heavy-duty vehicles on grades, Microsoft Excel is used to apply the equations listed in section 3.3.2 for each truck observation with unique gross vehicle weight and average speed. The coefficients and variables that are constant for all combinations of gross vehicle weight and speeds are as follows: $g=32.17 \mathrm{ft} / \mathrm{s}^{2}, r=0.92, k_{s}=0.0000682 \mathrm{~s} / \mathrm{ft}$, $k_{r}=0.01, k_{a}=0.0764, u_{0}=59.24 \mathrm{ft} / \mathrm{s}, u_{x}=95.69 \mathrm{ft} / \mathrm{s}, P=200 \mathrm{hp}$. The vehicle's weight $(W)$ and vehicle's initial speed $\left(u_{i}\right)$ are found in the WIM data as the up_gvw and up_speed respectively. The road grade $(G)$ for the example link (Link_211) ranged between $1 \%$ and $5 \%$. The rest of variables $\left(\alpha, \beta, a_{\circ}, a_{x}\right)$ are calculated using equations $3.2,3.3,3.4$, and 3.5 respectively.

After calculating all the above variables, the Excel Solver is used to find the final speed $\left(u_{f}\right)$ at a distance $(x)$ of $1000 \mathrm{ft}$. The definitions of the mentioned variables and coefficients are provided in detail in section 3.3.2. Figure 30 is an example for finding the final speeds $\left(u_{f}\right)$ for a truck with gross vehicle weight of $33.7 \mathrm{kips}$ and initial speed of $55 \mathrm{mph}$ on grades $1 \%$ to $5 \%$. 


\section{Estimating Link-Based NO $\mathrm{x}_{\mathrm{x}}$ Emissions}

The equations presented in section 3.3.3 are used for the estimation of linkbased $\mathrm{NO}_{\mathrm{x}}$ emissions. After dividing the studied link to an approximate grade segments as mentioned above, the $\mathrm{NO}_{x}$ emissions are calculated for each segment using the actual speed on each grade and the truck weight. Then these emission values are multiplied by the segment distance and summed up to get the link's total emissions (in grams).

These calculations are repeated for each truck observation (i.e. record) in WIM data file. For the level terrain and negative grades (downgrades), the speed is assumed to be the same as the entering speed. The values of the coefficients used to calculate the rear-axle horsepower in equation 3.7 are as follows: $C_{d}=0.076, A=8.32 \mathrm{~m}^{2}, g=9.81 \mathrm{~m} / \mathrm{s}^{2}, \mu=0.00938$, and $\rho=1.207 \mathrm{Kg} / \mathrm{m}^{3}$. An example of the calculations to estimate the $\mathrm{NO}_{\mathrm{x}}$ emissions for a truck with weight 33.7 kips with average speed 55 mph on Link_211 is shown in Figure 31. 
Microsoft Excel - Copy of Grade_Sp_Eqn_Final.xls

国 File Edit View Insert Format Iools Data Window $\underline{\text { Help }}$

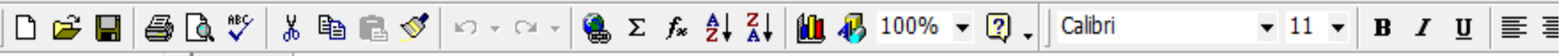

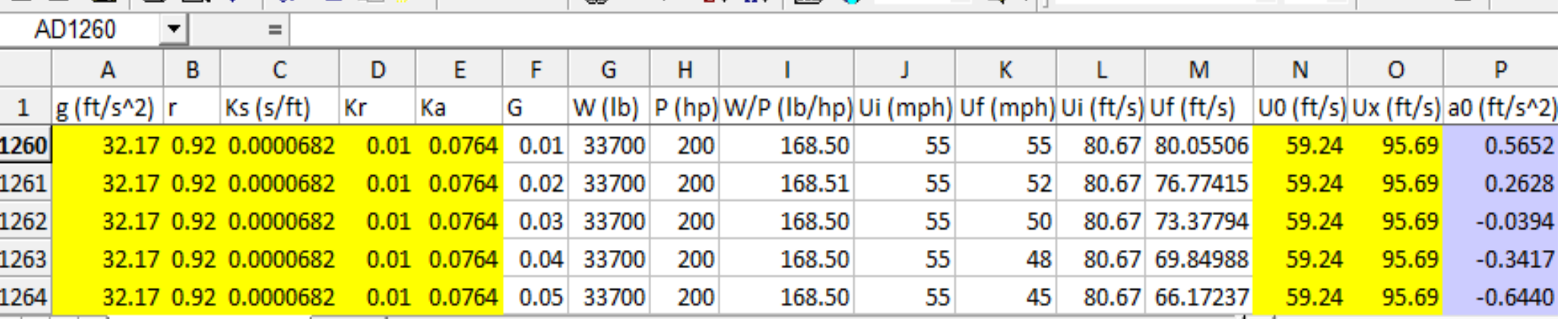

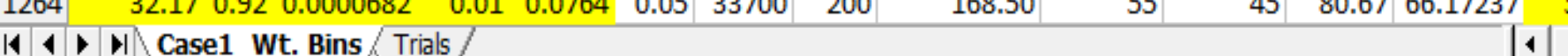

\begin{tabular}{|c|c|c|c|c|c|c|c|c|c|c|c|c|c|}
\hline \multicolumn{14}{|l|}{ iw $\underline{\text { Help }}$} \\
\hline $9 \Sigma$ & 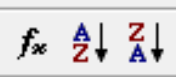 & \multicolumn{3}{|c|}{ 边 $100 \%$ 回。 } & \multicolumn{2}{|l|}{ Calibri } & - 11 . & $\mathbf{B}$ & \multicolumn{2}{|c|}{ 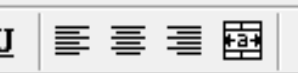 } & , $\quad .00 \quad .00$ & 㜪墔 & I- \\
\hline G & $\mathrm{H}$ & I & $\mathrm{J}$ & K & L & $\mathrm{M}$ & $\mathrm{N}$ & 0 & P & $\mathrm{Q}$ & $\mathrm{R}$ & s & $A B$ \\
\hline $\mathrm{W}(\mathrm{lb})$ & $P(h p)$ & W/P (lb/hp) L & $\mathrm{Ui}(\mathrm{mph})$ & $\mathrm{Uf}(\mathrm{mph})$ & $\mathrm{Ui}(\mathrm{ft} / \mathrm{s})$ & $\mathrm{Uf}(\mathrm{ft} / \mathrm{s})$ & UO (ft/s) & $U x(\mathrm{ft} / \mathrm{s})$ & $\mathrm{a} 0\left(\mathrm{ft} / \mathrm{s}^{\wedge} 2\right)$ & $\mathrm{ax}\left(\mathrm{ft} / \mathrm{s}^{\wedge} 2\right)$ & Alpha $\left(\mathrm{ft} / \mathrm{s}^{\wedge} 2\right)$ B & $\operatorname{Beta}\left(s^{\wedge}-1\right)$ & $\mathrm{X} 1(\mathrm{ft})$ \\
\hline 33700 & 200 & 168.50 & 55 & 55 & 80.67 & 80.05506 & 59.24 & 95.69 & 0.5652 & -0.4963 & $3 \quad 2.2903$ & 0.0291 & 999.999999 \\
\hline 33700 & 200 & 168.51 & 55 & 52 & 80.67 & 76.77415 & 59.24 & 95.69 & 0.2628 & -0.8085 & 2.0039 & 0.0294 & 1000.000572 \\
\hline 33700 & 200 & 168.50 & 55 & 50 & 80.67 & 73.37794 & 59.24 & 95.69 & -0.0394 & -1.1206 & 1.7178 & 0.0297 & 999.9999995 \\
\hline 33700 & 200 & 168.50 & 55 & 48 & 80.67 & 69.84988 & 59.24 & 95.69 & -0.3417 & -1.4327 & 1.4315 & 0.0299 & 999.9999992 \\
\hline 33700 & 200 & 168.50 & 55 & 45 & 80.67 & 66.17237 & 59.24 & 95.69 & -0.6440 & -1.7448 & 1.1452 & 0.0302 & 999.9999998 \\
\hline
\end{tabular}

Figure 30: Example for Estimation of Actual Speed in Microsoft Excel

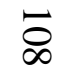




\begin{tabular}{|c|c|c|c|c|c|c|c|c|c|c|c|c|}
\hline $\mathbf{P}$ & Q & $R$ & $S$ & $\mathrm{~T}$ & U & V & W & $x$ & $Y$ & $z$ & AA & $A B$ \\
\hline \multirow[t]{5}{*}{ Coefficients } & $\mathrm{Cd}$ & $A\left(m^{\wedge} 2\right)$ & $\mathrm{g}\left(\mathrm{m} / \mathrm{s}^{\wedge} 2\right)$ & Meo & $\operatorname{Rho}\left(\mathrm{kg} / \mathrm{m}^{\wedge} 3\right)$ & & & & & & & \\
\hline & 0.76 & 8.32 & . 9.81 & 0.00938 & $\begin{array}{ll}8 & 1.207 \\
\end{array}$ & & & & & & & \\
\hline & & & & & & & & & & & & \\
\hline & & & & & & & & & & & & \\
\hline & & & & & & & & & & & & \\
\hline \multirow[t]{15}{*}{\begin{tabular}{|l|}
$15,286.06$ \\
\end{tabular}} & 33.7 & Dist (mi) & Grade $\%$ & Act_Sp (mph) & Act_Sp (mi/sec) & Act_Sp $(\mathrm{m} / \mathrm{s})$ & $\Pi(\mathrm{sec})$ & AHP (Watt) & $\operatorname{AHP}(\mathrm{hp})$ & NOx_Em $(\mathrm{g} / \mathrm{s})$ & NOx_Em (g) & Av_Link_Em $(\mathrm{g} / \mathrm{mi})$ \\
\hline & & 17.67 & -0.60 & 55 & $\begin{array}{l}5 \quad 0.01528 \\
\end{array}$ & 24.58 & \begin{tabular}{l|l}
3 & 1,157 \\
\end{tabular} & $7 \quad 467,022$ & 626 & $\quad 0.79$ & $\begin{array}{l}9 \\
9\end{array}$ & \\
\hline & & 2.38 & 1.37 & 54.6 & 0.01516 & 24.40 & 157 & 462,631 & 620 & 0.79 & 123.38 & \\
\hline & & 2.82 & -1.97 & 55 & 0.01528 & 24.58 & 185 & 467,022 & 626 & 0.79 & 146.40 & \\
\hline & & 12.51 & -0.07 & 55 & 0.01528 & 24.58 & 819 & 467,022 & 626 & 0.79 & 649.47 & \\
\hline & & 2.35 & -5.78 & 55 & 0.01528 & 24.58 & 154 & 467,022 & 626 & 0.79 & 122.00 & \\
\hline & & 2.13 & 4.19 & 47.6 & 0.01323 & 21.29 & 161 & 392,117 & 526 & 0.67 & 107.98 & \\
\hline & & 1.91 & -3.57 & 55 & 0.01528 & 24.58 & 125 & 467,022 & 626 & 0.79 & 99.16 & \\
\hline & & 2.24 & 0.15 & 55 & 0.01528 & 24.58 & 147 & 467,022 & 626 & 0.79 & 116.29 & \\
\hline & & 2.1 & 4.49 & 45.1 & 0.01253 & 20.17 & 168 & 367,898 & 493 & 0.63 & 105.74 & \\
\hline & & 1.32 & -5.86 & 55 & 0.01528 & 24.58 & 86 & 467,022 & 626 & 0.79 & 68.53 & \\
\hline & & 5 & 0.37 & 55 & 0.01528 & 24.58 & 327 & 467,022 & 626 & 0.79 & 259.58 & \\
\hline & & 3.77 & 2.26 & 52.4 & 0.01454 & 23.40 & 259 & 439,471 & 589 & 0.75 & 193.94 & \\
\hline & & 3.12 & -5.08 & 55 & 0.01528 & 24.58 & 204 & 467,022 & 626 & 0.79 & 161.98 & \\
\hline & & 8.58 & -1.04 & 55 & 0.01528 & 24.58 & 562 & 467,022 & 626 & 0.79 & 445.44 & \\
\hline
\end{tabular}

Figure 31: Example for Estimation of NOx Emissions for Link 211

\section{Estimating Link-Based $\mathrm{CO}_{2}$ Emissions}

The equations presented in Figure 7 are used for the estimation of link-based

$\mathrm{CO}_{2}$ emissions. The approximate grade of the link segment is used to choose

the appropriate curve equation. In case the segment grade is not an exact grade curve, a weighed average of two curves is calculated. Similar to that done when estimating nitrogen oxide $\left(\mathrm{NO}_{\mathrm{x}}\right)$ emissions, the values are multiplied by the segment distance and the total is the carbon dioxide $\left(\mathrm{CO}_{2}\right)$ emissions of the link in grams. Figure 32 gives an example of the calculations 
to estimate the $\mathrm{CO}_{2}$ emissions for a truck with weight 33.7 kips with average speed 55 mph on Link_211.

\begin{tabular}{|c|c|c|c|c|c|c|c|c|}
\hline & \multicolumn{8}{|c|}{ Wt. Bin_2 $(33,000-60,000)$} \\
\hline 33.7 & Dist (mi) & Grade $\%$ & Grade_Curve & Act_Sp (mph) & CO2_Em (g/mi) & CO2_Em (g) & Em_-ve (g/mi) & Av_Link_Em $(\mathrm{g} / \mathrm{mi})$ \\
\hline & 17.67 & -0.60 & 0 & 55 & 2,204 & 38,943 & & \\
\hline & 2.38 & 1.37 & Av_0_2 & 54.6 & 2,884 & 6,864 & & \\
\hline & 2.82 & -1.97 & -2 & 55 & 873 & 2,463 & & \\
\hline & 12.51 & -0.07 & 0 & 55 & 2,204 & 27,571 & & \\
\hline & 6.49 & 1.01 & Av_0_2 & 54.6 & 2,884 & 18,718 & & \\
\hline & 5.75 & -0.95 & Av_0_-2 & 55 & 1,539 & 8,847 & & \\
\hline & 3.44 & 4.74 & 5 & 45.1 & 5,548 & 19,085 & & \\
\hline & 2.35 & -5.78 & -6 & 55 & 0 & 0 & -70 & \\
\hline & 2.13 & 4.19 & 4 & 47.6 & 4,887 & 10,409 & & \\
\hline & 1.91 & -3.57 & -4 & 55 & 145 & 276 & & \\
\hline & 2.24 & 0.15 & 0 & 55 & 2,204 & 4,937 & & \\
\hline & 2.1 & 4.49 & Av_4_5 & 45.1 & 5,217 & 10,957 & & \\
\hline & 1.32 & -5.86 & -6 & 55 & 0 & 0 & -70 & \\
\hline & 5 & 0.37 & 0 & 55 & 2,204 & 11,019 & & \\
\hline & 3.77 & 2.26 & 2 & 52.4 & 3,564 & 13,438 & & \\
\hline & 3.12 & -5.08 & $A v_{-}-6 \_-4$ & 55 & 72 & 226 & & \\
\hline & 8.58 & -1.04 & Av_0_-2 & 55 & 1,539 & 13,201 & & \\
\hline & 10.06 & -0.23 & 0 & 55 & 2,204 & 22,171 & & \\
\hline Total & 93.64 & & & & & 209,126 & & 2,233 \\
\hline
\end{tabular}

Figure 32: Example for Estimation of $\mathrm{CO}_{2}$ Emissions for Link 211 